LEANDRO GONÇALVES DE AGUIAR

MODELAGEM MATEMÁTICA DO PROCESSO DE ENXERTO DE ANIDRIDO MALEICO EM POLIPROPILENO NA FORMA FUNDIDA 
LEANDRO GONÇALVES DE AGUIAR

\section{MODELAGEM MATEMÁTICA DO PROCESSO DE ENXERTO DE ANIDRIDO MALEICO EM POLIPROPILENO NA FORMA FUNDIDA}

Dissertação apresentada à Escola Politécnica da Universidade de São Paulo para a obtenção do título de Mestre em Engenharia. 


\section{MODELAGEM MATEMÁTICA DO PROCESSO DE ENXERTO DE ANIDRIDO MALEICO EM POLIPROPILENO NA FORMA FUNDIDA}

Dissertação apresentada à Escola Politécnica da Universidade de São Paulo para a obtenção do título de Mestre em Engenharia.

Área de concentração:

Engenharia Química

Orientador: Prof.Titular Reinaldo Giudici 
Este exemplar foi revisado e alterado em relação à versão original, sob responsabilidade única do autor e com a anuência de seu orientador.

São Paulo, 2 de março de 2009.

Assinatura do autor

Assinatura do orientador

FICHA CATALOGRÁFICA

Aguiar, Leandro Gonçalves de

Modelagem matemática do processo de enxerto de anidrido maleico em polipropileno na forma fundida / L.G. de Aguiar. -ed.rev. -- São Paulo, 2009.

$107 \mathrm{p}$.

Dissertação (Mestrado) - Escola Politécnica da Universidade de São Paulo. Departamento de Engenharia Química.

1. Polímeros (Materiais) 2. Modelos matemáticos 3. Termodinâmica (Físico-química) 4. Reações químicas l.Universidade de São Paulo. Escola Politécnica. Departamento de Engenharia Química II.t. 


\section{DEDICATÓRIA}

Aos meus pais Nanci e Paulo

e à minha avó Rosária. 


\section{AGRADECIMENTOS}

Ao professor Dr. Reinaldo Giudici pela excelente orientação e constante motivação transmitida durante todo o curso.

Ao professor Dr. Pedro Pessôa pela essencial colaboração no desenvolvimento do trabalho.

Aos professores: Roberto Guardani, Antonio Carlos, Maria Cristina, Paiva e Tah pelo auxílio nas disciplinas e na atividade docente.

Aos colegas do grupo de pesquisa: Dennis, Verônica e Wilson pela companhia e auxílio prestado no decorrer do curso.

À CAPES pelo auxílio financeiro.

e a todos que colaboraram direta ou indiretamente na execução deste trabalho. 


\section{RESUMO}

No presente trabalho, estudou-se a modelagem matemática do processo de enxerto de anidrido maleico em polipropileno na forma fundida. Reações de enxerto desempenham um importante papel na reciclagem de polímeros, agindo na qualidade do material reciclado e aumentando seu valor comercial. A mistura de polímeros entre si ou com outros materiais também é favorecida através das reações de enxerto, nas quais se utiliza um composto que fornecerá a compatibilidade do polímero com o material em questão. O objetivo do presente trabalho foi desenvolver um modelo matemático capaz de representar as principais variáveis do processo de enxerto de anidrido maleico em polipropileno. Na literatura encontra-se um modelo semelhante, o qual utiliza as mesmas considerações cinéticas, mas com a hipótese de meio homogêneo. O presente trabalho propõe dois modelos, os quais consideram a heterogeneidade do meio reacional de formas diferentes (Modelos $1 \mathrm{e}$ 2). Ambos os modelos utilizam um equacionamento baseado em balanços de massa e momentos para as espécies envolvidas e possuem parâmetros relacionados ao equilíbrio de fases entre os compostos no meio reacional. Os parâmetros termodinâmicos ajustados nos modelos são comparados favoravelmente com os valores obtidos através de estimativas pelo método UNIFAC. Como ferramenta para as simulações, utilizou-se o software MATLAB. Simulações feitas com dados de estudos experimentais, revelaram bons resultados para casos em que se utilizou a temperatura de $180^{\circ} \mathrm{C}$. Isto mostra que o comportamento real do processo nesta temperatura está compatível com as considerações utilizadas nos modelos. As simulações feitas com o Modelo 1 apresentaram bons resultados para casos com baixas concentrações de anidrido maleico e iniciador e mostraram uma certa melhora com relação ao modelo que considera meio homogêneo. O Modelo 2 está melhor fundamentado em relação ao Modelo 1, pois leva em conta o equilíbrio de fases entre $o$ anidrido maleico e $o$ iniciador e apresenta resultados um pouco melhores.

Palavras-chave: Modelagem. Enxerto. Polipropileno. 


\section{ABSTRACT}

The mathematical modeling of the grafting of maleic anhydride onto polypropylene in melt was studied in the present work. Grafting reactions play an important role in polymer recycling, improving the material quality and increasing its commercial value. Through grafting processes, it is possible to enhance the polymer compatibility with other polymers and other materials. The aim of this work was to develop a mathematical model able to represent the main variables of the grafting process carried out in melt phase. The literature shows a similar model for grafting reactions, which has the same kinetic considerations, but considers the hypothesis of homogeneous medium. In the present work two models that consider different behavior of heterogeneous medium (Models 1 and 2) were proposed. Both models use equations based on mass and moment balances and include phase equilibrium parameters. The values obtained for the thermodynamic parameters were compared with estimates from UNIFAC method. The simulations were carried out using the software MATLAB. Good results were obtained for simulations of experiments conducted at $180^{\circ} \mathrm{C}$. Hence, in these simulations, the process behavior is in agreement with the model considerations. The tests with the Model 1 show good results for low concentrations of maleic anhydride and initiator, and show a modest improvement in comparison to the model that considers homogeneous medium. The predictions from Model 2 were a little better than those from Model 1, in comparison with experimental data, because Model 2 takes into account the phase equilibrium between maleic anhydride and initiator in a more fundamental way.

Keywords: Modeling. Grafting. Polypropylene. 


\section{LISTA DE ILUSTRAÇÕES}

Figura 1 - Extrusora de rosca única.

Figura 2 - Degradação do peróxido de dicumila (DCP) e representação genérica da decomposição do iniciador no processo. 25

Figura 3 - Mecanismo das reações de enxerto de MAH em PP................................25

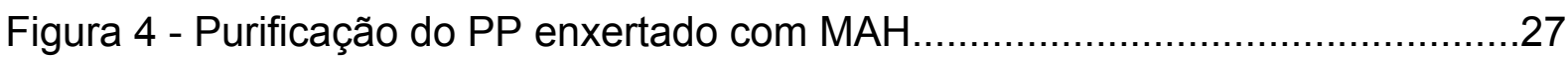

Figura 5 - Efeito da concentração [MA], sobre o grau de enxerto para o processo realizado no misturador. .28

Figura 6 - Efeito da concentração inicial de MAH sobre grau de enxerto para o processo realizado na extrusora.

Figura 7 - Grau de enxerto. Comparação entre o processo convencional e o processo que utiliza o nano-reator.

Figura 8 - Massa molecular média numérica. Comparação entre o processo convencional e o processo que utiliza o nano-reator (SHI et al, 2006). .32

Figura 9 - Esquema reacional simplificado do processo convencional. .33

Figura 10 - Mecanismo reacional do processo que utilizou nano-reatores.

Figura 11 - Resultados da simulação do processo através do método de Monte Carlo.

Figura 12 - Resultados da simulação realizada por Giudici (2007) com os dados de Shi et al (2001).

Figura 13 - Resultados da simulação realizada por Giudici (2007) com os dados de Cha e White (2001)

Figura 14 - Pré mistura (partículas secas).

Figura 15 - Modelo 1: Contato entre os reagentes no estado líquido (Etapa de aquecimento)

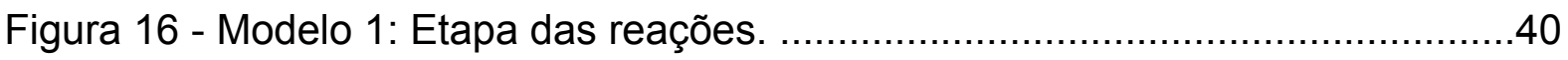

Figura 17 - Fases consideradas no Modelo 1 .....................................................

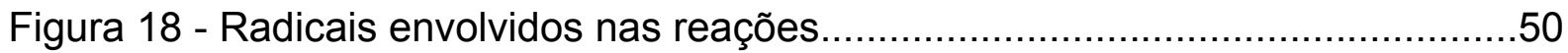

Figura 19 - Segregação devido a regiões internas de PP não atingidas pelos demais reagentes.

Figura 20 - Modelo 2: Etapa de aquecimento dos reagentes 52

Figura 21 - Modelo 2: Etapa de reação.. 


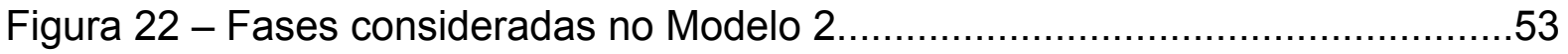

Figura 23 - Segregação devido à baixa concentração de iniciador no meio.

Figura 24 - Resultados da simulação com os dados de Güldoğan et al (2003), através do Modelo 1

Figura 25 - Resultados da simulação com os dados de Shi et al (2006), através

do Modelo 1

Figura 26 - Resultados da simulação com os dados de Shi et al (2001), através

do Modelo 1

Figura 27 - Resultados da simulação com os dados de Akzo (2007), através do Modelo 1

Figura 28 - Resultados da simulação com os dados de Cha e White (2001),

através do Modelo 1.

Figura 29 - Resultados da simulação com os dados de Chang e White (2003), através do Modelo 1.

Figura 30 - Modelo 1: Lei de Arrhenius aplicada aos valores ajustados de $k_{d} e$ $\mathrm{k}_{\mathrm{fp}, 0}$.

Figura 31 - Modelo 1: Lei de Arrhenius aplicada aos valores ajustados de $k_{f p} e$ $\mathrm{k}_{\mathrm{fp}}$...........

Figura 32 - Modelo 1: Lei de Arrhenius aplicada aos valores ajustados de $k_{a, 0}$ e $k_{a} . .75$

Figura 33 - Modelo 1: Lei de Arrhenius aplicada aos valores ajustados de $k_{c s}$ e $k_{t} \ldots 75$

Figura 34 - Curva típica de atividade em função da composição..............................78

Figura 35 - Caso específico de equilíbrio de fases..............................................79

Figura 36 - Variação da atividade do DCP com a composição na mistura DCP + PP em diferentes temperaturas

Figura 37 - Variação da atividade do PP com a composição na mistura DCP + PP em diferentes temperaturas.

Figura 38 - Curvas de atividade de iniciadores na mistura Iniciador + PP

Figura 39 - Curvas de atividade de MAH para a mistura MAH + PP em diferentes temperaturas.

Figura 40 - Análise dos valores de fração solúvel de MAH em PP.

Figura 41 - Resultados da simulação com os dados de Güldoğan et al (2003), através do Modelo 2.

Figura 42 - Resultados da simulação com os dados de Shi et al (2006), através do Modelo 2. 
Figura 43 - Resultados da simulação com os dados de Shi et al (2001), através do Modelo 2.

Figura 44 - Parâmetros ajustados no Modelo 2.

Figura 45 - Modelo 2: Lei de Arrhenius aplicada aos valores ajustados de $k_{d} \mathrm{e}$ $\mathrm{k}_{\mathrm{fp}, 0}$

Figura 46 - Modelo 2: Lei de Arrhenius aplicada aos valores ajustados de $\mathrm{k}_{\mathrm{fp}} \mathrm{e}$ $\mathrm{k}_{\mathrm{fp}}$

Figura 47 - Modelo 2: Lei de Arrhenius aplicada aos valores ajustados de $\mathrm{k}_{\mathrm{a}, 0}$ e $\mathrm{k}_{\mathrm{a}} . .88$ Figura 48 - Modelo 2: Lei de Arrhenius aplicada aos valores ajustados de $k_{c s}$ e $k_{t} \ldots 88$

Figura 49 - Diagrama de fases da mistura líquida DCP+MAH. .91 


\section{LISTA DE TABELAS}

Tabela 2.1 - Propriedades dos reagentes do processo de enxerto de MAH em PP..22

Tabela 4.1 - Condições dos experimentos..................................................67

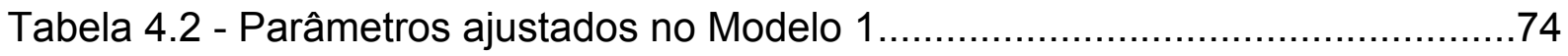

Tabela 4.3 - Valores de energia de ativação obtidos no Modelo 1 ...........................76

Tabela 4.4 - Modelo 1: Comparação entre os valores de kd................................77

Tabela 4.5 - Modelo 1: Comparação de constantes de velocidade à $185^{\circ} \mathrm{C} \ldots \ldots \ldots \ldots . . . .77$

Tabela 4.6 - Modelo 1: Comparação de constantes de velocidade à $230^{\circ} \mathrm{C} \ldots \ldots \ldots \ldots . . . .77$

Tabela 4.7 - Modelo 1: Comparação das energias de ativação obtidas....................78

Tabela 4.8 - Comparação dos valores de solubilidade do iniciador no PP...............82

Tabela 4.9 - Valores de energia de ativação obtidos no Modelo 2 ...........................89

Tabela 4.10 - Modelo 2: Comparação entre os valores de kd.................................89

Tabela 4.11 - Modelo 2: Comparação de constantes de velocidade à $185^{\circ} \mathrm{C} \ldots \ldots \ldots . . . .89$

Tabela 4.12 - Modelo 2: Comparação das energias de ativação obtidas...................90

Tabela 4.13 - Modelo 2: Comparação dos valores de solubilidade de MAH em PP..90

Tabela 4.14 - Coeficientes de partição utilizados nas simulações..........................91 


\section{LISTA DE SÍMBOLOS}

A

$\mathrm{A}_{\mathrm{g}}$

$a_{i}$

$a_{1,1}$

$a_{1,2}$

$a_{n m}$

$b_{n m}$

$\mathrm{C}_{\mathrm{nm}}$

C

$\mathrm{C}_{\mathrm{A}}$

$\mathrm{C}_{\mathrm{A} 1}$

$\mathrm{C}_{\mathrm{A} 2}$

$\mathrm{C}_{11}$

$\mathrm{f}$

f1

$\mathrm{F}_{\mathrm{As} 1}$

$\mathrm{F}_{\mathrm{i}}$

$\hat{f}_{i}$

$f_{i}^{r e f}$

GE'

$\mathrm{GE}_{2}$

$\mathrm{GE}_{4}$

$I_{1}$

$\mathrm{I}_{2}$

$\mathrm{l}_{\mathrm{ef}}$

$K_{i}$

$\mathrm{K}_{\mathrm{j}}$

$\mathrm{K}_{\mathrm{PI}}$

$\mathrm{m}_{1}$

Concentração do anidrido maleico não reagido (mol/L)

Concentração do anidrido maleico enxertado (mol/L)

Atividade do componente i na mistura

Atividade do iniciador na Fase 1

Atividade do iniciador na Fase 2

Parâmetro de interação associado inversamente à temperatura

Parâmetro de interação não associado à temperatura

Parâmetro de interação associado diretamente à temperatura

Parte combinatorial do coeficiente de atividade

Concentração global de MAH (mol/L)

Concentração de MAH na Fase 1 (mol/L)

Concentração de MAH na Fase 2 (mol/L)

Concentração de iniciador na Fase 1 (mol/L)

Eficiência do iniciador

Eficiência do iniciador na Fase 1

Taxa de transferência de MAH da Fase 1 para a Fase $2\left(\mathrm{~mol} / \mathrm{L}_{\text {Fase } 1 . \mathrm{S})}\right.$

Fração da área superficial do composto i na mistura

Fugacidade do componente i na mistura

Fugacidade do componente i num estado de referência

Grau de enxerto corrigido (\% massa).

Grau de enxerto obtido no volume ativo (\%massa)

Grau de enxerto obtido no volume inativo (\%massa)

Concentração global de iniciador (mol/L)

Concentração de iniciador na Fase 1 (mol/L)

Concentração de iniciador na Fase 2 (mol/L)

Concentração efetiva do iniciador (mol/L)

Coeficiente de partição do componente i

constante de velocidade para a reação do tipo $\mathrm{j}$

Coeficiente de partição do iniciador.

Massa da Fase 1 (g) 


\begin{tabular}{|c|c|}
\hline$\overline{M_{1}}$ & Massa molecular média da Fase 1 \\
\hline$\overline{M_{2}}$ & Massa molecular média da Fase 2 \\
\hline $\mathrm{M}_{\mathrm{A}}$ & Massa molecular do MAH (g/mol) \\
\hline $\mathrm{m}_{\mathrm{A} 1}$ & Massa de MAH na Fase 1 (g) \\
\hline $\mathrm{MAH}_{\text {sol }}$ & Concentração do MAH que se solubilizou no PP (mol/L) \\
\hline $\mathrm{MAH}_{\mathrm{ad}}$ & Concentração de MAH com base na quantidade adicionada (mol/L) \\
\hline$M_{1}$ & Massa molecular do iniciador $(\mathrm{g} / \mathrm{mol})$ \\
\hline $\mathrm{N}_{\mathrm{A} 1}$ & Número de mols de MAH na Fase $1(\mathrm{~mol})$ \\
\hline $\mathrm{N}_{11}$ & Número de mols de iniciador na Fase $1(\mathrm{~mol})$ \\
\hline $\mathrm{n}_{\mathrm{l}, \mathrm{ad}}$ & Número de mols de iniciador adicionado (mol); \\
\hline $\mathrm{n}_{\mathrm{MAH}, \mathrm{ad}}$ & Número de mols de MAH adicionado (mol); \\
\hline $\mathrm{Pr}_{\mathrm{r}}$ & Polímero com r unidades monoméricas \\
\hline $\mathrm{Q}_{1}$ & Momento de ordem 1 das cadeias de polímero \\
\hline$q_{i}$ & Área superficial relativa de Van der Waals do composto i na mistura \\
\hline$Q_{k}$ & Área superficial relativa de Van der Waals do subgrupo k na mistura \\
\hline $\mathrm{R}$ & Parte residual do coeficiente de atividade \\
\hline $\mathrm{R}_{0}^{\bullet}$ & Radical gerado pela decomposição do iniciador (Radical primário) \\
\hline $\mathrm{R}_{01}$ & Concentração de radicais $R_{0}$ na Fase 1. (mol/L) \\
\hline $\mathrm{R}_{02}$ & Concentração de radicais $R_{0}$ na Fase 2. (mol/L) \\
\hline $\mathrm{R}_{\mathrm{OA}}{ }^{\bullet}$ & Radical primário enxertado \\
\hline $\mathrm{R}_{\mathrm{o}}^{\mathrm{e} \bullet}$ & $\begin{array}{l}\text { Radical polimérico com } r \text { meros cujo centro ativo está em alguma das } \\
\text { extremidades da cadeia (Radical end) }\end{array}$ \\
\hline $\mathrm{R}_{\mathrm{OA}}^{\mathrm{e}}{ }^{\bullet}$ & Radical end enxertado, com $r$ meros \\
\hline $\mathrm{R}_{\mathrm{A} 01}$ & Concentração de radicais $\mathrm{R}_{\mathrm{A} 0}$ na Fase 1 (mol/L) \\
\hline$r_{i}$ & Volume relativo de Van der waals do composto i na mistura \\
\hline$r_{n}$ & Numero médio de unidades monoméricas num dado instante \\
\hline$r_{\text {no }}$ & Número médio inicial de unidades monoméricas \\
\hline $\mathrm{R}_{\mathrm{r}}^{\mathrm{Ab} \bullet}$ & Radical backbone enxertado, com $r$ meros \\
\hline $\mathrm{R}_{\mathrm{r}}^{\mathrm{b} \bullet}$ & $\begin{array}{l}\text { Radical polimérico com } r \text { meros cujo centro ativo está em alguma } \\
\text { região do meio da cadeia (Radical backbone) }\end{array}$ \\
\hline $\mathrm{R}_{\mathrm{r}}^{\mathrm{k}}$ & Concentração do radical do tipo $\mathrm{k}$ e tamanho $\mathrm{r}(\mathrm{mol} / \mathrm{L})$ \\
\hline S & Produto secundário e inerte \\
\hline$S_{A}$ & Solubilidade de MAH em PP (mol/L) \\
\hline
\end{tabular}




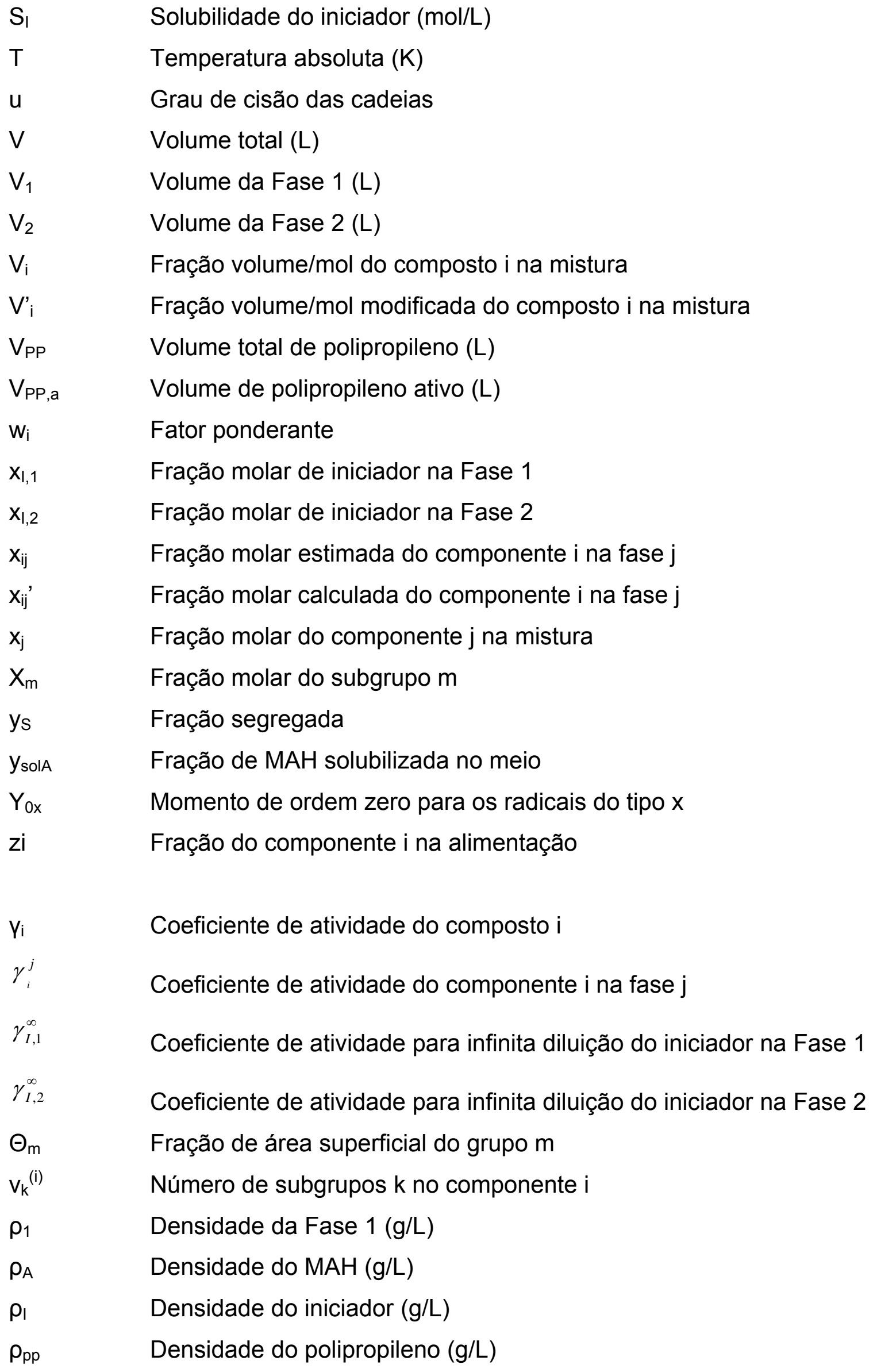


$\Psi:$

Fração da fase $L 1$ na mistura

$\Psi_{\mathrm{nm}}$

Parâmetro de interação de grupos

$\Gamma_{\mathrm{k}}$

Coeficiente de atividade de grupo para o subgrupo $\mathrm{k}$ 


\section{SUMÁRIO}

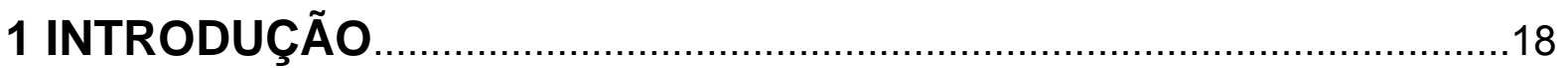

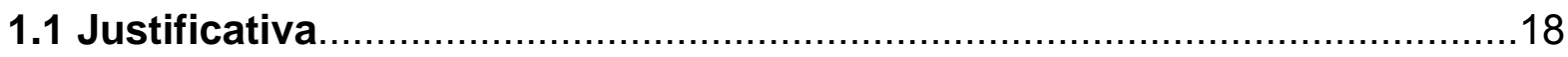

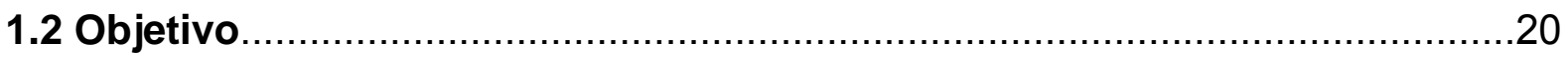

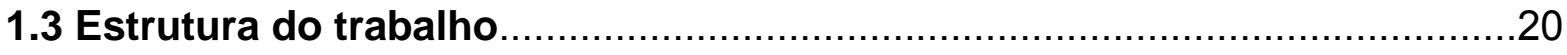

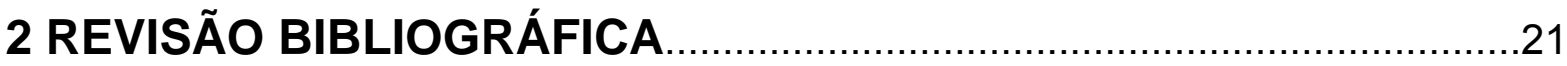

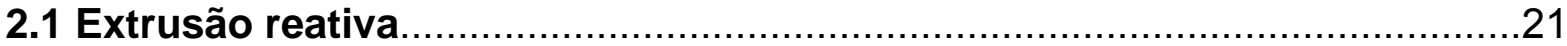

2.2 Enxerto de anidrido maleico (MAH) em Polipropileno (PP) na forma

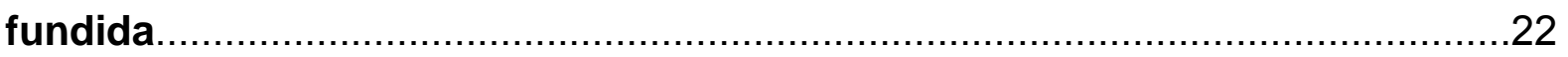

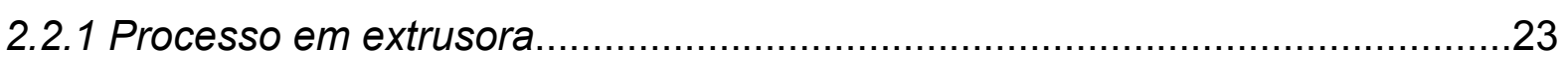

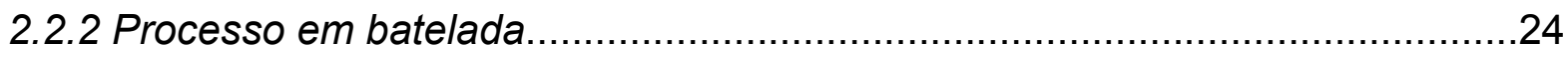

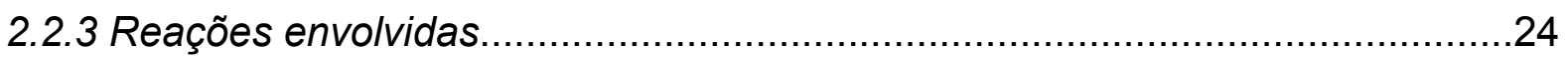

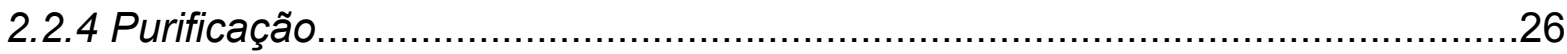

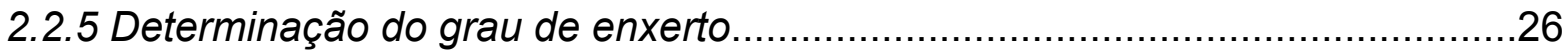

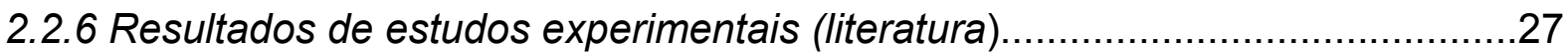

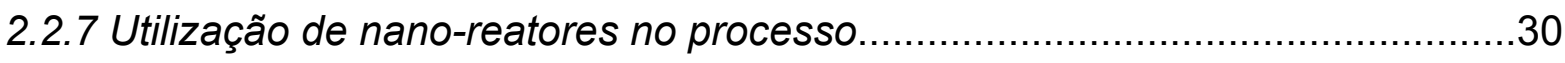

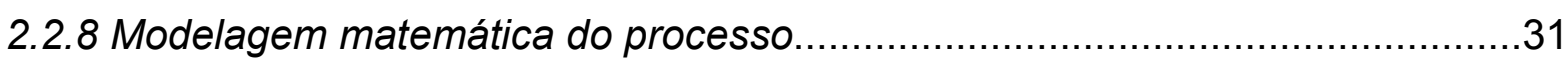

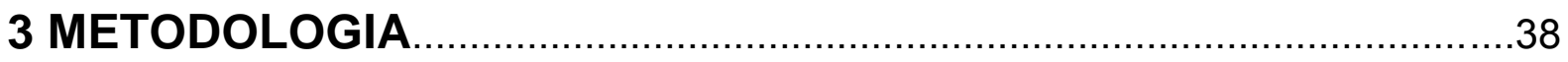

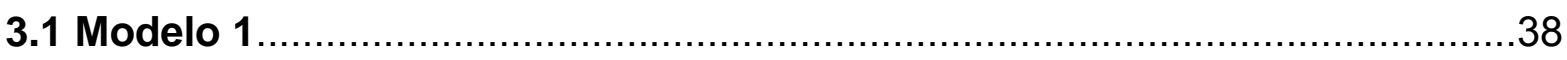

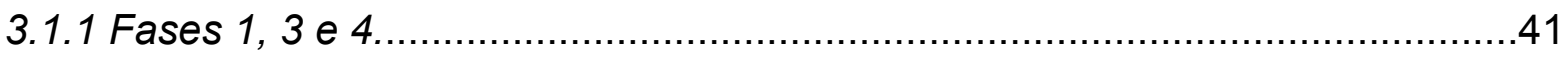

3.1.2 Fase 2

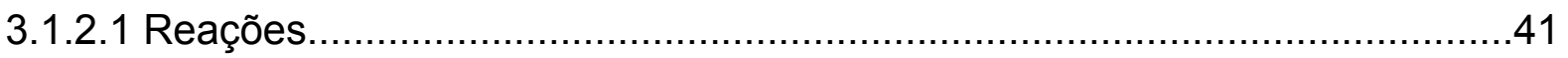

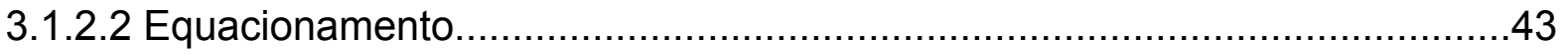

3.1.3 Parâmetros físicos utilizados no Modelo 1...............................................48

3.1.3.1 Solubilidade do Iniciador no meio reacional............................................48

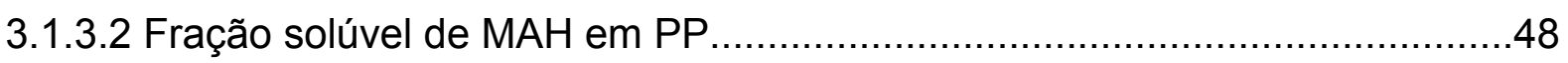

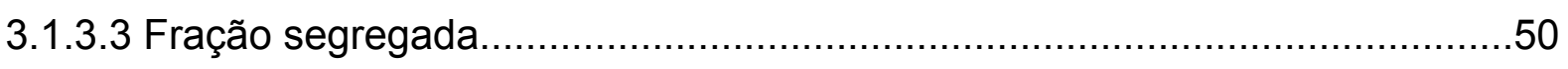

3.1.4 Condições iniciais para o Modelo 1.......................................................50 


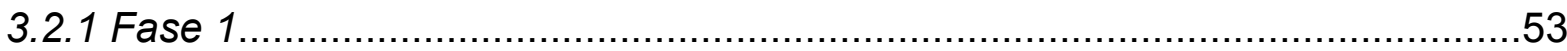

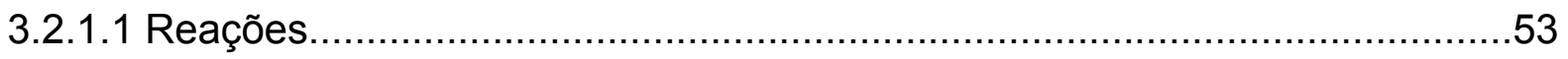

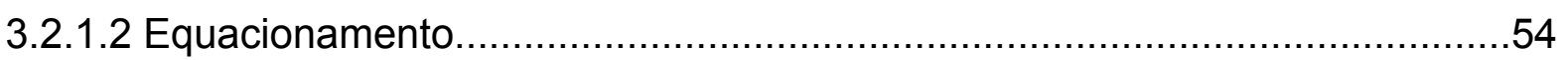

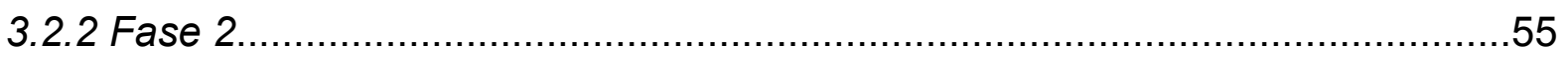

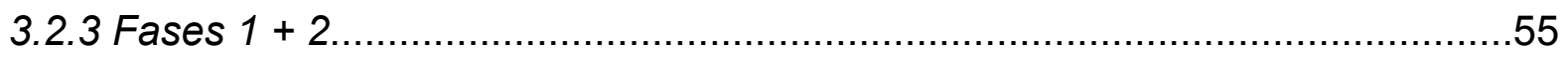

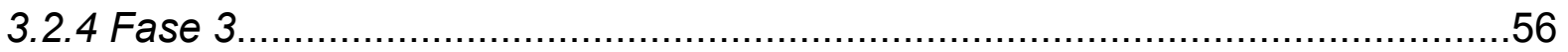

3.2.5 Parâmetros físicos utilizados no Modelo 2 ..................................................56

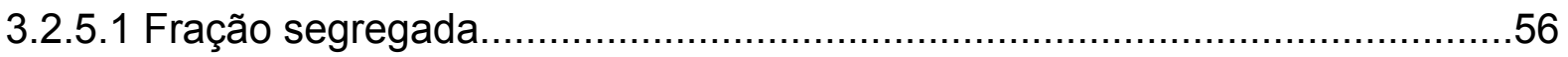

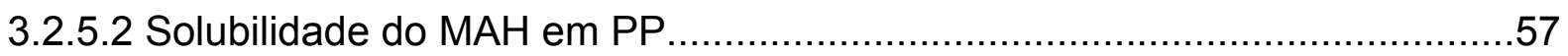

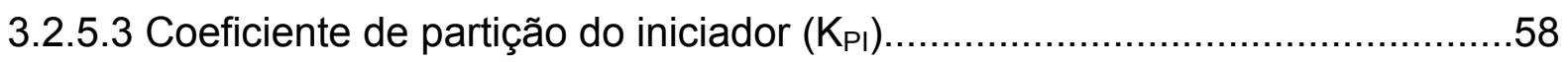

3.2.6 Condições iniciais para o Modelo 2 .....................................................58

3.3 Análise dos valores ajustados para os parâmetros................................60

3.3.1 Análise de parâmetros cinéticos............................................................60

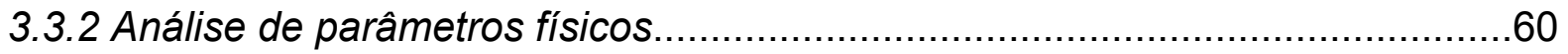

3.3.2.1 Obtenção do coeficiente de atividade (Método UNIFAC)..........................60

3.3.2.2 Estimativa do coeficiente de partição do iniciador.....................................63

3.3.2.3 Estimativa da solubilidade entre reagentes.........................................64

3.3.2.4 Análise do parâmetro fração segregada................................................65

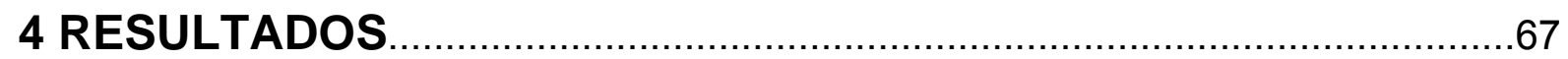

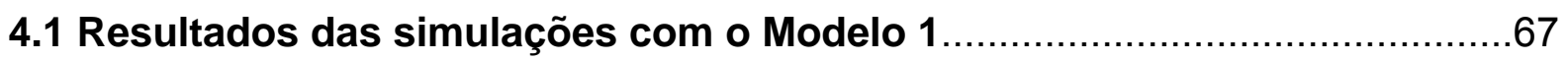

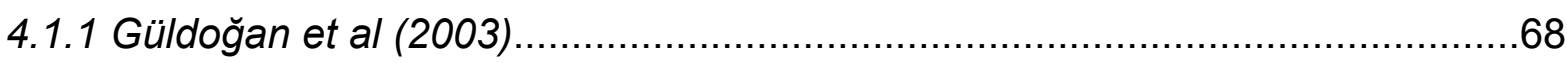

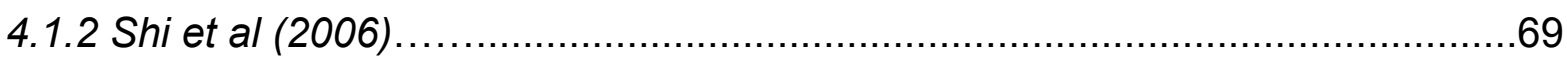

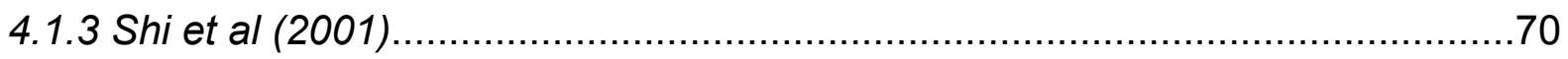

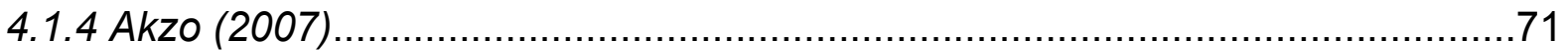

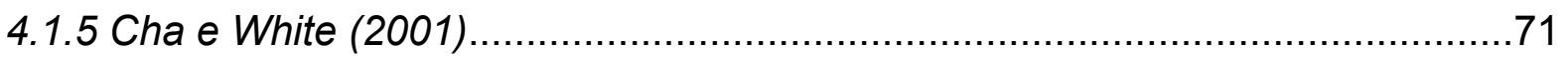

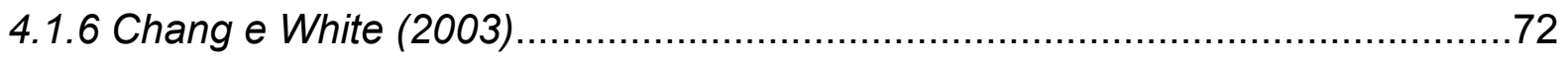

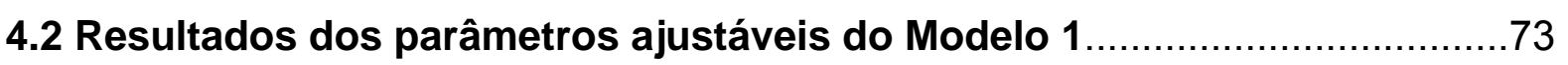

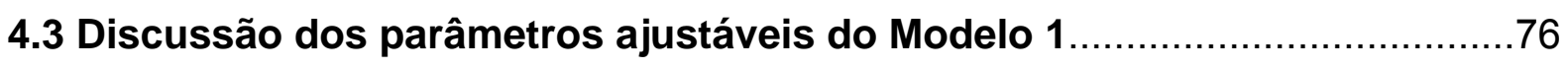

4.3.1 Discussão das constantes de velocidade ajustadas no Modelo 1...................76

4.3.2 Discussão dos valores de solubilidade do iniciador no meio reacional............78

4.3.3 Discussão dos valores de fração solúvel de MAH em PP..............................82 
4.3.4 Discussão dos valores de fração segregada ajustados no Modelo 1

4.4 Resultados das simulações com o Modelo 2 .......................................85

4.5 Resultados dos parâmetros ajustáveis do Modelo 2 ..............................87

4.6 Discussão dos parâmetros ajustáveis do Modelo 2 ..............................89

4.6.1 Discussão das constantes de velocidade ajustadas no Modelo 2....................89

4.6.2 Discussão dos valores de solubilidade do MAH em PP.................................90

4.6.3 Discussão dos valores de coeficiente de partição do iniciador $\left(K_{P I}\right)$...............90

4.6.4 Discussão dos valores de fração segregada ajustados no Modelo 2...............92

5 DISCUSSÃO

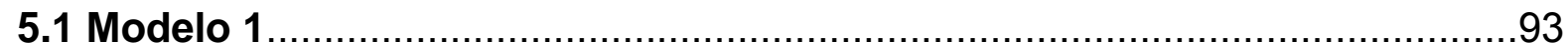

5.1.1 Discussão dos resultados das simulações com o Modelo 1..........................93

5.1.2 Discussão dos parâmetros ajustados do Modelo 1......................................95

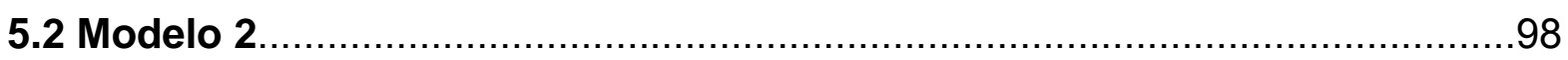

5.2.1 Discussão dos resultados das simulações com o Modelo 2..........................98

5.2.2 Discussão dos parâmetros ajustados do Modelo 2......................................100

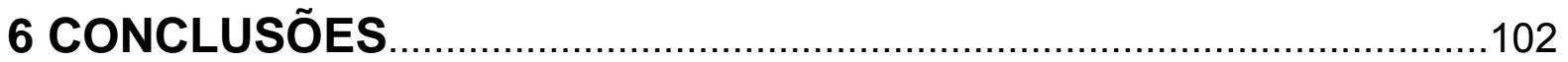

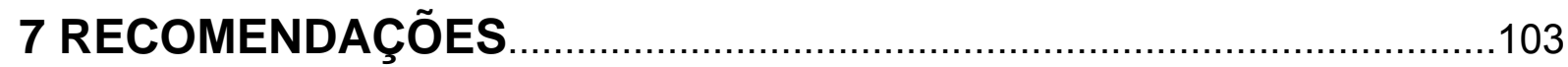

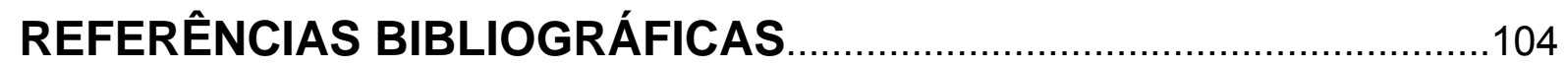

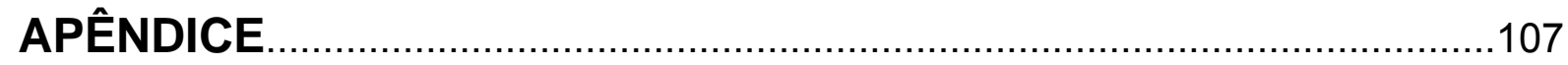




\section{INTRODUÇÃO}

\subsection{Justificativa}

O crescente uso de materiais poliméricos tem gerado preocupações com relação ao seu impacto sobre o meio ambiente. A reutilização de polímeros tem sido um tema importante, o qual recebeu muita atenção nas últimas décadas, visando à minimização desse impacto ambiental. De um modo geral, a mistura de diferentes tipos de polímero não gera materiais de boas propriedades mecânicas. Este processo de mistura é prejudicado devido à separação das fases referentes aos diferentes polímeros. Durante o processo, um dos polímeros deve se misturar ao outro na forma de gotas, sendo que, quanto menor forem estas gotas, melhor é a qualidade do material resultante da mistura. A adição de um compatibilizante favorece este processo, pois ele reduz o tamanho das gotas durante a mistura. Uma alternativa viável para processar a reação do polímero com o compatibilizante é a utilização de extrusoras. Este processo permite reaproveitar polímeros, com bom controle sobre as propriedades do material reciclado. Além de reciclar, este método permite modificar polímeros apolares, como as poliolefinas, a fim de melhorar algumas de suas propriedades, como polaridade, adesão com metal, vidro ou cerâmica e a compatibilidade com poliamidas e poliésteres. Este tipo de processo pode ser estudado para se produzir novos materiais para diferentes aplicações. O polímero que incorpora o compatibilizante ligado em suas cadeias denomina-se polímero enxertado, ou seja, ele foi modificado a nível molecular e possui uma pequena fração deste novo material.

A modificação química tem sido estudada em poliolefinas como o polipropileno e o polietileno. Em geral, os compatibilizantes usados são: anidrido maleico, anidrido ftálico e ácido acrílico.

Estudos específicos têm sido realizados nessa área. Foi investigado que o polipropileno na forma fundida pode ser enxertado com anidrido maleico, gerando um material compatível com outros polímeros e que possui melhor adesão interfacial com vidro e fibra de carbono (SHI et al, 2001). 
De acordo com Severini et al (1999), o polipropileno é o polímero ideal para fabricação de filmes para embalagem. Porém, apesar de ser impermeável à umidade, ele não é impermeável ao oxigênio, o qual pode afetar alimentos e outros materiais. Portanto, necessita-se de uma barreira que seja capaz de impedir a passagem do oxigênio através do polipropileno, protegendo o produto. A obtenção deste tipo de propriedade é possível através da adição de materiais polares ao filme de polipropileno (enxerto). Nesse estudo, Severini et al (1999) mostram que a reação de enxerto de anidrido maleico em polipropileno pode ser realizada com um filme do polímero em contato com os demais reagentes em fase vapor.

A reação de enxerto de anidrido maleico em polipropileno tem início através da decomposição de um peróxido orgânico (iniciador), o qual age como fonte de radicais livres. Este tipo de reação, além de ser processada com o polímero na forma de filme, também pode ser realizada com o mesmo na forma fundida ou em solução. As reações podem ser processadas continuamente em extrusoras e também, em regime descontínuo, dentro de recipientes (reômetros de torque, etc.).

Nos estudos experimentais realizados com polipropileno e anidrido maleico, obtém-se um grau de enxerto que é função das variáveis: tipo e concentração do peróxido (iniciador), concentração do anidrido maleico, tempo de reação, temperatura, velocidade de mistura, sequência de alimentações, presença de estabilizantes, etc. Vários trabalhos experimentais tem sido publicados com foco no estudo empírico da influência das principais variáveis envolvidas no processo de enxerto de anidrido maleico em polipropileno. Os resultados experimentais desses trabalhos mostram que o grau de enxerto (quantidade de anidrido incorporada ao polímero) varia de maneira relativamente complexa (não linear) com as quantidades de anidrido e iniciador adicionadas. Alem disso, vários trabalhos da literatura discutem possíveis reações que comporiam o mecanismo reacional do processo de enxerto, que possibilitariam explicar pelo menos qualitativamente as observações.

Por outro lado, comparativamente, poucos trabalhos foram publicados com 0 foco na modelagem matemática do processo, visando não apenas a interpretação qualitativa, mas também a previsão quantitativa dos resultados. O presente trabalho insere-se nesta linha de pesquisa no sentido de obter um modelo capaz de representar de forma quantitativa as principais variáveis deste processo. 


\subsection{Objetivo}

O objetivo do presente trabalho foi desenvolver um modelo matemático para a modificação química do polipropileno com anidrido maleico em extrusora ou misturador, capaz de representar as principais variáveis deste processo. O processo pode ser realizado em batelada (tanque de mistura) ou continuamente (extrusora). O modelo é baseado nas equações de balanço de massa e de momentos para as espécies envolvidas nas reações, conforme o modelo desenvolvido por Giudici (2007). No presente trabalho, são propostas novas considerações neste modelo, a fim de melhor representar as tendências dos dados experimentais e obter uma melhor previsão dos mesmos. Para a validação foram empregados dados experimentais de reações de enxerto, tanto em extrusoras como em misturadores.

\subsection{Estrutura do trabalho}

O presente trabalho está estruturado conforme descrito a seguir.

No capítulo 2 é feita a revisão da literatura, a qual descreve o uso da extrusora em processos de enxerto, os diferentes estudos experimentais realizados em laboratórios de pesquisa e os modelos matemáticos já desenvolvidos. No capítulo 3 é apresentada a metodologia utilizada, a qual descreve os dois modelos desenvolvidos e os métodos utilizados para a verificação dos valores dos parâmetros utilizados em cada um.

O capítulo 4 contém os resultados das simulações, validando o modelo com dados experimentais da literatura e também das comparações dos parâmetros ajustados. O capítulo 5 apresenta as discussões referentes aos resultados de cada modelo e às comparações dos parâmetros utilizados.

Nos capítulos 6 e 7 são apresentadas as conclusões e recomendações respectivamente. 


\section{REVISÃO BIBLIOGRÁFICA}

\subsection{Extrusão reativa}

A extrusora é um equipamento que permite processar materiais viscosos, tanto no aspecto de homogeneização física de misturas como no de reações químicas, sendo que neste ultimo caso o processo se denomina extrusão reativa. $\mathrm{A}$ extrusora é constituída de um cilindro aquecido contendo uma ou duas roscas em seu interior (single ou twin screw extruder). A Figura 1 mostra o esquema de uma extrusora de rosca única.

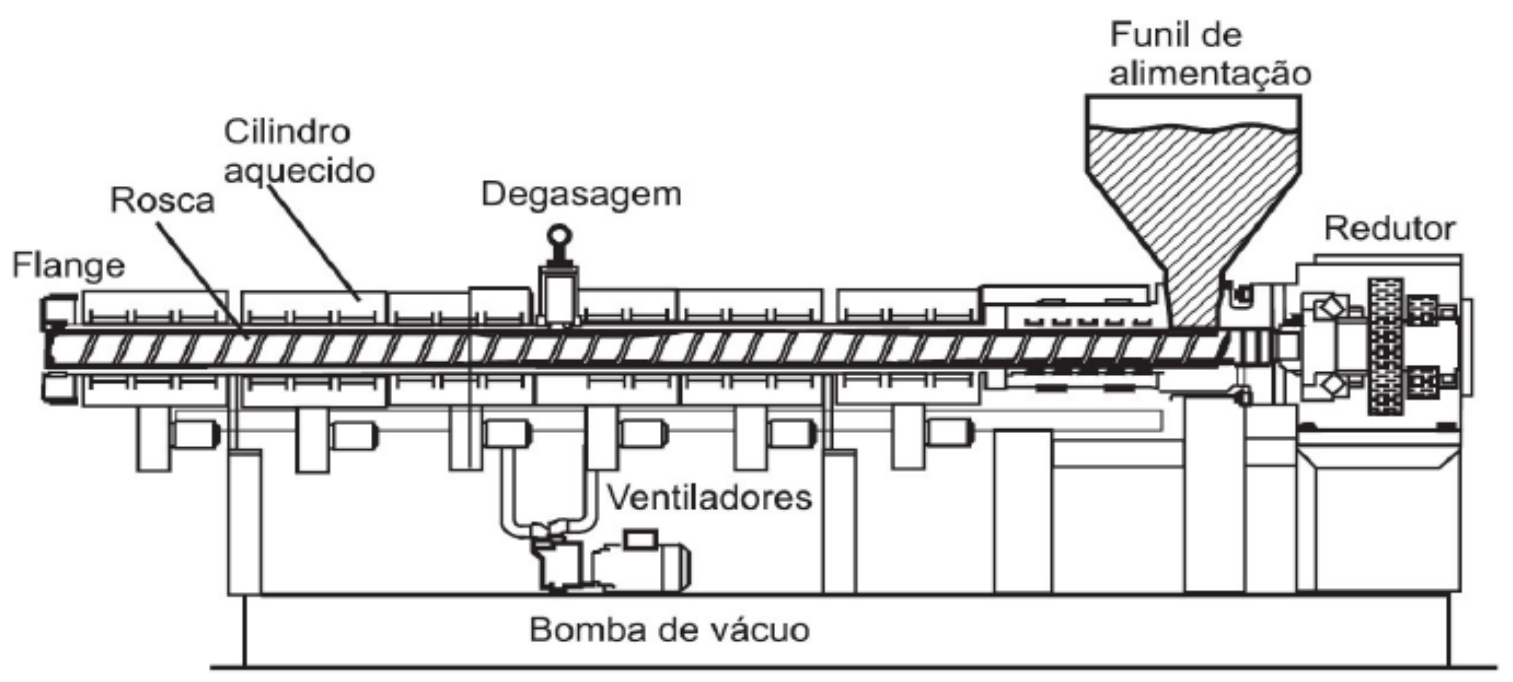

Figura 1 - Extrusora de rosca única (ALBUQUERQUE, 2000 apud SBRT, 2006).

Estudos mais antigos envolviam extrusoras de rosca única. O primeiro registro de aplicação da extrusora de rosca dupla foi feito por I.G. Farbenindustrie, na década de 1940. A modificação de polímeros tem sido um dos temas mais comuns de extrusão reativa. Esforços para modificar poliolefinas com peróxidos e combinações de peróxidos com um segundo monômero estão em progresso desde a década de 1960. Maior atenção tem sido dada para o enxerto de anidrido maleico $(\mathrm{MAH})$ em poliolefinas, o qual tem se mostrado capaz de produzir com sucesso, agentes compatibilizantes entre poliolefinas e poliamidas (CHANG e WHITE, 2003). 


\subsection{Enxerto de anidrido maleico (MAH) em Polipropileno (PP) na forma fundida}

Em comparação com outros monômeros vinílicos, o anidrido maleico é mais adequado para o processo de enxerto devido ao seu baixo custo e baixa tendência à homopolimerização. Segundo Heinen et al (1996), a temperatura teto de homopolimerização do MAH (temperatura acima da qual a reação de propagação é termodinamicamente desfavorável) é de $108^{\circ} \mathrm{C}^{1}$. No processo convencional de produção de polipropileno enxertado com anidrido maleico, o iniciador se decompõe termicamente gerando radicais primários que vão abstrair hidrogênio das cadeias de polipropileno, as quais se tornam macro-radicais. O MAH difundido através do polímero fundido, reage com os macro-radicais formando o polímero enxertado (PAN et al, 2003).

Este processo, em geral, utiliza peróxidos orgânicos como iniciadores. A Tabela 2.1 mostra propriedades do $\mathrm{MAH}$, do PP e de alguns peróxidos utilizados como iniciador.

Tabela 2.1 - Propriedades dos reagentes do processo de enxerto de MAH em PP.

\begin{tabular}{|c|c|c|c|c|c|}
\hline Composto & Sigla & $\begin{array}{c}\text { Massa } \\
\text { molecular } \\
(\mathrm{g} / \mathrm{mol}) \\
\end{array}$ & $\begin{array}{l}\text { Ponto de } \\
\text { fusão }\left({ }^{\circ} \mathrm{C}\right)\end{array}$ & $\begin{array}{c}\text { Ponto de } \\
\text { ebulição } \\
\left({ }^{\circ} \mathrm{C}\right)\end{array}$ & $\begin{array}{c}\text { Densidade } \\
(\mathrm{g} / \mathrm{mL})\end{array}$ \\
\hline Polipropileno & PP & $45000^{(b)}$ & $162-171^{(\mathrm{e})}$ & $N A^{(e)}$ & $0,90-0,91^{(\mathrm{e})}$ \\
\hline Anidrido maleico & $\mathrm{MAH}$ & $98^{(d)}$ & $57-60^{(d)}$ & $202^{(d)}$ & $1,50^{(d)}$ \\
\hline Peróxido de dicumila & $\mathrm{DCP}$ & $270^{(\mathrm{c})}$ & $39,5^{(f)}$ & $130^{(\mathrm{f})}$ & $1,10^{(\mathrm{c})}$ \\
\hline $\begin{array}{l}2,5 \text {-dimetil-2,5-bis-(t- } \\
\text { butilperoxi) hexano }\end{array}$ & DBHA & $290^{(\mathrm{c})}$ & $1-10^{(g)}$ & $N A^{(g)}$ & $1,60^{(\mathrm{c})}$ \\
\hline $\begin{array}{l}\text { 2,5-dimetil-2,5-di-(t- } \\
\text { butilperoxi) hexano }\end{array}$ & DHBP & $230^{(i)}$ & $1-10^{(g)}$ & $N A^{(g)}$ & $1,60^{(\mathrm{c})}$ \\
\hline $\begin{array}{c}\text { Di (terc- } \\
\text { butilperoxiisopropil) } \\
\text { Benzeno }\end{array}$ & $P \times 14^{(a)}$ & $338^{(c)}$ & $N A^{(h)}$ & $N A^{(h)}$ & $0,87^{(\mathrm{c})}$ \\
\hline
\end{tabular}

NA: Não aplicável, o composto se decompõe antes de mudar de estado. (a) Sigla referente a um nome comercial (AKZO, 2007). (b) Massa molecular média numérica considerada no presente trabalho, com base na referência: Shi et al (2001). Fontes consultadas: (c) Akzo (2007); (d) Perry (1984); (e) Brandrup (1989); (f) Shoshenskiy (2006a); (g) Shoshenskiy (2006b) e (h) Shoshenskiy (2006c); (i) Chang e White (2003). O hífen indica faixa de valores.

\footnotetext{
${ }^{1}$ Temperatura teto para uma concentração de $1 \mathrm{M}$ de MAH.
} 
Breves descrições de alguns estudos envolvendo polipropileno e anidrido maleico, estão relatadas a seguir.

Bettini e Agnelli (1999) estudaram o enxerto de polipropileno em um reômetro de torque, variando as concentrações de peróxido e anidrido maleico, velocidade de mistura e tempo de reação. Eles mediram a quantidade de anidrido maleico enxertado e o índice de fluidez do polímero e analisaram os resultados através de um modelo empírico.

Martinez et al (1994) estudaram o processo na forma fundida e em solução (em xileno), variando as concentrações de peróxido e anidrido maleico e o tempo de reação.

Machado et al (2001) estudaram o processo contínuo em uma extrusora e mediram o grau de enxerto e a viscosidade dinâmica em amostras coletadas ao longo do eixo da extrusora.

Shi et al (2001) mediram o grau de enxerto e os pesos moleculares médios de polipropileno enxertado em uma extrusora. Eles também tentaram caracterizar a estrutura química encontrada no polímero enxertado e propuseram um mecanismo para explicar os resultados.

Heine et al (1996) caracterizaram diferentes poliolefinas enxertadas com anidrido maleico e discutiram possíveis etapas do mecanismo reacional para explicar as estruturas observadas.

Trolez et al (1990) analisaram dados experimentais de polipropileno enxertado com anidrido maleico e mostraram que o número de cadeias enxertadas é maior que o número de radicais gerados pela decomposição do peróxido, o que seria uma evidência da ocorrência de transferência de cadeia entre radicais enxertados e moléculas de polímero.

A seguir, são descritos os processos utilizados na produção do polímero enxertado e as etapas realizadas no laboratório, para fins de pesquisa.

\subsubsection{Processo em extrusora}

Antes de ser processada a reação, os reagentes (polipropileno, anidrido maleico e iniciador) são pré-misturados e alimentados à extrusora. Dentro da 
extrusora, o conteúdo reacional passa por diferentes regiões. Na primeira região ocorre a fusão dos componentes e sua mistura no estado líquido. A segunda região é responsável pelo processamento das reações e na terceira região é feita a retirada do produto final a ser purificado. Shi et al (2001) estudaram o processo de enxerto em extrusora e utilizaram $175^{\circ} \mathrm{C}$ na região de alimentação, $190^{\circ} \mathrm{C}$ na região de reação e $180^{\circ} \mathrm{C}$ na saída da extrusora. Neste estudo, eles utilizaram um tempo de residência de 2 minutos.

\subsection{Processo em batelada}

Neste processo usa-se um tanque de mistura e as reações são processadas em regime descontínuo. Antes de serem adicionados ao tanque de mistura, os reagentes são pré-misturados em um tambor rotativo. Cha e White (2001) estudaram o enxerto de anidrido maleico em polipropileno em um tanque de mistura. Eles utilizaram a temperatura de $230^{\circ} \mathrm{C}$ e um período de reação de 10 minutos. Neste estudo foi observado que a reação já se completou antes dos 3 primeiros minutos, que é um período próximo ao tempo de residência utilizado na extrusora.

\subsubsection{Reações envolvidas}

As reações se iniciam no instante em que a temperatura é suficiente para decompor termicamente o iniciador (peróxido orgânico). Na literatura foram encontrados trabalhos em que se utilizam iniciadores monofuncionais, que possuem um único grupo peróxido e bifuncionais, que possuem dois grupos peróxido. A Figura 2 mostra a reação de degradação térmica de um iniciador monofuncional. 

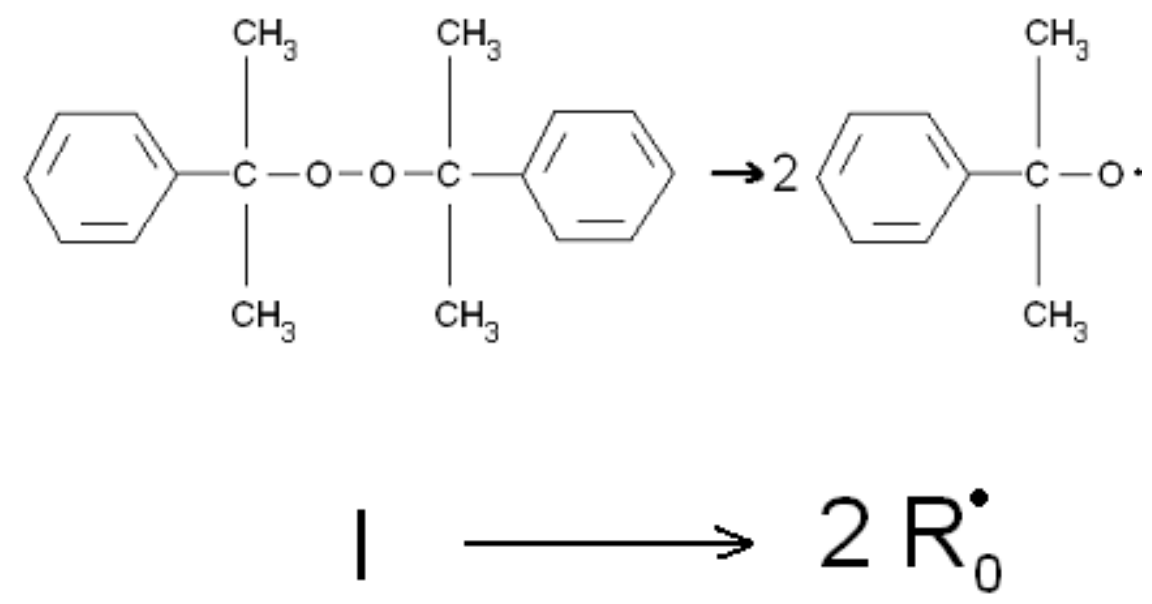

Figura 2: Degradação do peróxido de dicumila (DCP) e representação genérica da decomposição do iniciador no processo.

Na Figura 3, apresenta-se um conjunto das prováveis reações envolvidas no mecanismo do processo de enxerto de MAH em PP, conforme proposto por Shi et al (2001).

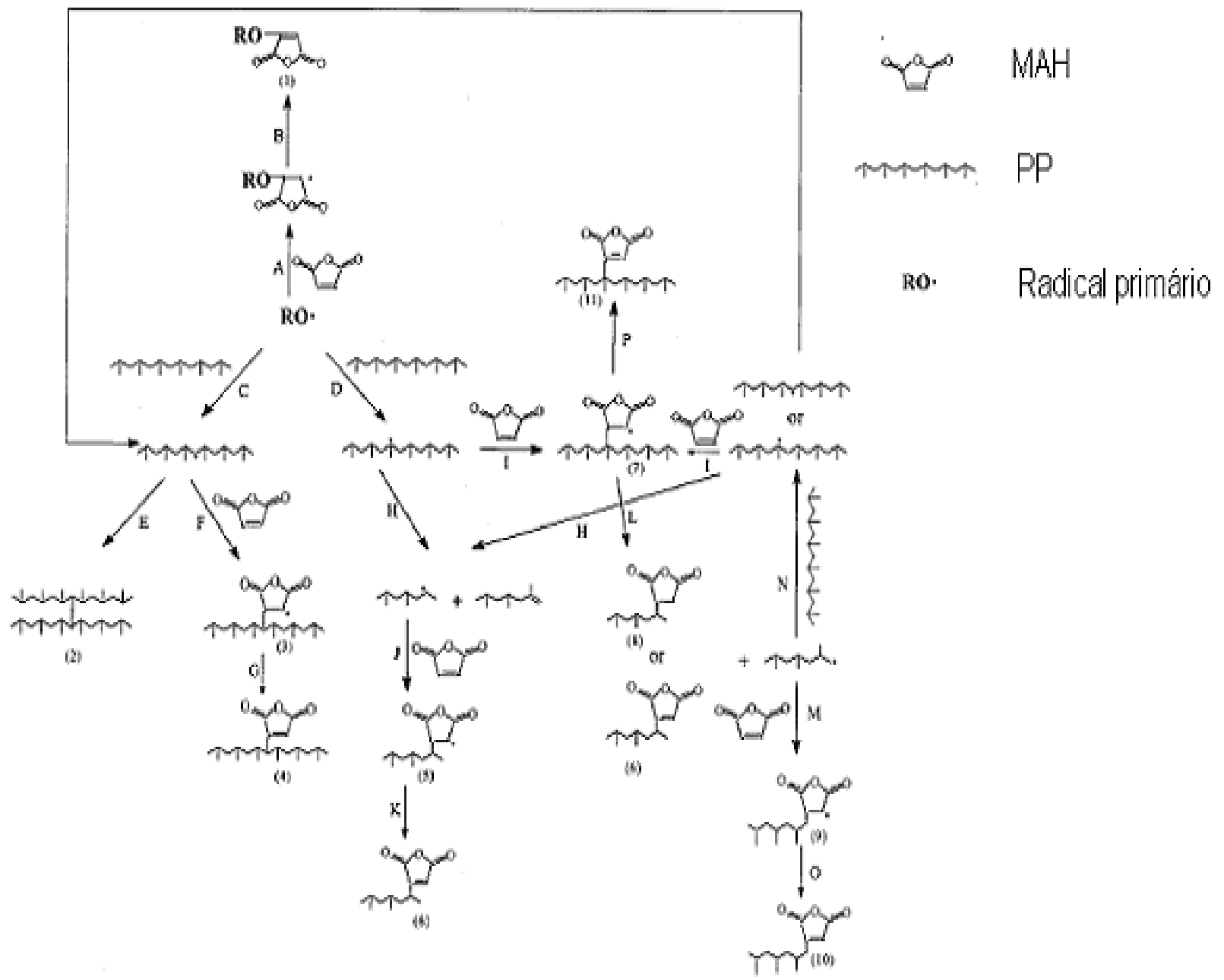

Figura 3 - Mecanismo das reações de enxerto de MAH em PP (SHI et al, 2001). 
A decomposição do iniciador gera radicais primários, os quais abstraem hidrogênio de cadeias de polímero (reações C e D), formando radicais backbone, (cujo elétron ativo se encontra em alguma unidade monomérica intermediária da cadeia). Esses radicais gerados pelo iniciador também podem reagir com anidrido maleico (reação A) consumindo parte de sua quantidade adicionada ao processo. Os radicais backbone formados podem se combinar entre si formando ligações cruzadas (reação E), porém a terminação predominante neste processo é por desproporcionamento (reações $B, G, K, L, O$ e P). Outra reação possível é a cisão beta do radical backbone (reação $\mathrm{H}$ ), formando uma cadeia de polímero morto (inativa) e um radical com elétron desemparelhado na extremidade da cadeia. Esta reação de cisão contribui para a redução do peso molecular médio do polímero. Os macro-radicais reagem também com o anidrido maleico, formando cadeias enxertadas (reações F, I, J e M).

\subsubsection{Purificação}

A purificação do produto obtido pode ser feita através de extrações e secagens. Ao sair do reator, o conteúdo sofre uma primeira extração com acetona, a qual solubiliza o MAH não reagido e seus oligômeros formados durante reação. Após esta etapa, a parte não solúvel na acetona é submetida à secagem e então é dissolvida em xileno à $135^{\circ} \mathrm{C}$. A solução resultante é adicionada lentamente em acetona gerando um precipitado que contém a maior quantidade do PP enxertado e uma solução contendo uma pequena quantidade de PP de baixo peso molecular. A Este procedimentos de purificação foi utilizados por Shi et al (2001) e está esquematizado na Figura 4.

\subsubsection{Determinação do grau de enxerto}

No estudo experimental de Shi et al (2001), o resíduo de PP enxertado, extraído na etapa de purificação, é analisado. 


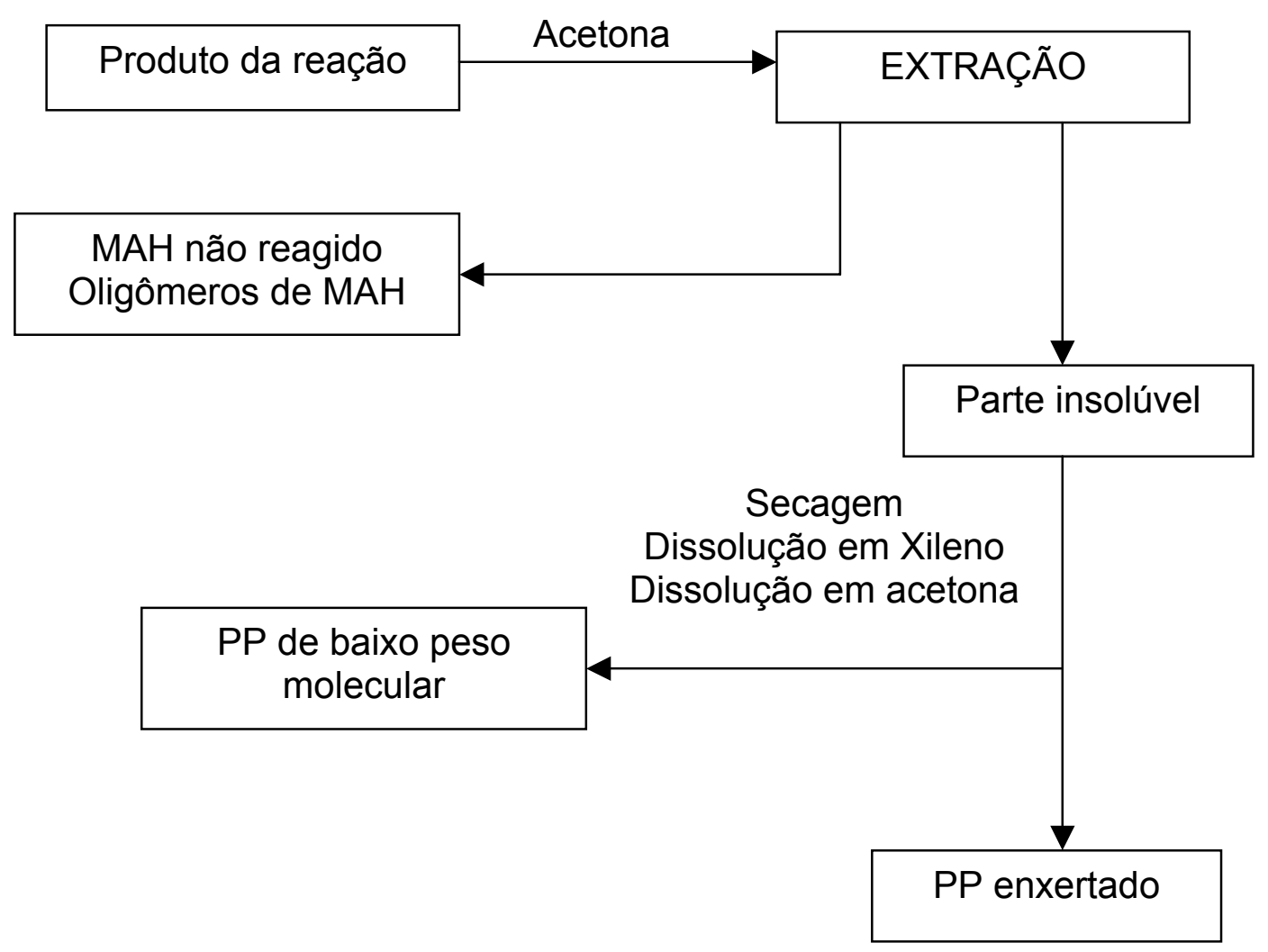

Figura 4 - Purificação do PP enxertado com MAH.

Após a secagem deste resíduo durante $24 \mathrm{~h}$ em um forno à vácuo na temperatura de $90^{\circ} \mathrm{C}$, uma amostra de $1 \mathrm{~g}$ é retirada para análise. Esta amostra é dissolvida em $100 \mathrm{~mL}$ de xileno em ebulição num frasco cônico, juntamente com poucas gotas de água para hidrolisar todas funções anidrido. Após esta etapa, são adicionados ao frasco $10 \mathrm{~mL}$ de uma solução de hidróxido de potássio à $0,05 \mathrm{~N}$. 0 conteúdo é titulado com uma solução tricloroacética em xileno à $0,03 \mathrm{~N}$, utilizando vermelho de cresol como indicador.

Cha e White (2003) também separam o PP enxertado através de extração e secagem, porém utilizam espectroscopia de infravermelho para quantificar o grau de enxerto.

\subsubsection{Resultados de estudos experimentais (Literatura)}

Nos trabalhos de Shi et al (2001) e Cha e White (2003) foram observadas semelhanças nos resultados de grau de enxerto obtidos (Figuras 5 e 6). Em ambos 
os casos (reação em extrusora e em misturador), nota-se um grau de enxerto máximo para cada série de dados (\% de iniciador) em relação à concentração de MAH. A Figura 5 mostra os resultados do estudo feito no misturador, utilizando o iniciador 2,5-Di-metil-2,5-bis-(t-butilperoxi) hexano (DBHA).

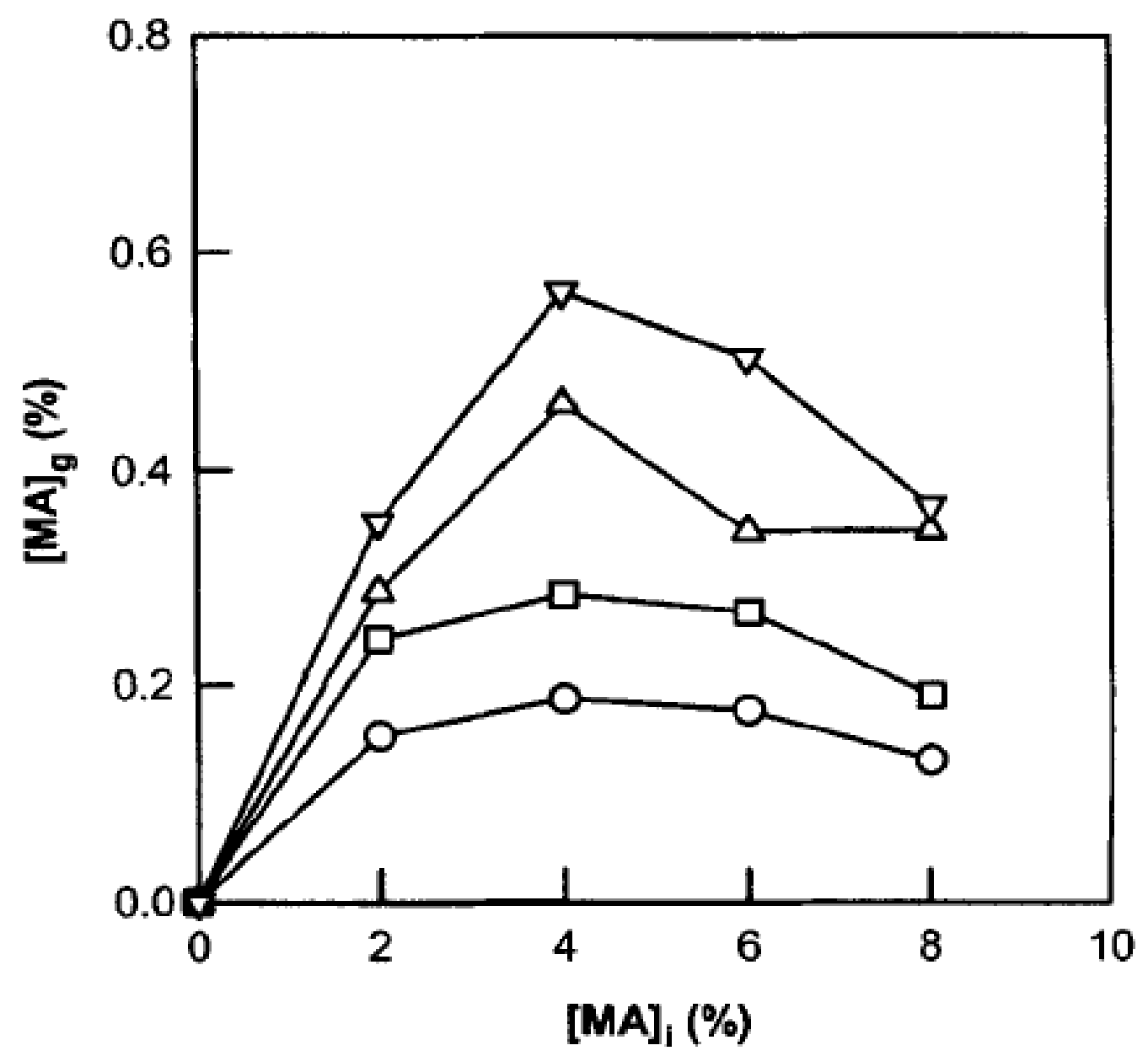

Figura 5 - Efeito da concentração $[\mathrm{MA}]_{\mathrm{i}}\left(\mathrm{MAH}\right.$ inicial) sobre o grau de enxerto $\left([\mathrm{MA}]_{\mathrm{g}}\right)$ para o processo realizado no misturador. Concentrações de iniciador (\% massa): $(\mathbf{O}): 0,18 \%,(\square): 0,37 \%$, $(\boldsymbol{A}): 0,55 \%,(\boldsymbol{\nabla}): 0,73 \%$ (CHA e WHITE, 2001).

Observa-se que à medida que se aumenta a concentração de iniciador, obtêm-se maiores graus de enxerto. Uma explicação para este comportamento é que o aumento da concentração de iniciador gera maior número de radicais primários, ocorrendo assim maior taxa de abstração de hidrogênio das cadeias de polímero. Com isto, há um aumento da concentração de macro-radicais e consequente geração de mais polímero enxertado. Na Figura 5 observa-se um ponto de máximo em torno de $4 \%$ de MAH para os quatro casos. Entende-se que quanto maior a concentração de $\mathrm{MAH}$, maior é a taxa da reação de enxerto. Porém, 
após esse ponto de máximo, ocorre um comportamento contrário (decréscimo no grau de enxerto). Uma explicação para este comportamento é que o excesso de MAH aumenta a taxa de reação deste com radicais primários. Desta forma diminuise a taxa de geração de macro-radicais e conseqüentemente diminui-se o grau de enxerto.

No estudo de Shi et al (2001), observa-se um detalhe adicional que modifica um pouco as tendências das curvas com relação à Figura 5. A Figura 6 mostra os resultados da reação de enxerto realizada em uma extrusora, utilizando-se o iniciador peróxido de dicumila (DCP).

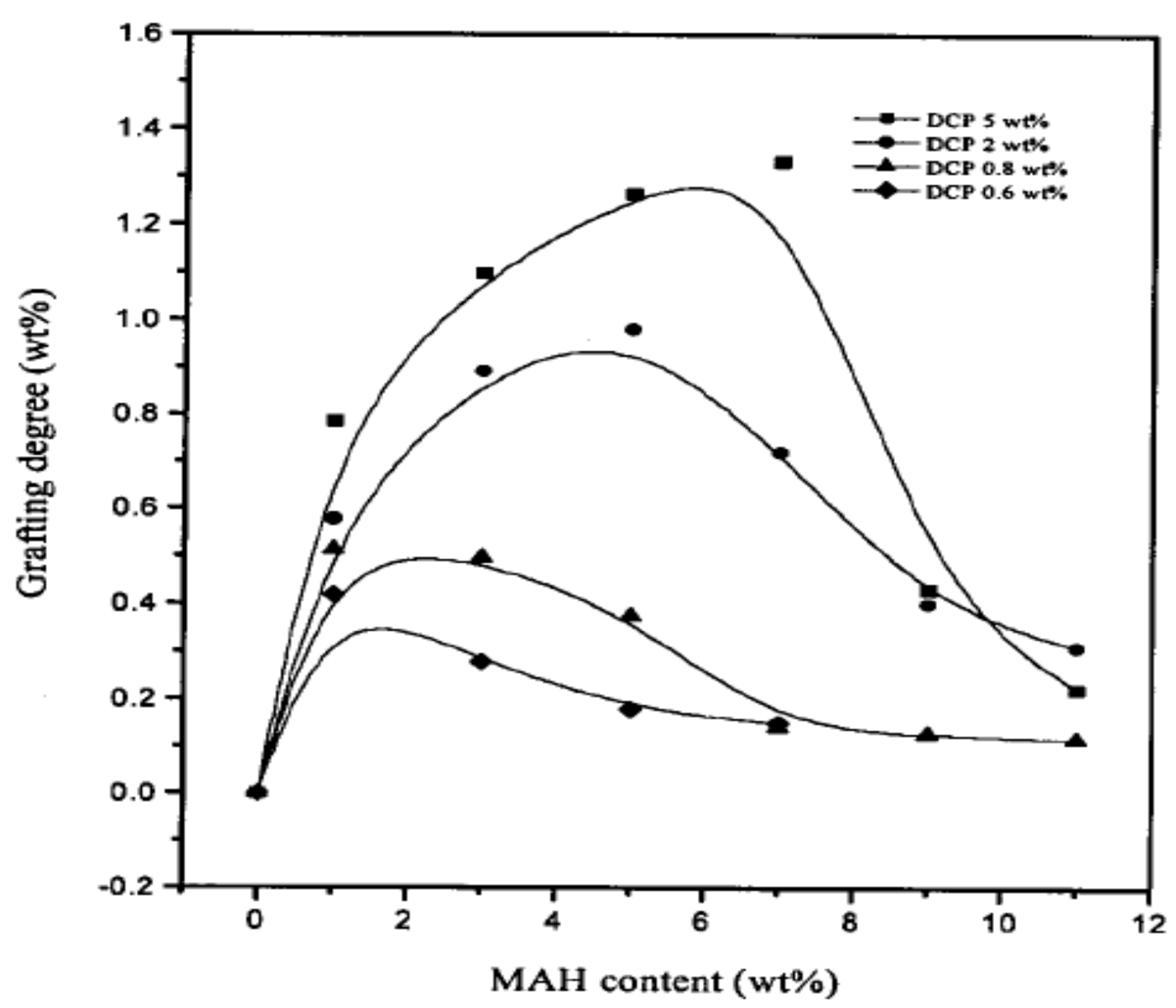

Figura 6 - Efeito da concentração inicial de MAH sobre grau de enxerto para o processo realizado na extrusora (SHI et al, 2001).

Neste estudo observa-se que a concentração de MAH que corresponde ao máximo de grau de enxerto para cada caso não é a mesma, ou seja, varia com a concentração de DCP. Fatores como solubilidade e difusão do anidrido maleico e do iniciador no polipropileno fundido, afetam os resultados de grau de enxerto, uma vez que o meio é muito viscoso. Considerando estes fatores e as diferenças na 
preparação e operação de cada um dos dois processos, supõe-se que os diferentes comportamentos observados nas figuras 5 e 6 podem ser explicados com base nas diferentes taxas de reação (diferentes concentrações dos reagentes) e nos fenômenos físicos envolvidos. Desta forma torna-se importante estudar a variação de parâmetros como solubilidades, segregação de reagentes, etc.

\subsubsection{Utilização de nano-reatores no processo}

O processo de enxerto de anidrido maleico em polipropileno na forma fundida tem sido largamente empregado na indústria devido suas vantagens econômica e operacional. Entretanto o maior problema deste processo é a quebra das cadeias de polímero (SHI et al, 2006). Estudos recentes visaram o controle da seletividade, ou seja, diminuição da quebra de cadeias, através da inserção de nano-reatores no processo. A seguir, é descrito o processo que utiliza nano-reatores, conforme apresentado por Shi et al (2006).

De acordo com os mecanismos de reação até aqui citados, durante as reações de enxerto, um radical primário (formado pela fragmentação do peróxido) pode reagir com MAH ou cadeias de polipropileno. A reação deste radical com uma molécula de $\mathrm{MAH}$ resulta num radical primário enxertado. Este pode terminar por desproporcionamento ou ser um agente de transferência de cadeia, mas não pode crescer para formar oligômeros de MAH e nem participar das reações de enxerto através de terminação por combinação. Supõe-se que os radicais primários são muito mais reativos com os átomos de hidrogênio de carbonos terciários do que secundários ou primários das cadeias de polímero. Espera-se que a concentração de radicais terciários seja muito maior do que a de radicais secundários ou primários. Um macro-radical terciário sofre cisão ou enxerto com MAH. De acordo com os mecanismos já citados, a única maneira de reduzir a cisão de cadeias e manter ou aumentar o grau de enxerto é promovendo a reação entre macro-radicais (predominantemente terciários) e MAH. A idéia básica para favorecer esta reação é criar condições que permitam o aumento localizado da concentração de macroradicais e MAH. Para por isto em prática, uma opção é aplicar o conceito de nanoreatores. Estes podem ter qualquer geometria e devem ter uma de suas dimensões 
da ordem de nanômetros. Sua presença no sistema de reações de enxerto visa confinar as moléculas de peróxido dentro de uma estrutura de escala nanométrica. Os radicais primários formados nestes espaços confinados devem se difundir para fora para que possam reagir com as demais espécies. Supõe-se que a liberação controlada de radicais livres no meio reacional melhora significativamente a eficiência do iniciador, aumenta o grau de enxerto de MAH em PP e diminui o grau de cisão de radicais. Segundo Shi et al (2006), a diferença principal entre os métodos é que em um deles o iniciador foi tratado com o-MMT antes de ser processado. Supõe-se que o alto desempenho no grau de enxerto em relação ao processo convencional é devido ao confinamento do DCP no nano-reator através desse tratamento. Neste estudo, foi utilizado, como nano-reator, montmorilonita modificada organicamente (o-MMT) e foram obtidos os resultados mostrados nas Figuras 7 e 8.

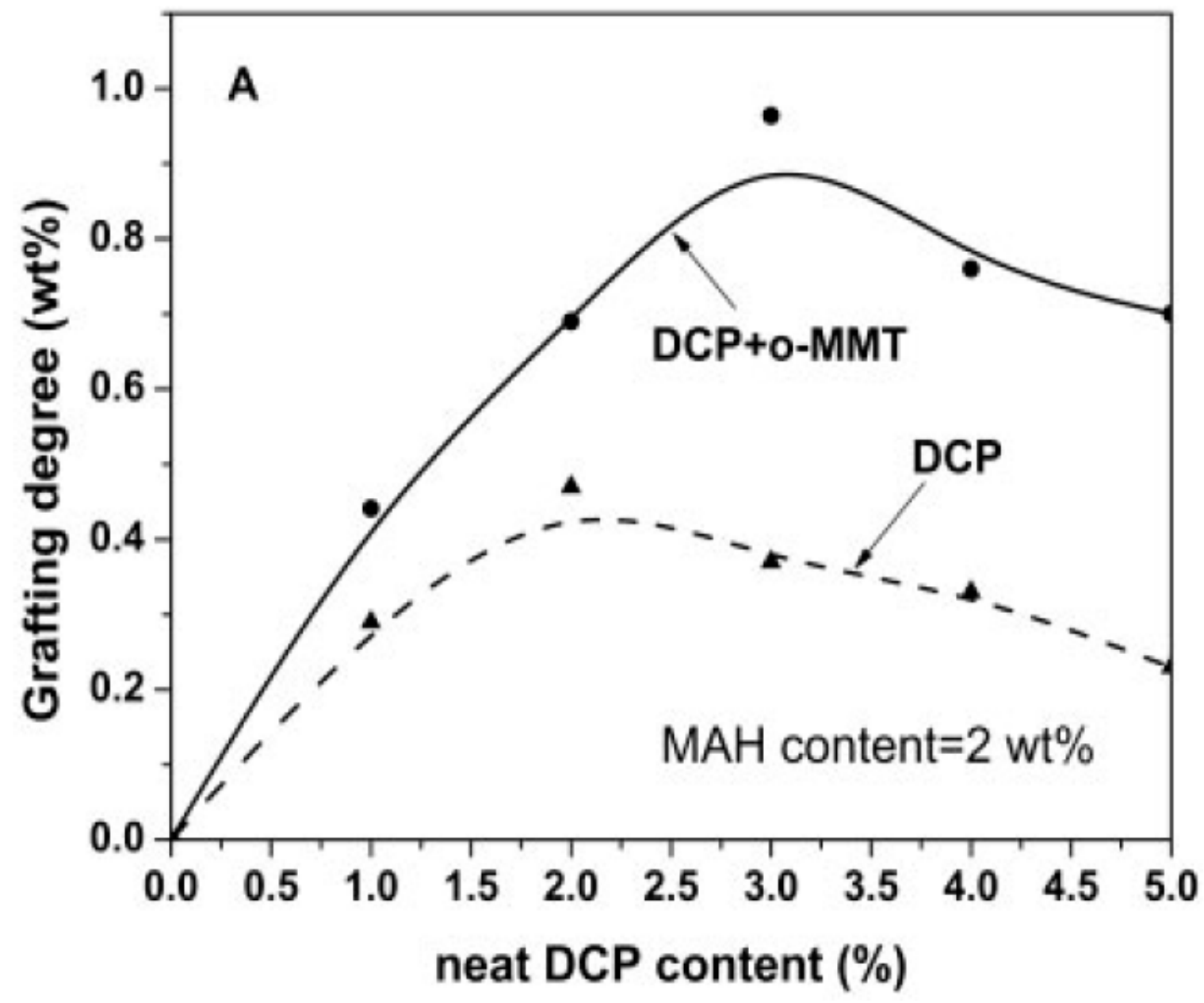

Figura 7 - Grau de enxerto. Comparação entre o processo convencional e o processo que utiliza o nano-reator (SHI et al, 2006). 


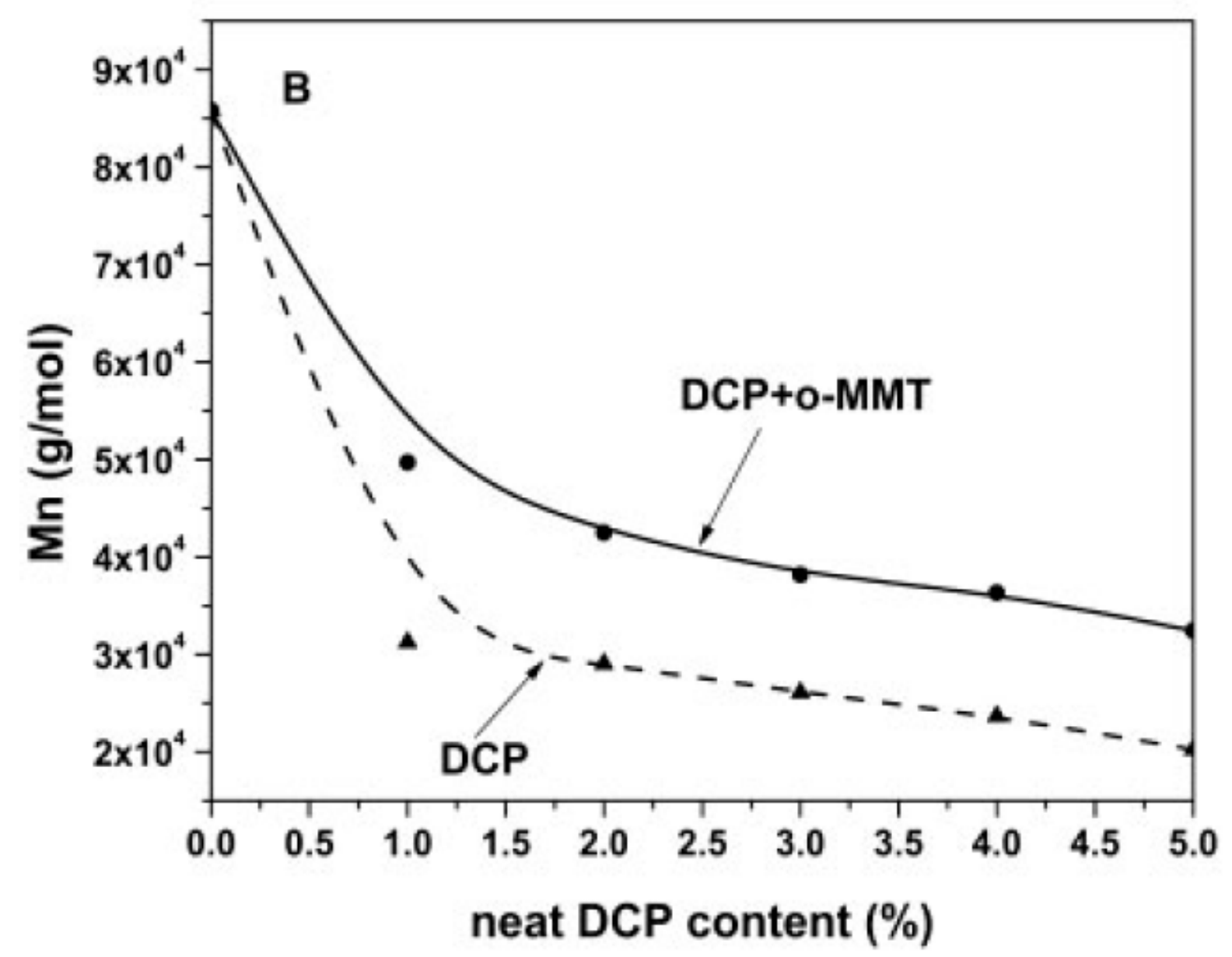

Figura 8 - Massa molecular média numérica. Comparação entre o processo convencional e o processo que utiliza o nano-reator (SHI et al, 2006).

$\mathrm{Na}$ Figura 3, o mecanismo reacional está bem detalhado envolvendo inúmeras reações que, possivelmente, ocorrem no processo de enxerto. A Figura 9 apresenta um mecanismo simplificado com relação à Figura 3, mostrando somente as principais reações para efeito de comparação com o processo que utiliza o nanoreator. De acordo com o mecanismo apresentado na Figura 9, radicais formados por moléculas de peróxido podem seguir os diferentes caminhos:

Caminho $\mathrm{A}$ : $\mathrm{O}$ radical primário reage com $\mathrm{MAH}$ para formar um radical primário enxertado. Este não participa de nenhuma reação de enxerto porque ele não pode propagar, pode somente transferir cadeia $(\mathrm{C})$ ou terminar por desproporcionamento (B).

Caminho D: O radical primário reage com um átomo de hidrogênio do PP para formar um macro-radical. 


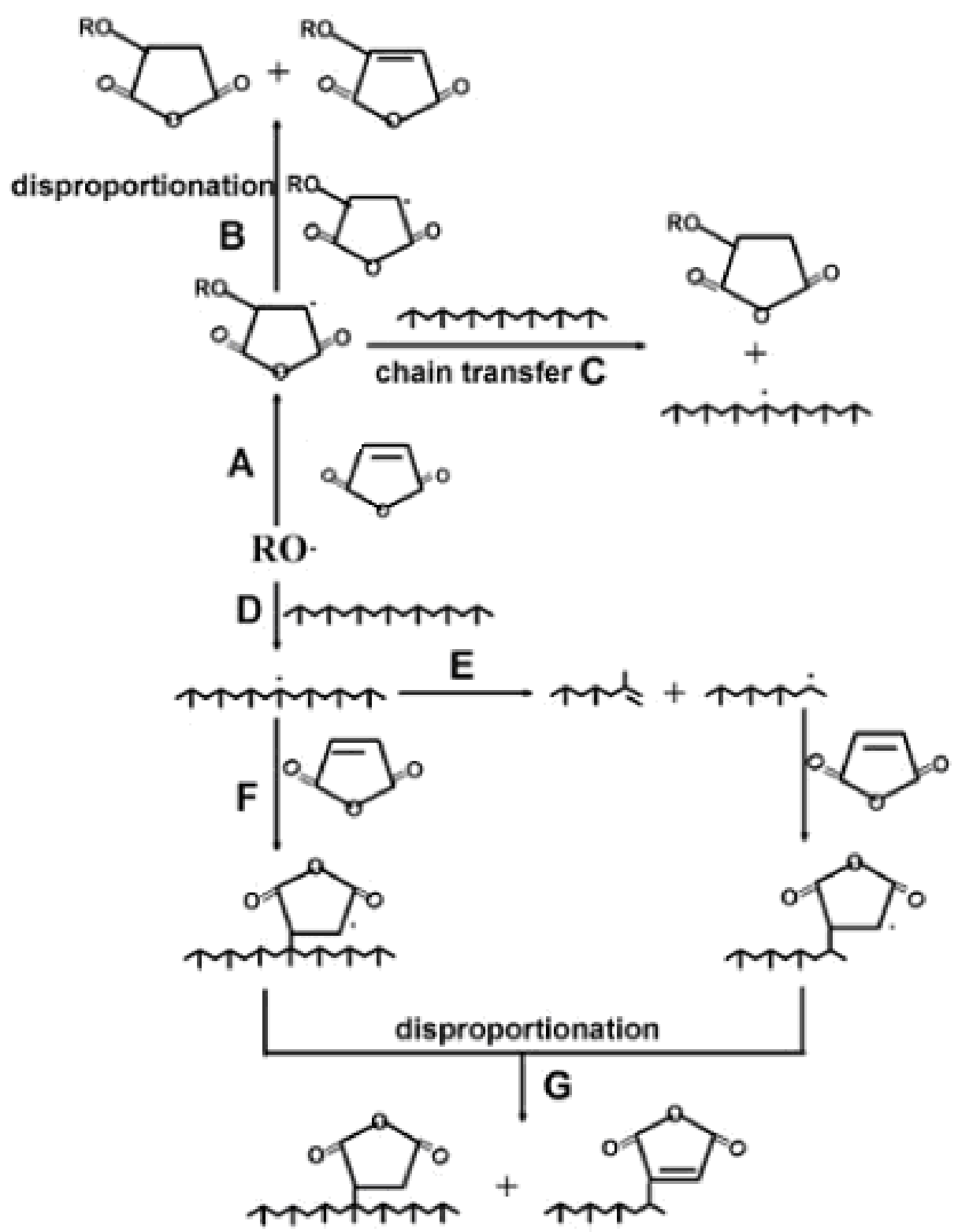

Figura 9 - Esquema reacional simplificado do processo convencional (SHI et al, 2006).

Os macro-radicais formados podem seguir os diferentes caminhos:

Caminho E: Cisão beta de radicais.

Caminho F: Enxerto de MAH para formar o produto desejado.

Enquanto o caminho $E$ é a principal reação prejudicial, o caminho $F$ é a principal reação desejada. Estas reações competem entre si. O mecanismo sugere que para dadas quantidades de PP e MAH, a maximização do grau de enxerto se dá através da adição de mais iniciador ao meio reacional para formar mais macroradicais. Entretanto, a cisão aumentará também. 
Uma diferença importante entre o sistema convencional e o sistema que usa o nano-reator é que, no convencional, os radicais primários são formados dentro de todo o volume reacional. Uma vez formados, eles estão em contato imediato com $\mathrm{PP}$ e/ou MAH. Com o nano-reator, os radicais primários são formados somente dentro das galerias do o-MMT. Eles não podem reagir com MAH ou PP antes de se difundir para fora do o-MMT. Uma vez que a decomposição do DCP é uma reação reversível, a taxa de geração de radicais primários passa a ser muito menor em relação ao sistema convencional. Em outras palavras, o papel desempenhado pelo o-MMT é diminuir a taxa de lançamento de radicais primários dentro do meio reacional. Desta forma, a taxa de geração de radicais primários não é mais controlada apenas pela temperatura, mas também pela difusão. Como as interações de o-MMT com MAH são relativamente fortes, durante o processo, as moléculas de MAH são dirigidas para a superfície das partículas de o-MMT. Portanto, haverá um excesso de MAH nas proximidades da superfície das partículas de o-MMT, onde irão ocorrer as reações de enxerto. Isto pode conduzir a altos graus de enxerto e baixa cisão de radicais.

De acordo com o mecanismo de reação mostrado na Figura 10, o MAH se encontra concentrado na superfície externa das partículas de o-MMT, permitindo interações favoráveis entre estes compostos.

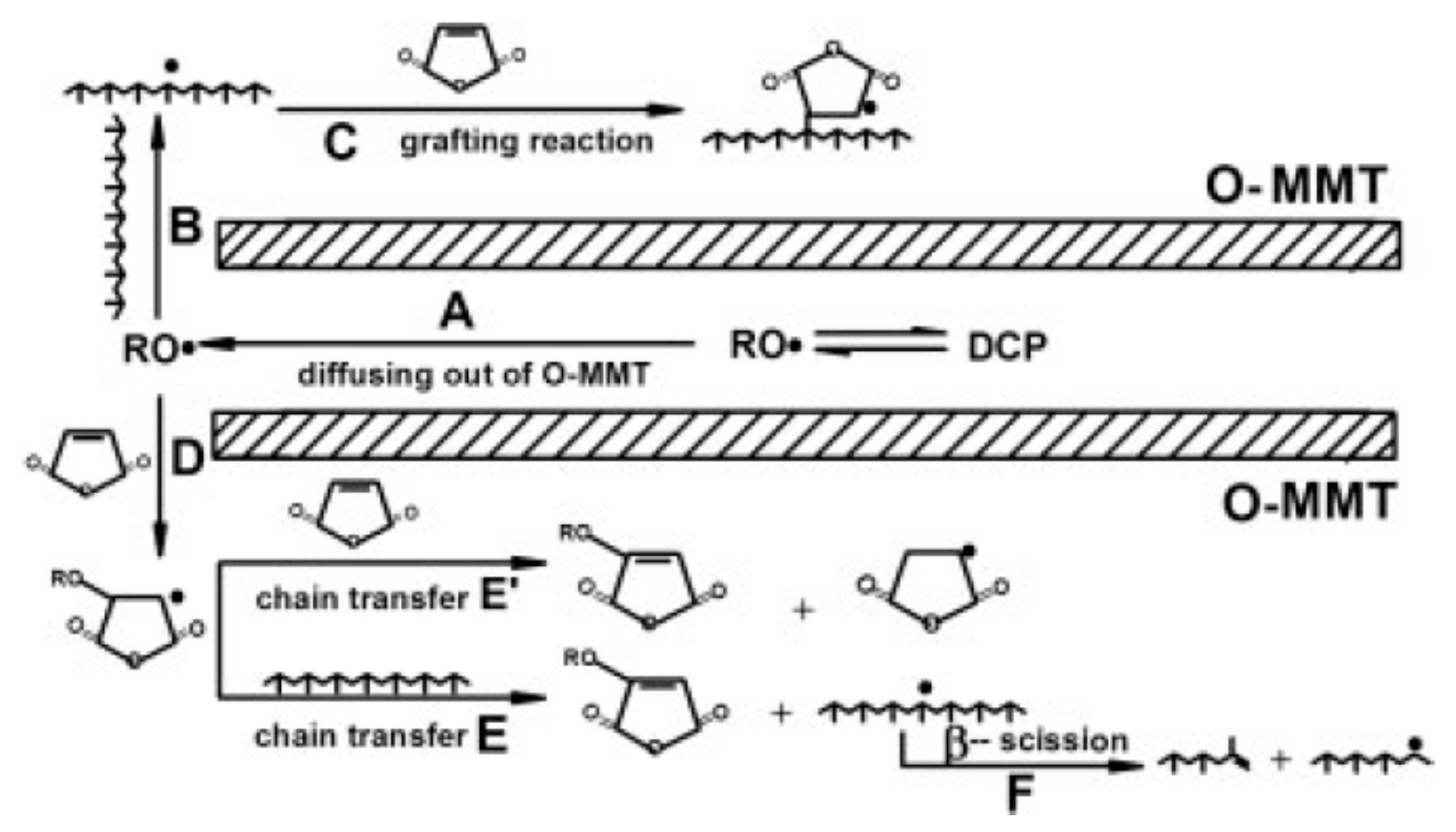

Figura 10 - Mecanismo reacional do processo que utilizou nano-reatores (SHI et al, 2006). 
Entretanto, não há MAH dentro das galerias de o-MMT. Um argumento que opõe esta afirmação é que o MAH é uma molécula pequena e possui interações favoráveis com as galerias de o-MMT, portanto, poderia se difundir rapidamente para dentro delas. No entanto, é possível notar que sob as condições de enxerto no estado fundido, o DCP se decompõe muito mais rápido do que a difusão do MAH para dentro das galerias de o-MMT, havendo assim uma interceptação do anidrido pelos radicais livres que se difundem para fora.

\subsubsection{Modelagem matemática do processo}

Em alguns trabalhos como o de Cha e White (2001), Shi et al (2001) e Severini (1999), foram propostos mecanismos para as reações do processo de enxerto, a fim de explicar os resultados experimentais. Cha e White (2001) descrevem também um equacionamento baseado no mecanismo proposto. Porém, apesar de apresentar mecanismos para as reações, os três autores abordam somente de forma qualitativa os resultados observados. Um modelo quantitativo foi desenvolvido por Zhu et al (2003). Eles consideraram um mecanismo de reação semelhante aos já citados, porém, simularam a reação de enxerto através do método de Monte Carlo. Esta é uma ferramenta poderosa, capaz de prever a estrutura individual de cada cadeia de polímero, mas requer muito esforço computacional. Neste estudo, o modelo desenvolvido foi validado com os dados experimentais apresentados por Shi et al (2001), que estão representados na Figura 5. A Figura 11 mostra o resultado obtido no estudo de Zhu et al (2003) para a simulação com dados de grau de enxerto em função da concentração inicial de $\mathrm{MAH}$.

Giudici (2007) desenvolveu um modelo matemático para a simulação do processo de enxerto de anidrido maleico em polipropileno na forma fundida. Este modelo é baseado em balanços de massa e momentos e considera que o meio reacional é homogêneo. Comparado ao modelo desenvolvido por Zhu et al (2003), esse modelo exige menor esforço computacional e, consequentemente, possui uma resposta mais rápida. 


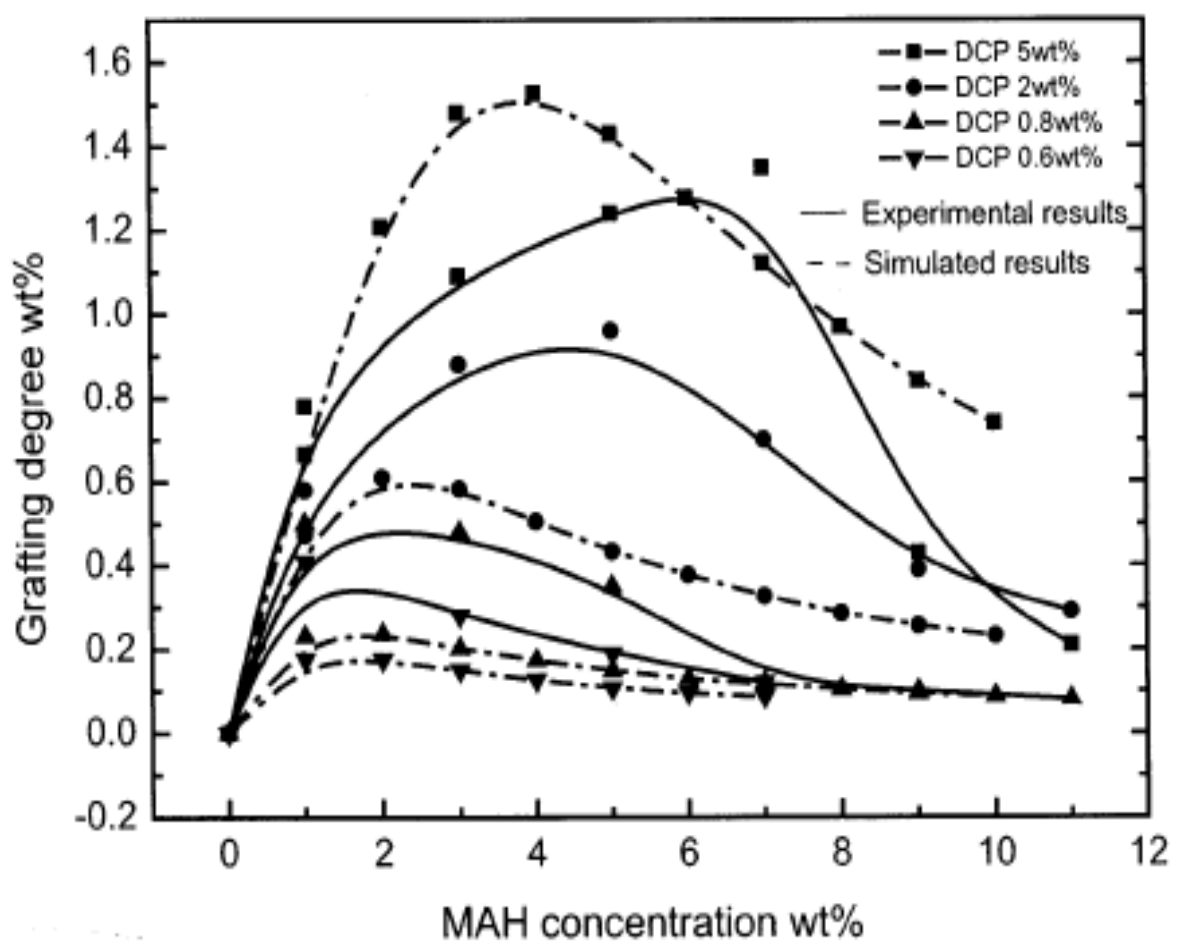

Figura 11 - Resultados da simulação do processo através do método de Monte Carlo (ZHU et al, 2003).

As Figuras 12 e 13 mostram alguns resultados de simulações feitas com o modelo desenvolvido por Giudici (2007).
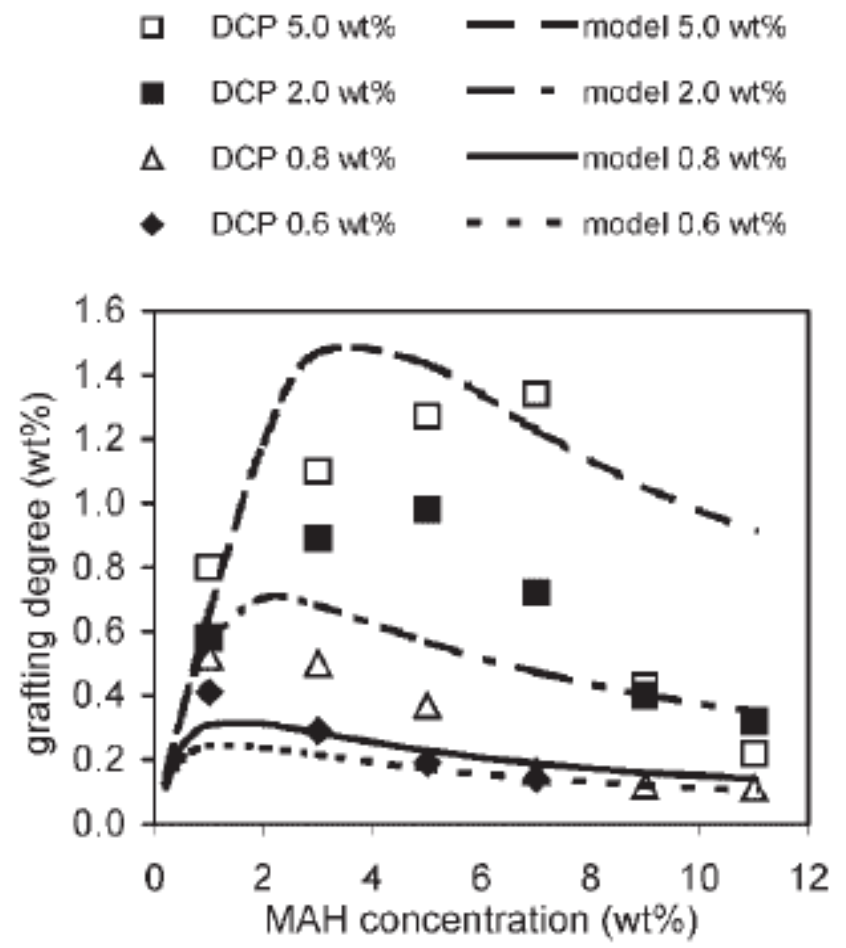

Figura 12 - Resultados da simulação realizada por Giudici (2007) com os dados de Shi et al (2001). 
- $0.36 \%$ wt DBHA, exp.

- $0.36 \%$ wt DBHA, model

- $0.18 \%$ wt DBHA, exp.

- - 0.19\%wt DBHA, model

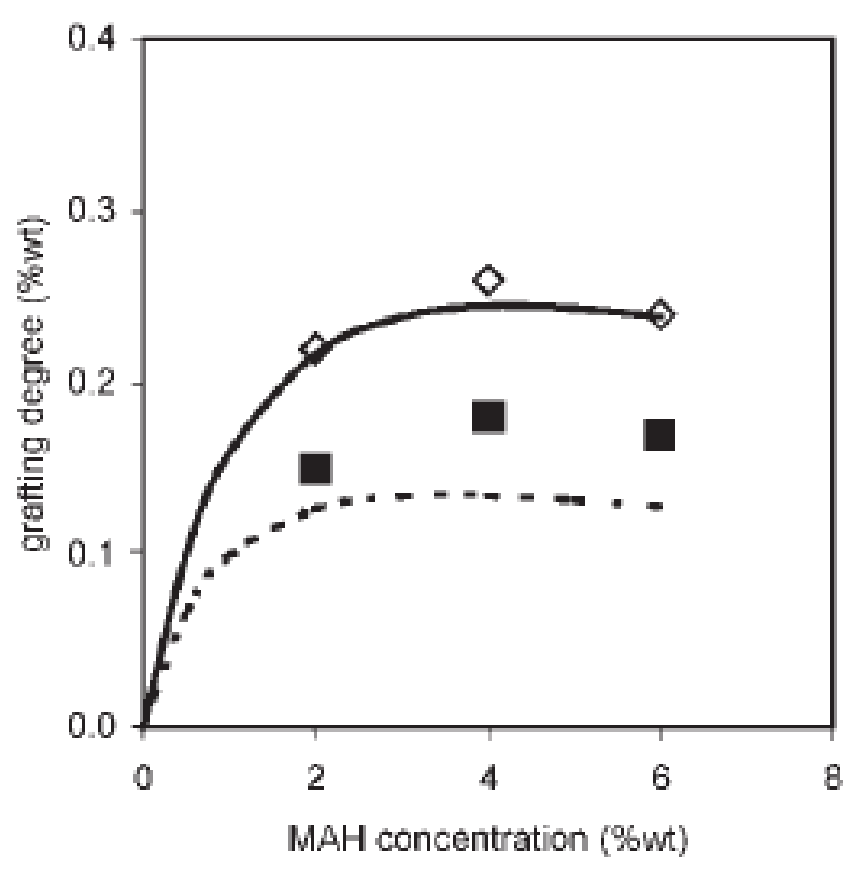

Figura 13 - Resultados da simulação realizada por Giudici (2007) com os dados de Cha e White (2001).

Observa-se que o modelo representa bem as tendências dos dados experimentais. Os parâmetros utilizados neste modelo consistem de constantes de velocidade para as diferentes reações. Portanto, as tendências geradas estão associadas ao comportamento cinético do processo.

Para aplicações industriais, onde se necessita de resposta rápida, que são os casos de otimização e controle de processo, o método de Monte Carlo se torna inviável e modelos baseados em equações de balanço de massa e de momentos (modelo determinístico) são definitivamente mais adequados.

Espera-se que o estudo físico do processo (solubilidades entre os reagentes, taxa de transferência de massa, etc.) permita incrementar o modelo em questão, com novos parâmetros. Com estes parâmetros adicionais, espera-se que o modelo se aproxime mais do comportamento real do processo, fornecendo melhor predição de resultados experimentais. 


\section{METODOLOGIA}

No presente trabalho, são propostos e testados dois modelos matemáticos diferentes para simular o processo de enxerto de anidrido maleico em polipropileno na forma fundida (Modelos 1 e 2), nos quais a heterogeneidade do meio é considerada. Nos dois modelos desenvolvidos, são ajustados os valores das constantes de velocidade das reações envolvidas. As hipóteses, reações e equações utilizadas em ambos os modelos estão descritas a seguir.

\subsection{Modelo 1}

Neste modelo considera-se que houve uma pré-mistura dos reagentes (PP, MAH e I) no estado sólido em forma de pó e/ou grãos maiores. Esta mistura pode ser feita com o auxilio de um solvente (seguida de evaporação do mesmo) ou sem solvente conforme mostrado na Figura 14.

\section{Tambor rotativo}

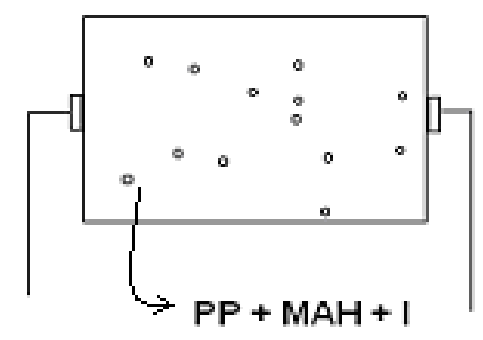

Figura 14 - Pré mistura (partículas secas)

Após a pré-mistura, o conteúdo é adicionado ao reator, que pode ser uma extrusora ou misturador em batelada (considerado como um tanque de mistura). Nesta etapa ocorre o aquecimento e conseqüente fusão dos reagentes, havendo assim o primeiro contato entre os mesmos na fase líquida. A Figura 15 ilustra esta etapa em um tanque de mistura. 


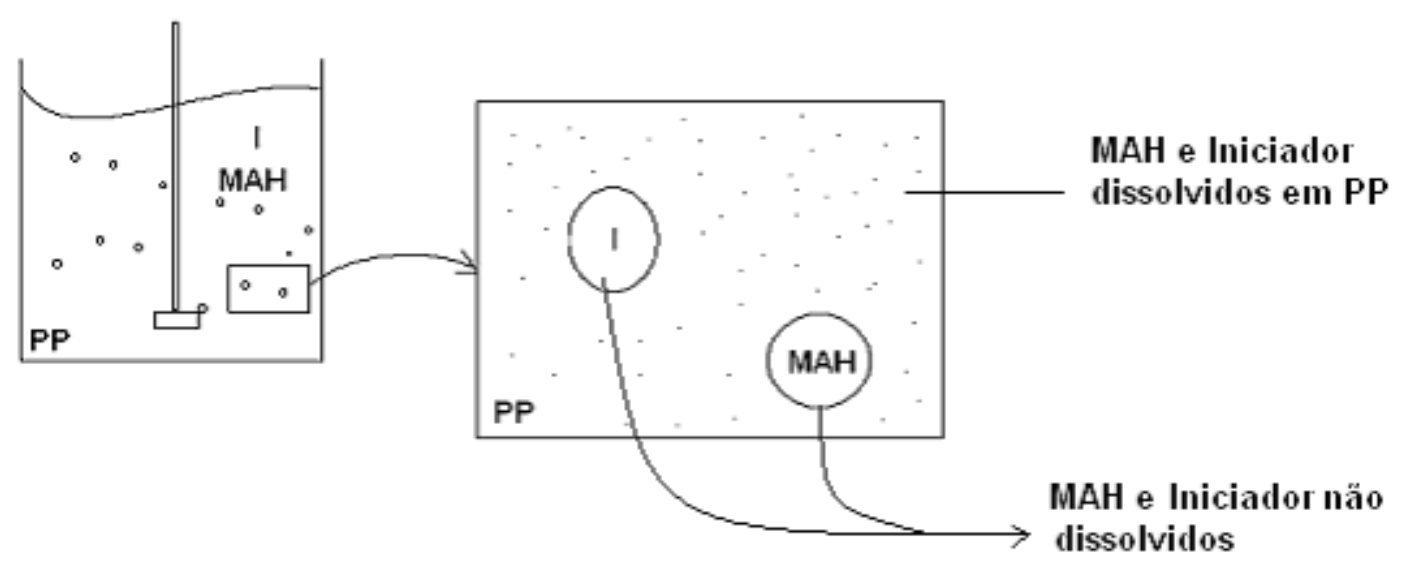

Figura 15 - Modelo 1: Contato entre os reagentes no estado líquido (Etapa de aquecimento).

Na etapa de aquecimento, o anidrido maleico e o iniciador, ambos no estado líquido, tendem a atingir o equilíbrio de fases com o PP. O MAH tem sua dissolução limitada devido à sua baixa solubilidade em PP. Uma parte da quantidade adicionada de MAH se dissolve no PP durante esta etapa, tal que, esta fração pode ou não corresponder à solubilidade deste composto em PP. Uma vez que a difusão de massa está limitada pela viscosidade (cerca de 5000 Pa.s, segundo Cha e White, 2003), a obtenção do equilíbrio passa a depender fortemente da velocidade de mistura dos reagentes. Como os iniciadores utilizados no processo de enxerto são peróxidos orgânicos, espera-se que eles possuam mais afinidade do que o MAH em relação ao PP. Isto permite supor maior facilidade de transporte de massa do iniciador em PP quando comparado com o MAH. Portanto, neste modelo, é definido um valor de solubilidade para o iniciador em PP, considerando equilíbrio de fases instantâneo entre estes compostos durante a reação.

Após a etapa de aquecimento, a temperatura de reação é atingida. As reações se iniciam e as quantidades de iniciador e $M A H$, dissolvidas no $P P$, passam a ser consumidas. Supõe-se neste modelo que as velocidades das reações são altas com relação à taxa de transporte de massa do MAH no meio reacional (alta viscosidade). Desta forma, pode-se considerar que durante o curto período de reação, a quantidade de MAH transferido de sua fase pura (gotícula) para o PP é desprezível. Portanto, considera-se que a quantidade de MAH que participa das reações é uma fração $\left(\mathrm{y}_{\text {solA }}\right)$ da quantidade total adicionada. A Figura 16 ilustra a etapa de reações. 


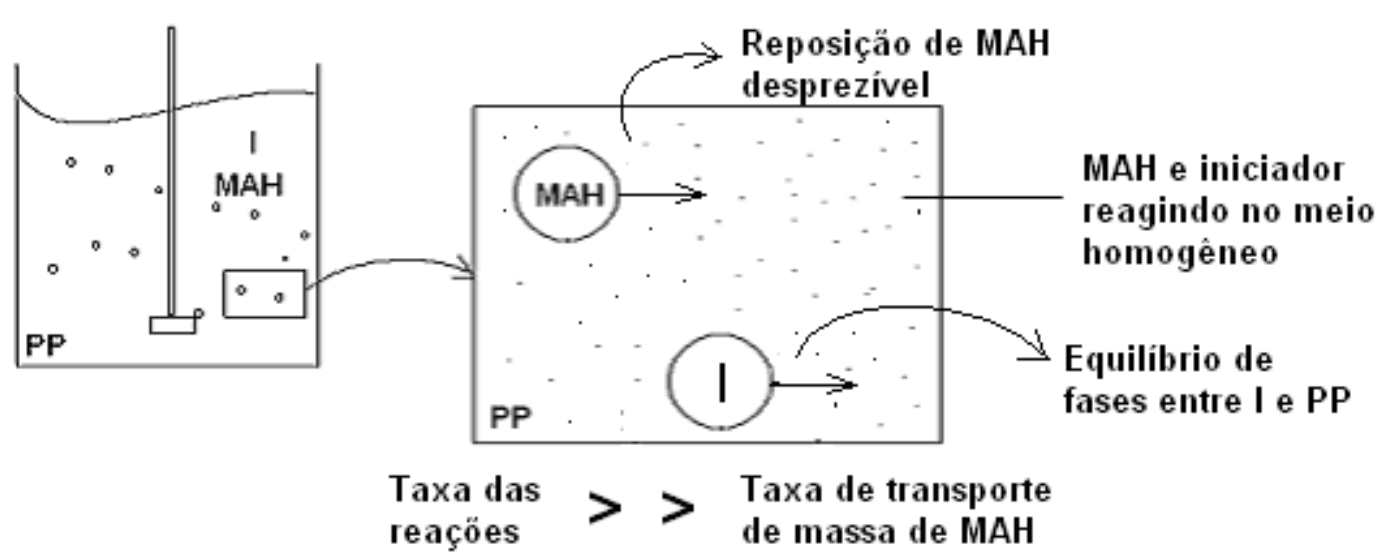

Figura 16 - Modelo 1: Etapa das reações.

As Figuras 15 e 16 mostram as interações entre as fases puras de MAH e I (gotículas) e o meio homogêneo (PP). Porém, em alguns casos pode haver regiões isoladas de PP (segregação). Portanto, de modo geral, o Modelo 1 considera também uma fase contendo PP puro. A Figura 17 mostra o esquema simplificado do Modelo 1, com identificação das fases.

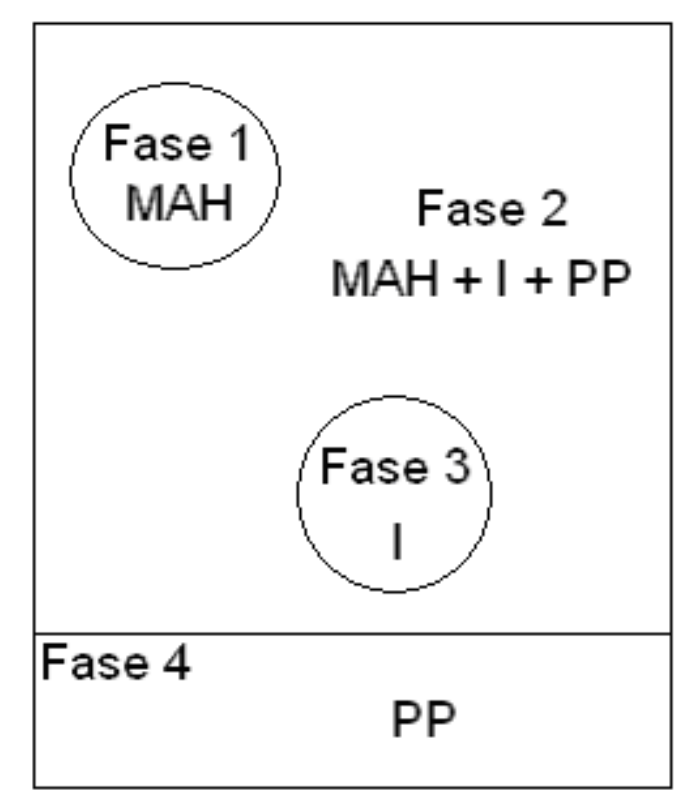

Figura 17 - Fases consideradas no Modelo 1.

A seguir são listadas as hipóteses utilizadas no desenvolvimento do modelo:

- Baixa concentração e dissolução desprezível de MAH na Fase 2 durante a reação;

- Regime pseudo-estacionário para os radicais;

- Não há variação considerável do volume da Fase 2 durante a reação;

- Reação isotérmica; 
- Densidade dos reagentes e dos produtos constantes e iguais à $1000 \mathrm{~g} / \mathrm{L}$;

- Solubilidades desprezíveis de PP em MAH e nos iniciadores;

- Equilíbrio instantâneo entre as fases 2 e 3 durante a reação.

3.1.1 Fases 1,3 e 4

Não há reação nas Fases 1, 3 e 4, neste modelo.

\subsubsection{Fase 2}

\subsubsection{Reações}

Decomposição do iniciador formando radicais primários (fragmentos do iniciador):

$$
I \stackrel{k d}{\longrightarrow}(2 f) R_{o}^{\bullet}
$$

Abstração de hidrogênio (transferência de cadeia para polímero), formando radicais backbone:

$$
\begin{aligned}
& R_{o}^{\bullet}+P_{s} \stackrel{k f p, 0}{\longrightarrow} S+R_{s}^{b \bullet} \\
& R_{r}^{b \bullet}+P_{s} \stackrel{k f p}{\longrightarrow} P_{r}+R_{s}^{b \bullet} \\
& R_{r}^{e \bullet}+P_{s} \stackrel{k f p}{\longrightarrow} P_{r}+R_{s}^{b \bullet}
\end{aligned}
$$

Cisão beta de radical backbone, formando cadeia inativa e radical com elétron desemparelhado na extremidade da cadeia (radical end):

\footnotetext{
${ }^{2} \mathrm{O}$ iniciador pode formar dois radicais primários (Ex.: DCP). Alguns iniciadores possuem dois grupos peróxido e formam quatro elétrons desemparelhados por molécula. Neste caso o 2 deve ser substituído por 4 na modelagem.
} 


$$
R_{r}^{b \bullet} \stackrel{k c s}{\longrightarrow} R_{s}^{e \bullet}+P_{r-s}
$$

Enxerto de anidrido maleico $(\mathrm{A})$, formando radicais enxertados:

$$
\begin{aligned}
& R_{o}^{\bullet}+A \stackrel{k a, 0}{\longrightarrow} R_{o}^{A \bullet} \\
& R_{r}^{b \bullet}+A \stackrel{k a}{\longrightarrow} R_{r}^{A b \bullet} \\
& R_{r}^{e \bullet}+A \stackrel{k a}{\longrightarrow} R_{r}^{A e \bullet}
\end{aligned}
$$

Transferência de cadeia dos radicais enxertados para as cadeias de polímero:

$$
\left(\begin{array}{l}
R_{o}^{A \bullet} \\
R_{r}^{A b \bullet} \\
R_{r}^{A e \bullet}
\end{array}\right)+P_{s} \stackrel{k f p^{\prime}}{\longrightarrow}\left(\begin{array}{l}
S \\
P_{r}
\end{array}\right)+R_{s}^{b \bullet}
$$

Terminação entre dois radicais de qualquer tipo:

$$
\left(\begin{array}{l}
R_{o}^{\bullet} \\
R_{r}^{b \bullet} \\
R_{r}^{e \bullet} \\
R_{o}^{A \bullet} \\
R_{r}^{A b \bullet} \\
R_{r}^{A e \bullet}
\end{array}\right)+\left(\begin{array}{llllll}
R_{o}^{\bullet} & R_{s}^{b \bullet} & R_{s}^{e \bullet} & R_{o}^{A \bullet} & R_{s}^{A b \bullet} & R_{s}^{A e \bullet}
\end{array}\right) \stackrel{k t}{\longrightarrow}\left(\begin{array}{c}
S \\
P_{r}+P_{s} \\
P_{r+s}
\end{array}\right)
$$

sendo que:

f: Eficiência do iniciador;

$\mathrm{k}_{\mathrm{j}}$ : constante de velocidade para a reação do tipo j;

I: Iniciador (peróxido);

A: Anidrido maleico;

S: Produto secundário e inerte;

$\mathrm{P}_{\mathrm{r}}$ : Polímero com $\mathrm{r}$ unidades monoméricas;

$\mathrm{R}_{\circ}{ }^{\bullet}$ : Radical gerado pela decomposição do iniciador (radical primário); 
$\mathrm{R}_{\mathrm{o}}{ }^{\mathrm{A} \bullet}$ : Radical primário enxertado;

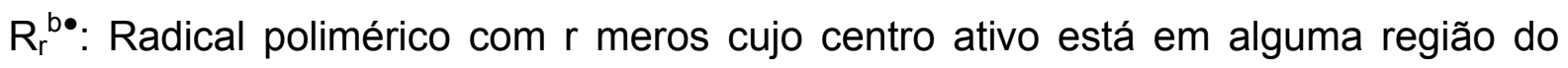
meio da cadeia (Radical backbone);

$\mathrm{R}_{\mathrm{r}}{ }^{\mathrm{e}}$ : Radical polimérico com $\mathrm{r}$ meros cujo centro ativo está em alguma das extremidades da cadeia (Radical end);

$\mathrm{R}_{\mathrm{r}}{ }^{\mathrm{Ab}}$ : Radical backbone enxertado, com $\mathrm{r}$ meros;

$\mathrm{R}_{\mathrm{r}}^{\mathrm{Ae}}{ }^{\mathrm{A}}$ : Radical end enxertado, com $\mathrm{r}$ meros.

A Figura 18 mostra os diferentes tipos de radicais envolvidos nas reações.

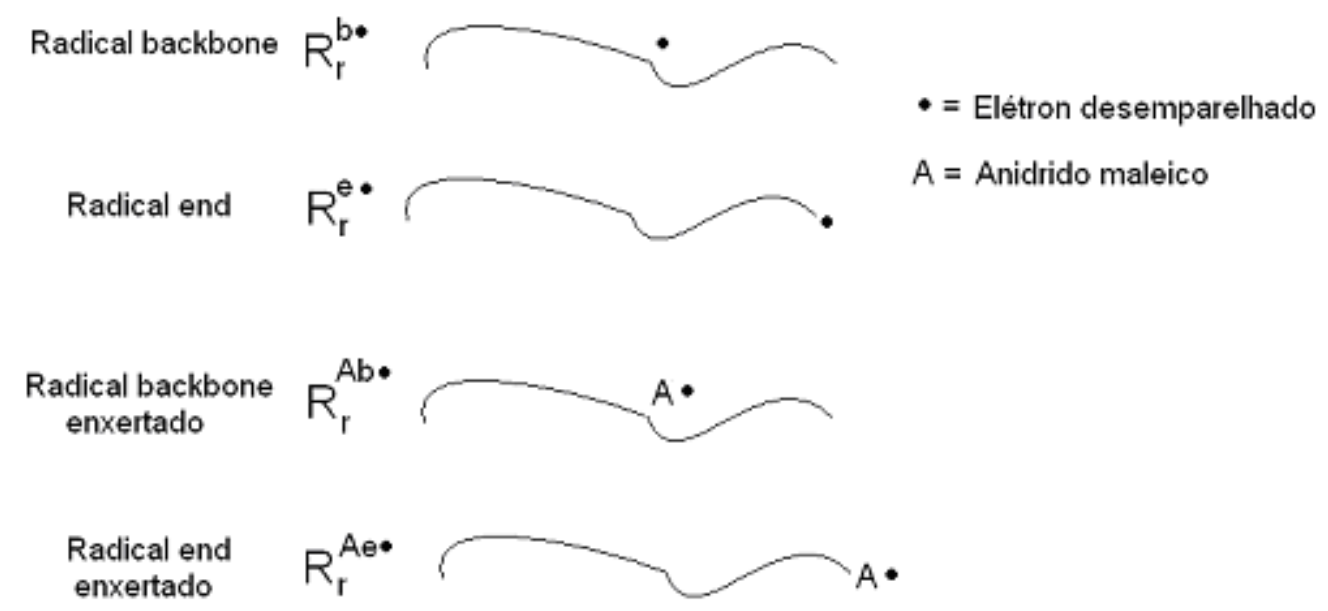

Figura 18 - Radicais envolvidos nas reações.

\subsubsection{Equacionamento}

Aplicando o balanço de massa para as diferentes espécies obtêm-se as equações a seguir.

Iniciador:

$$
\frac{d I}{d t}=-k_{d} I
$$

\footnotetext{
${ }^{3}$ Esta equação é válida quando a concentração global de iniciador é menor do que a sua solubilidade no meio reacional (Vide item 3.1.3.1).
} 
Anidrido maleico não reagido:

$\frac{d A}{d t}=-k_{a, 0} A R_{o}-k_{a} A\left(Y_{0 e}+Y_{0 b}\right)$

Anidrido maleico enxertado:

$\frac{d A_{g}}{d t}=k_{a} A\left(Y_{0 e}+Y_{0 b}\right)$

Radicais primários:

$0=\frac{d R_{o}}{d t}=2 f k_{d} I-k_{f p, 0} Q_{1} R_{o}-k_{a, 0} A R_{o}-k_{t} R_{o} R_{t o t}$

Radicais backbone:

$$
\begin{aligned}
& 0=\frac{d R_{r}^{b}}{d t}=k_{f p, 0} R_{o} r P_{r}+k_{f p} Y_{0 b} r P_{r}+k_{f p} Y_{0 e} r P_{r}+ \\
& k_{f p^{\prime}} r P_{r}\left(R_{A o}+Y_{0 A b}+Y_{0 A e}\right)-k_{f p} R_{r}^{b} Q_{1}-k_{c s} R_{r}^{b}-k_{a} A R_{r}^{b}-k_{t} R_{r}^{b} R_{t o t}
\end{aligned}
$$

Radicais end:

$$
0=\frac{d R_{r}^{e}}{d t}=k_{c s} \sum_{s=r+1}^{\infty} \frac{R_{s}^{b}}{s}-k_{f p} R_{r}^{e} Q_{1}-k_{a} A R_{r}^{e}-k_{t} R_{r}^{e} R_{t o t}
$$

Radicais primários enxertados:

$$
0=\frac{d R_{A o}}{d t}=k_{a, 0} A R_{o}-k_{f p^{\prime}} Q_{1} R_{A o}-k_{t} R_{A o} R_{t o t}
$$

Radicais backbone enxertados: 
$0=\frac{d R_{r}^{A b}}{d t}=k_{a} A R_{r}^{b}-k_{f p^{\prime}} Q_{1} R_{r}^{A b}-k_{t} R_{r}^{A b} R_{t o t}$

Radicais end enxertados:

$0=\frac{d R_{r}^{A e}}{d t}=k_{a} A R_{r}^{e}-k_{f p^{\prime}} Q_{1} R_{r}^{A e}-k_{t} R_{r}^{A e} R_{t o t}$

Cadeias inativas (Polímero morto):

$$
\begin{aligned}
& \frac{d P_{r}}{d t}=-k_{f p, 0} R_{o} r P_{r}-k_{f p} Y_{0 b} r P_{r}-k_{f p} Y_{0 e} r P_{r} \\
& -k_{f p^{\prime}}\left(R_{A o}+Y_{0 A b}+Y_{0 A e}\right) r P_{r}+k_{c s} \sum_{s=r+1}^{\infty} \frac{R_{s}^{b}}{s}+k_{f p} Q_{1}\left(R_{r}^{b}+R_{r}^{e}\right) \\
& +k_{f p^{\prime}} Q_{1}\left(R_{r}^{A b}+R_{r}^{A e}\right)+k_{t}\left(R_{r}^{b}+R_{r}^{e}+R_{r}^{A b}+R_{r}^{A e}\right) R_{t o t}
\end{aligned}
$$

No equacionamento, I é a concentração do iniciador (mol/L), $A_{g}$ é a concentração do anidrido maleico enxertado (mol/L), A é a concentração do anidrido maleico não reagido ( $\mathrm{mol} / \mathrm{L}), \mathrm{R}_{\mathrm{r}}{ }^{\mathrm{k}}$ é a concentração do radical do tipo $\mathrm{k}$ e tamanho $r$ (mol/L), $Q_{1}$ é o momento de ordem 1 das cadeias de polímero (corresponde ao número total de mols de unidades monoméricas nas cadeias poliméricas por unidade de volume de polipropileno).

O momento de ordem 1 para as cadeias de polímero é definido conforme a equação 3.11 .

$$
Q_{1}=\sum_{r=1}^{\infty} r P_{r}=\frac{\rho_{P P}}{42}
$$

onde $\rho_{P P}$ é a densidade do PP fundido e 42 é o valor da massa molar da unidade monomérica de PP $(\mathrm{g} / \mathrm{mol})$.

No equacionamento, foi assumido que ocorre, preferencialmente, terminação por desproporcionamento em relação à combinação. O momento de ordem zero para os diferentes tipos de radicais é definido conforme as equações representadas por 3.12. 


$$
Y_{0 b}=\sum_{r=1}^{\infty} R_{r}^{b} \quad Y_{0 e}=\sum_{r=1}^{\infty} R_{r}^{e} \quad Y_{0 A b}=\sum_{r=1}^{\infty} R_{r}^{A b} \quad Y_{0 A e}=\sum_{r=1}^{\infty} R_{r}^{A e}
$$

A concentração de radicais totais é definida conforme a equação 3.13.

$$
R_{\text {tot }}=R_{0}+Y_{0 b}+Y_{0 e}+R_{A 0}+Y_{0 A b}+Y_{0 A e}
$$

Substituindo 3.12 nas equações 3.5, 3.6, 3.8 e 3.9, obtêm-se:

$$
\begin{aligned}
& 0=\frac{d Y_{0 b}}{d t}=k_{f p, 0} Q_{1} R_{o}+k_{f p} Q_{1} Y_{0 e}+k_{f p^{\prime}} Q_{1}\left(R_{A o}+Y_{0 A b}+Y_{0 A e}\right) \\
& -k_{c s} Y_{0 b}-k_{a} A Y_{0 b}-k_{t} Y_{0 b} R_{t o t} \\
& 0=\frac{d Y_{0 e}}{d t}=k_{c s} Y_{0 b}-k_{f p} Q_{1} Y_{0 e}-k_{a} A Y_{0 e}-k_{t} Y_{0 e} R_{t o t} \\
& 0=\frac{d Y_{0 A b}}{d t}=k_{a} A Y_{0 b}-k_{f p^{\prime}} Q_{1} Y_{0 A b}-k_{t} Y_{0 A b} R_{t o t} \\
& 0=\frac{d Y_{0 A e}}{d t}=k_{a} A Y_{0 e}-k_{f p^{\prime}} Q_{1} Y_{0 A e}-k_{t} Y_{0 A e} R_{t o t}
\end{aligned}
$$

Combinando as equações $3.4,3.7$ e 3.14 à 3.17, obtém-se a concentração de radicais totais, resultando na equação 3.18 .

$$
R_{t o t}=R_{0}+Y_{0 b}+Y_{0 e}+R_{A 0}+Y_{0 A b}+Y_{0 A e}=\sqrt{\frac{2 f k_{d} I}{k_{t}}}
$$

O grau de enxerto (\% massa) é calculado através da equação 3.19.

$$
G E=\frac{98 A_{g}}{42 Q_{1}}
$$


O grau de cisão é definido conforme mostrado na equação 3.20 .

$$
\frac{d u}{d t}=\frac{k_{c s} Y_{0 b}}{Q_{1}}
$$

O grau de cisão u representa a fração de ligações entre as unidades monoméricas do polímero que sofreu cisão. O grau de cisão está relacionado com o tamanho médio numérico (ou grau de polimerização médio numérico) na forma:

$$
u=\frac{1}{r_{n}}-\frac{1}{r_{n 0}}
$$

sendo que 98 e 42 são as massas moleculares do MAH e da unidade monomérica de PP respectivamente; $u$ é o grau de cisão das cadeias; $r_{n o}$ tamanho médio numérico inicial das cadeias das cadeias de PP e $r_{n}$ é o tamanho médio numérico num dado instante.

Para o cálculo do grau de enxerto, é necessária a resolução de um sistema que envolve as equações 3.1 à 3.4, 3.7 e 3.14 à 3.19. Como este é um sistema contendo equações diferenciais e algébricas, aplica-se um método numérico para a resolução. Como ferramenta para este trabalho, foi utilizada a função ODE45 do MATLAB. Toda a modelagem do processo de modificação química do polipropileno foi realizada em MATLAB, uma vez que este possui todas as funções e operações necessárias para a simulação.

O modelo foi testado em diferentes temperaturas e os valores de constante cinética foram obtidos para cada temperatura. Posteriormente, utilizou-se a lei de Arrhenius, representada pela equação 3.22 , para obter 0 valor de energia de ativação (E) para cada reação (j).

$$
k_{j}=A_{j} \exp \left(-\frac{E_{j}}{R T}\right)
$$




\subsubsection{Parâmetros físicos utilizados no Modelo 1}

\subsubsection{Solubilidade do Iniciador no meio reacional}

Este é um parâmetro ajustável, que é considerado diretamente no Modelo 1, interferindo na concentração de iniciador que participa efetivamente da reação. De acordo com a equação 3.1, a taxa de decomposição do iniciador depende de sua concentração efetiva, porém, esta concentração depende da sua solubilidade no meio reacional, conforme descrito a seguir.

$$
\begin{aligned}
& \text { Se } I>S_{\mid} \text {, então } I_{\text {ef }}=S_{\mid} \\
& \text {Se } I<S_{1} \text {, então } I_{\text {ef }}=I
\end{aligned}
$$

em que:

I: Concentração de iniciador baseada em sua quantidade total presente no meio $(\mathrm{mol} / \mathrm{L})$;

$\mathrm{S}_{\mathrm{I}}$ : Solubilidade do iniciador no polipropileno (mol/L);

I ef: Concentração efetiva do iniciador no meio reacional, Fase 2 (mol/L).

Estas considerações são válidas admitindo-se que o equilíbrio de fases entre o iniciador e o PP seja atingido instantaneamente durante a reação. Se a solubilidade do iniciador em PP for alta em relação à quantidade adicionada, podese considerar que esta quantidade foi completamente dissolvida antes do início da reação (etapa de aquecimento). Os valores ajustados para este parâmetro podem ser comparados com valores estimados através de conceitos termodinâmicos.

\subsubsection{Fração solúvel de MAH em PP}

Estudos experimentais têm constatado baixa solubilidade de anidrido maleico em polipropileno. Severini et al (1999) encontraram um limite de 0,35\% (massa) de 
MAH em PP para a temperatura de $120^{\circ} \mathrm{C}$, que se encontra próxima à faixa a qual são realizadas as reações de enxerto $\left(130^{\circ} \mathrm{C}-230^{\circ} \mathrm{C}\right)$. Frente a este dado e considerando as porcentagens de $\mathrm{MAH}$ utilizadas nas reações de enxerto $(0,5-$ $12 \%$ em massa), conclui-se que, apenas uma fração do MAH adicionado é solubilizada antes do início das reações. Esta fração é um parâmetro ajustável, que foi considerado no Modelo 1. A equação 3.23 fornece a definição de fração solúvel de MAH em PP.

$$
y_{\text {SolA }}=\frac{M A H_{s o l}}{M A H_{a d}}
$$

sendo:

$\mathrm{MAH}_{\text {sol: }}$ Concentração do MAH que se solubilizou no PP (mol/L);

$\mathrm{MAH}_{\mathrm{ad}}$ : Concentração de MAH com base na quantidade adicionada (mol/L);

YsolA: Fração de MAH solubilizada no meio.

Esta fração pode não corresponder à solubilidade do MAH em $P P$, pois a taxa de transferência de massa da Fase 1 para a Fase 2 pode ser baixa e o equilíbrio de fases pode não ocorrer antes do início das reações. Os valores de ysolA podem ser discutidos através de estimativas utilizando o método UNIFAC.

\subsubsection{Fração segregada}

O parâmetro fração segregada considera que o MAH e o iniciador estão misturados em uma parte do PP, ou seja, o meio homogêneo não abrange todo o PP. A equação 3.24 define o parâmetro fração segregada.

$$
y_{S}=\frac{V_{P P}-V_{P P, a}}{V_{P P}}=\frac{V_{4}}{V_{2}+V_{4}}
$$

em que:

$\mathrm{V}_{\mathrm{PP}, \mathrm{a}}$ : Volume de polipropileno ativo, que está em contato com MAH e I (L); 
$\mathrm{V}_{\mathrm{PP}}$ : Volume total de polipropileno $(\mathrm{L})$;

$\mathrm{V}_{2}$ : Volume da Fase $2(\mathrm{~L})$;

$\mathrm{V}_{4}$ : Volume da Fase $4(\mathrm{~L})$;

ys: Fração segregada.

A fração segregada é um parâmetro ajustável e está associada às regiões internas das partículas de PP que não foram atingidas pelo MAH e pelo iniciador (Fase 4). Entende-se que a fusão do polipropileno acontece primeiramente nas camadas mais externas das partículas conforme mostrado na Figura 19.

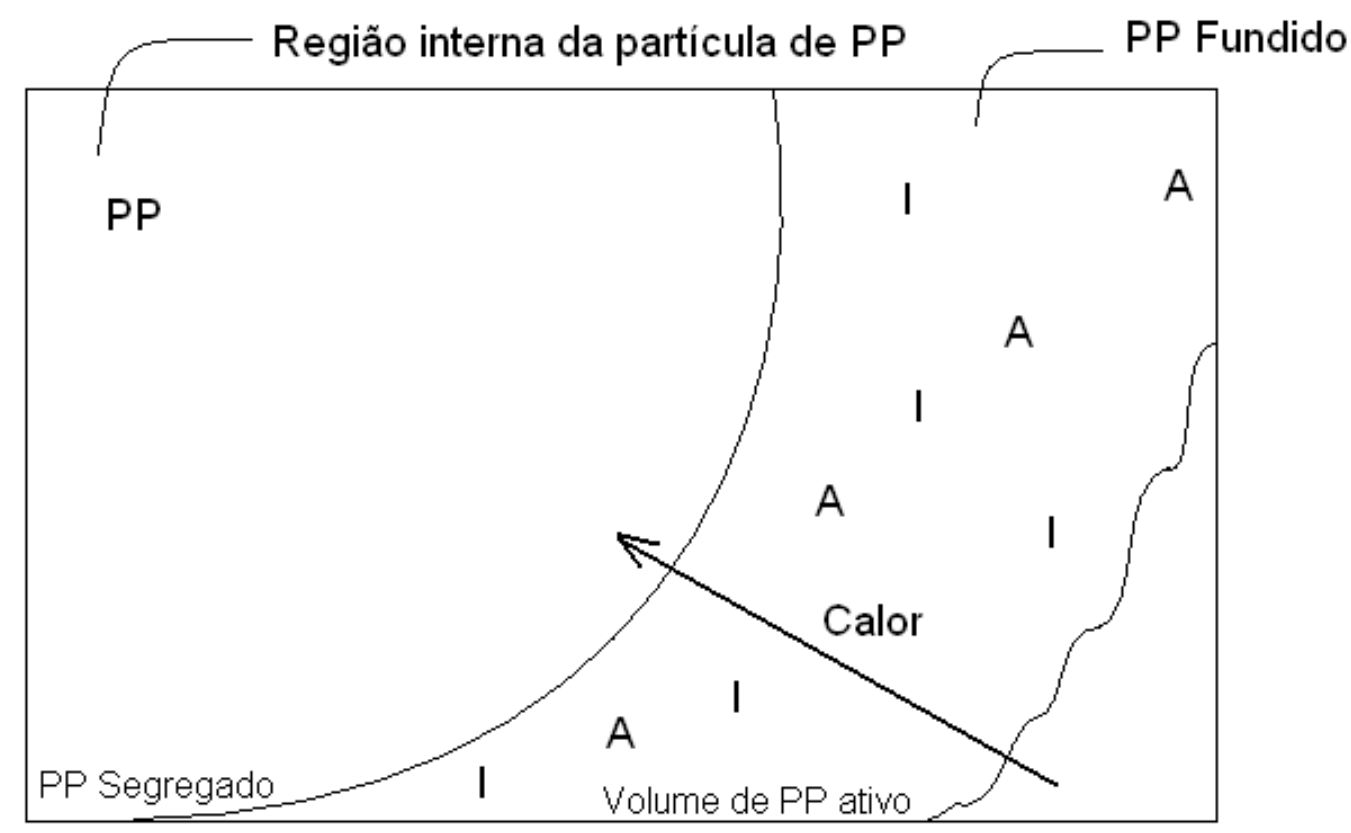

Figura 19 - Segregação devido a regiões internas de PP não atingidas pelos demais reagentes.

O grau de enxerto obtido através da equação 3.19 deve ser corrigido de forma a ter, como base, o volume total de PP ao invés do volume da Fase 2. Esta correção é feita através da equação 3.25.

$$
G E^{\prime}=\left(1-y_{s}\right) G E_{2}+y_{s} G E_{4}=\left(1-y_{s}\right) \frac{98 A_{g}}{42 Q_{1}}
$$

em que:

$\mathrm{GE}_{2}$ : Grau de enxerto obtido no volume ativo, Fase 2 (\%massa); 
$\mathrm{GE}_{4}$ : Grau de enxerto obtido no volume inativo, Fase 4 (igual a zero, pois não há reação nesta fase);

GE': Grau de enxerto corrigido (\% massa).

\subsubsection{Condições iniciais para o Modelo 1}

No sistema de equações diferenciais gerado pelo Modelo 1, são necessários os valores de concentração inicial de MAH e I. Utilizando os parâmetros fração solúvel de MAH e fração segregada, calcula-se essas concentrações através das equações 3.26 e 3.27 .

$$
\begin{aligned}
& M A H_{i}=\frac{y_{\text {SolA }} n_{M A H, a d}}{V_{P P, a}}=\frac{y_{\text {SolA }} n_{M A H, a d}}{V_{P P, a}} \frac{V_{P P}}{V_{P P}}=\frac{y_{\text {SolA }} M A H_{a d}}{\left(1-y_{s}\right)} \\
& I_{i}=\frac{n_{I, a d}}{V_{P P, a}}=\frac{n_{I, a d}}{V_{P P, a}} \frac{V_{P P}}{V_{P P}}=\frac{I_{a d}}{\left(1-y_{s}\right)}
\end{aligned}
$$

sendo que:

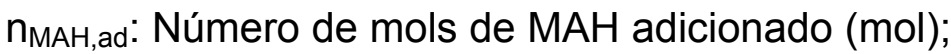

$\mathrm{n}_{\mathrm{l}, \mathrm{ad}}$ : Número de mols de iniciador adicionado (mol).

\subsection{Modelo 2}

Este modelo considera menor dificuldade de transferência de massa do anidrido maleico no meio reacional em relação ao Modelo 1. No Modelo 2 também é considerada a pré-mistura descrita no Modelo 1, porém, nas etapas seguintes, são consideradas novas interações entre os reagentes. As Figuras 20 e 21 mostram estas interações. 


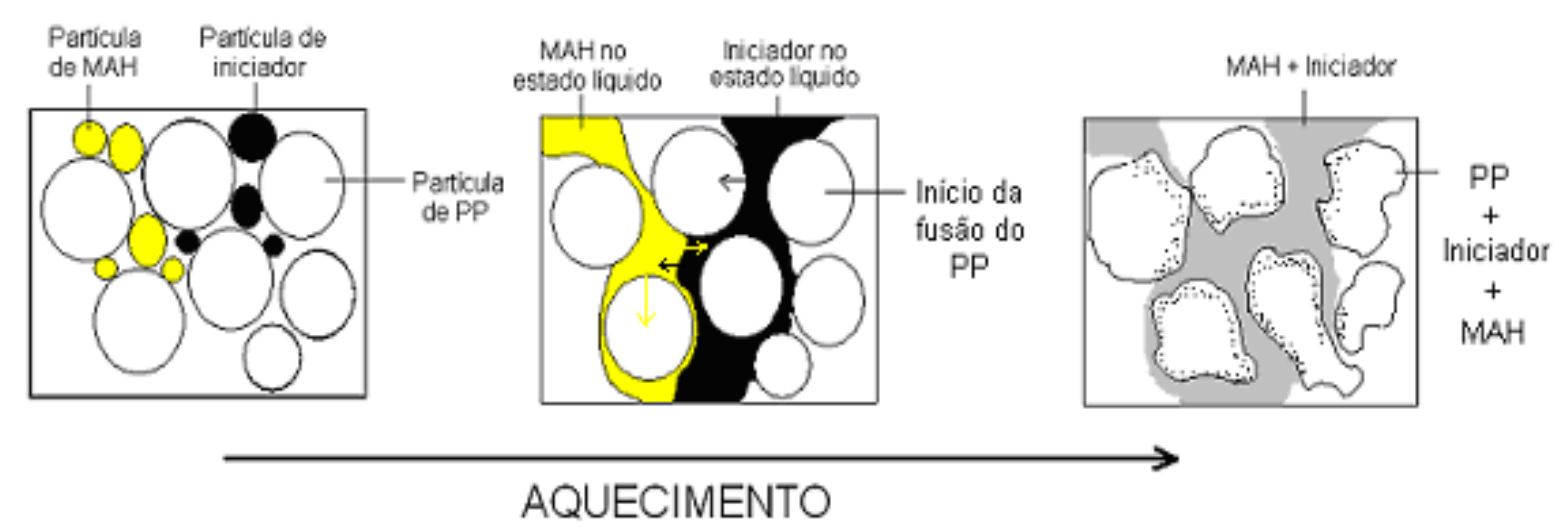

Figura 20 - Modelo 2: Etapa de aquecimento dos reagentes.

Os pontos de fusão do MAH e dos iniciadores em geral, são menores do que o ponto de fusão do PP. Esta observação indica que o iniciador tem um contato com o MAH no estado líquido durante o período de fusão do polipropileno. Certas quantidades de $\mathrm{MAH}$ e iniciador se dissolvem no $\mathrm{PP}$ à medida que este se funde. $\mathrm{O}$ $\mathrm{MAH}$ forma uma fase separada devido à sua baixa solubilidade em PP. Nesta fase é dissolvida a quantidade de iniciador que não se dissolveu no PP.

Assim, o Modelo 2 considera uma partição do iniciador entre fases. As porcentagens de iniciador e $\mathrm{MAH}$ em cada fase determinam as condições iniciais das reações.

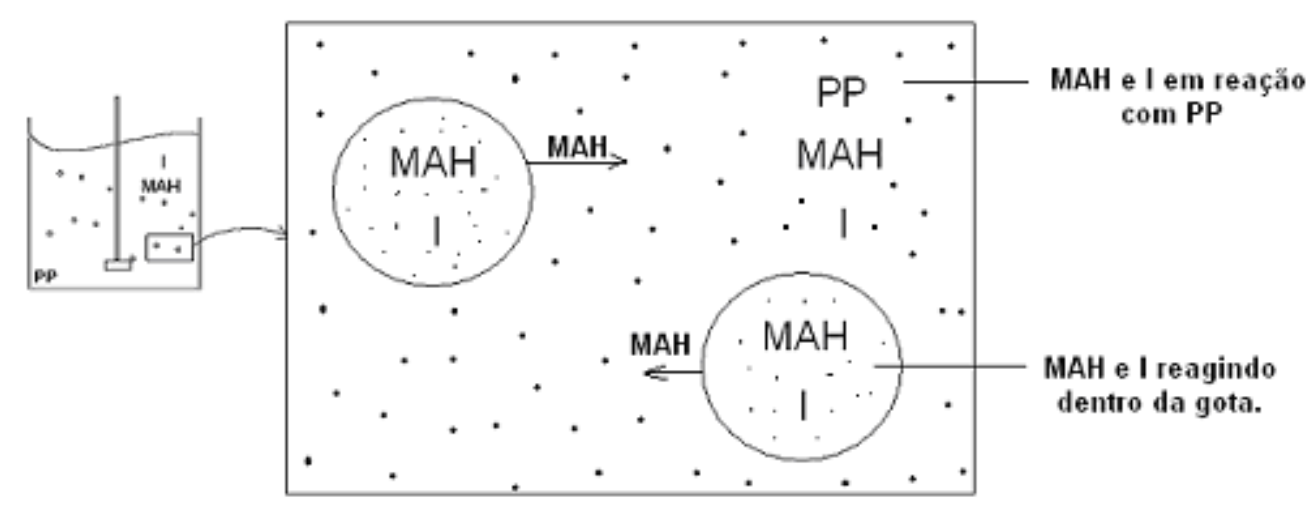

Figura 21 - Modelo 2: Etapa de reação.

$\mathrm{Na}$ etapa de reações, o Modelo 2 apresenta diferentes volumes reacionais (PP fundido e gotas de $\mathrm{MAH}+\mathrm{I}$ ). Considera-se que o iniciador está, inicialmente em equilíbrio entre as fases, não havendo transferência deste reagente de uma fase para outra durante as reações. A Figura 21 mostra somente as interações com o volume ativo de PP, porém, neste modelo também é considerada a segregação. 
A Figura 22 mostra o esquema simplificado do Modelo 2, com identificação das fases.

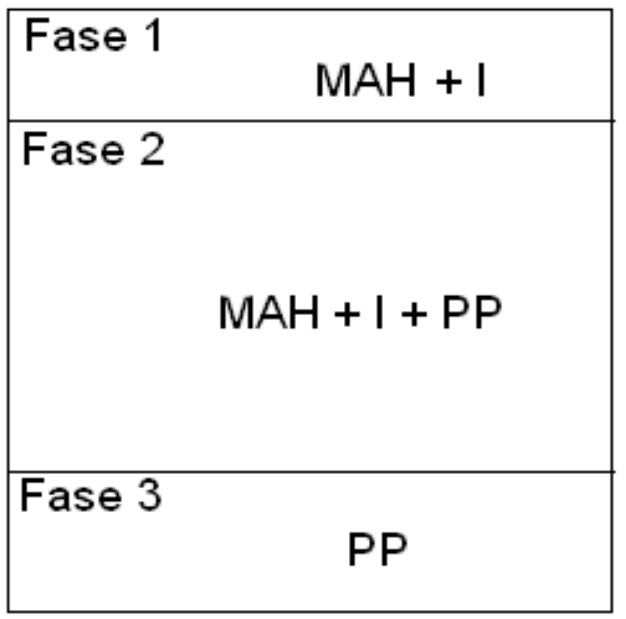

Figura 22 - Fases consideradas no Modelo 2.

Neste modelo foram consideradas as seguintes hipóteses:

- O iniciador está inicialmente distribuído nas fases 1 e 2 segundo um coeficiente de partição.

- Os produtos das reações na Fase 1 não saem da mesma enquanto ela existir;

- Não há transferência de iniciador entre as fases 1 e 2 durante a reação;

- Reposição imediata de MAH da Fase 1 para a Fase 2 durante a reação (Equilíbrio de fases);

- Regime pseudo-estacionário para os radicais;

- Não há variação considerável do volume da Fase 2 durante a reação;

- Reação isotérmica;

- Densidade dos reagentes e dos produtos constantes e iguais à $1000 \mathrm{~g} / \mathrm{L}$;

- Solubilidades desprezíveis de PP no MAH e nos iniciadores.

\subsubsection{Fase 1}

\subsubsection{Reações}

Como somente anidrido maleico e iniciador existem na Fase 1, as reações possíveis nesta fase são:

$$
I \stackrel{k d}{\longrightarrow}(2 f) R_{o}^{\bullet}
$$




$$
\begin{aligned}
& R_{o}^{\bullet}+A \stackrel{k a, 0}{\longrightarrow} R_{o}^{A \bullet} \\
& \left(\begin{array}{l}
R_{o}^{\bullet} \\
R_{o}^{A \bullet}
\end{array}\right)+\left(\begin{array}{ll}
R_{o}^{\bullet} & R_{o}^{A \bullet}
\end{array}\right) \stackrel{k t}{\longrightarrow} S
\end{aligned}
$$

\subsubsection{Equacionamento}

Aplicando o balanço de massa para as diferentes espécies na Fase 1 obtêmse:

$$
\begin{aligned}
& \frac{d N_{I 1}}{d t}=\frac{d\left(C_{I 1} V_{1}\right)}{d t}=C_{I 1} \frac{d V_{1}}{d t}+V_{1} \frac{d C_{I 1}}{d t}=-k_{d} C_{I 1} V_{1} \\
& \frac{d N_{A 1}}{d t}=\frac{d\left(C_{A 1} V_{1}\right)}{d t}=C_{A 1} \frac{d V_{1}}{d t}+V_{1} \frac{d C_{A 1}}{d t}=-k_{a 0} C_{A 1} R_{01} V_{1}-F_{A s 1}
\end{aligned}
$$

De acordo com a hipótese de reposição imediata de MAH durante a reação, a taxa de saída de $\mathrm{MAH}$ da Fase $1, \mathrm{~F}_{\mathrm{As} 1}$, é igual a taxa de consumo deste reagente na Fase 2, conforme mostrado na equação 3.30 .

$$
\begin{aligned}
& F_{A s 1}=\left[k_{a 0} R_{02}+k_{a}\left(Y_{0 b}+Y_{0 e}\right)\right] C_{A 2} V_{2} \\
& 0=\frac{\left(d R_{01} V_{1}\right)}{d t}=2 f_{1} k_{d} C_{I 1} V_{1}-k_{a 0} C_{A 1} R_{01} V_{1}-k_{t}\left(R_{01}^{2}+R_{A 01} R_{01}\right) V_{1} \\
& 0=\frac{\left(d R_{A 01} V_{1}\right)}{d t}=k_{a 0} C_{A 1} R_{01} V_{1}-k_{t} R_{A 01}\left(R_{01}+R_{A 01}\right) V_{1} \\
& \frac{d m_{1}}{d t}=\frac{\rho_{1} d V_{1}}{d t}=F_{A s 1} M_{A}=-\left[k_{a 0} R_{02}+k_{a}\left(Y_{0 b}+Y_{0 e}\right)\right] C_{A 2} V_{2} M_{A}
\end{aligned}
$$

\footnotetext{
${ }^{4}$ Os termos $Y_{0 b}$ e $Y_{0 e}$ seguem a mesma definição feita para o Modelo 1.
} 


$$
\frac{d V_{1}}{d t}=-\left[k_{a 0} R_{02}+k_{a}\left(Y_{0 b}+Y_{0 e}\right)\right] C_{A 2} \frac{V_{2}}{\rho_{1}} M_{A}
$$

onde $\mathrm{m}_{1}$ é a massa da Fase 1 e $\mathrm{V}_{1}$ é o volume da Fase 1.

Combinando as equações (3.31) e (3.32) obtém-se:

$$
R_{01}=\frac{2 f_{1} k_{d} C_{I 1}}{k_{t} \sqrt{\frac{2 f_{1} k_{d} C_{I 1}}{k_{t}}}+k_{a 0} C_{A 1}}
$$

Durante a reação, a Fase 1 é consumida através da transferência de MAH para a Fase 2. As equações 3.28, 3.29 e 3.34 são aplicadas enquanto existir Fase 1. A partir do momento que a Fase 1 se esgota, os valores de $\frac{d V_{1}}{d t}, \frac{d C_{I 1}}{d t}$ e $\frac{d C_{A 1}}{d t}$ se tornam zero. A condição de existência da Fase 1 está descrita no item 3.2.3.

\subsubsection{Fase 2}

Na Fase 2 deste modelo, utiliza-se o mesmo equacionamento desenvolvido para a Fase 2 do Modelo 1. Porém, a equação 3.2 é utilizada somente quando não existir mais a Fase 1, caso contrário, o valor de $\frac{d C_{A 2}}{d t}$ é zero. Esta condição faz com que prevaleça o valor inicial de concentração de $\mathrm{MAH}$, que é a sua solubilidade em PP. Este valor é mantido constante durante a existência da Fase 1 devido à reposição imediata de MAH da Fase 1 para a Fase 2.

\subsubsection{Fases $1+2$}

Devido à transferência de MAH da Fase 1 para a Fase 2, é necessário um balanço de massa global para este reagente. 
A equação 3.36 define a variação total de MAH no sistema.

$$
\frac{d C_{A}}{d t}=-\frac{k_{a 0} C_{A 1} R_{01} V_{1}}{V}-\frac{\left[k_{a 0} R_{02}+k_{a}\left(Y_{0 b}+Y_{0 e}\right)\right] C_{A 2} V_{2}}{V}
$$

A concentração global de $\mathrm{MAH}\left(\mathrm{C}_{\mathrm{A}}\right)$ está associada à quantidade total deste reagente presente no meio reacional. Durante a reação, enquanto esta quantidade não for completamente solúvel na Fase 2, haverá Fase1. As expressões à seguir descrevem algebricamente esta condição.

Se $S_{A}<\frac{C_{A} V}{V_{2}}$, então $\frac{d C_{A 2}}{d t}=0$

Se $S_{A} \geq \frac{C_{A} V}{V_{2}}$, então $\frac{d C_{A 2}}{d t}=-\left[k_{a, 0} R_{o 2}+k_{a}\left(Y_{0 e}+Y_{0 b}\right)\right] C_{A 2}$

Esta condição determina o instante em que a Fase 1 deixa de existir.

\subsubsection{Fase 3}

Não há reação na Fase 3.

\subsubsection{Parâmetros físicos utilizados no Modelo 2}

\subsubsection{Fração segregada}

No Modelo 2, a segregação é considerada de forma mais minuciosa, abrangendo duas parcelas. Uma referente à segregação devido à região interna inativa da partícula de PP (conforme mostrado no item 3.1.3.3) e outra referente à 
segregação que varia com a concentração inicial de iniciador, conforme mostrado na Figura 23.

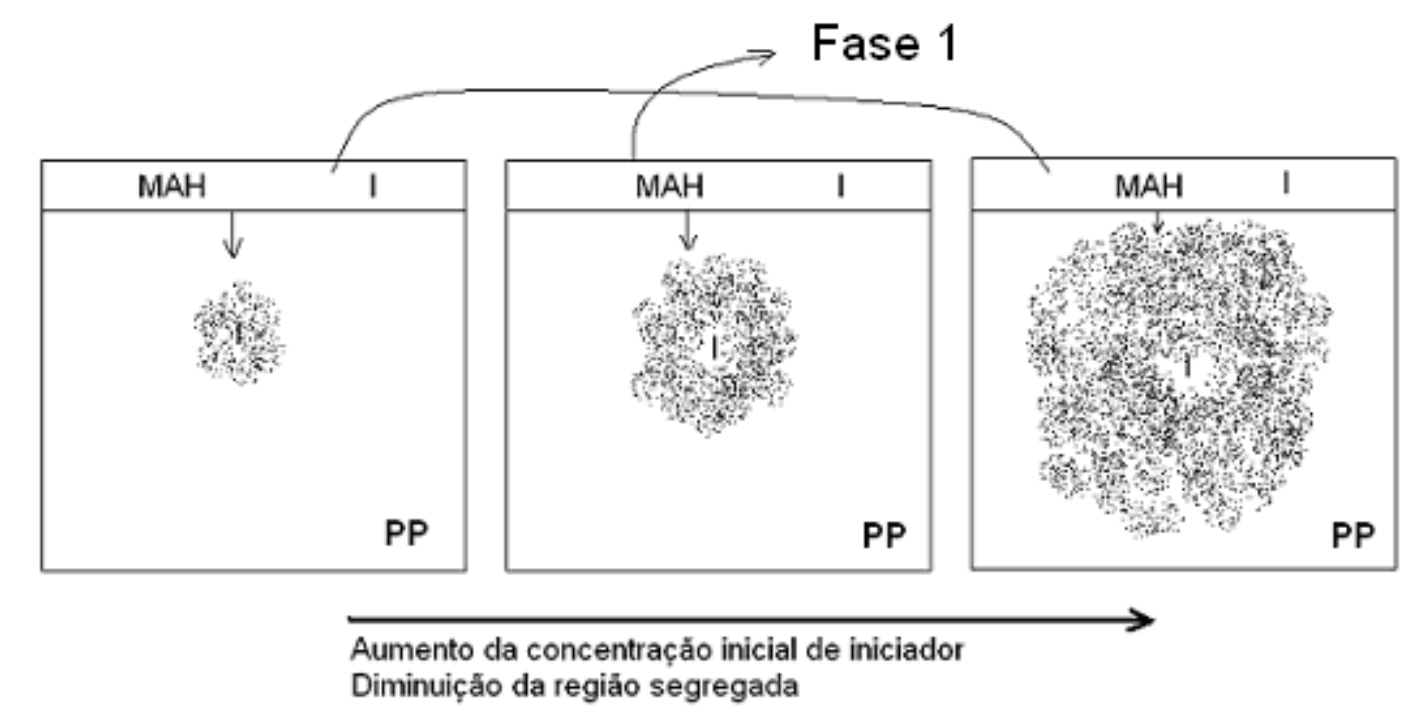

Figura 23 - Segregação devido à baixa concentração de iniciador no meio. Quanto maior a quantidade de iniciador, menor o tamanho da região segregada.

Quanto menor a quantidade de iniciador adicionada ao processo, maior a segregação devido à ausência deste reagente em regiões ao longo do conteúdo reacional. O parâmetro fração segregada, neste caso, também é um parâmetro ajustável e tem a mesma definição apresentada pela equação 3.24. Porém, além de variar com o tamanho da partícula de $\mathrm{PP}$, supõe-se que este parâmetro também varie com a concentração inicial de iniciador em uma determinada faixa de valores.

Assim como no Modelo 1, o valor do grau de enxerto deve ser corrigido através da equação 3.25 .

\subsubsection{Solubilidade do MAH em PP}

Este parâmetro é ajustável e se aplica ao Modelo 2, conforme descrito no item 3.2.3. Os valores ajustados são comparados com valores estimados através do método UNIFAC. 
3.2.5.3 Coeficiente de partição do iniciador $\left(K_{\mathrm{PI}}\right)$

Este é um parâmetro ajustável que determina a relação entre as concentrações de iniciador nas fases 1 e 2. A equação 3.37 define o coeficiente de partição do iniciador.

$$
K_{P I}=\frac{I_{1}}{I_{2}}
$$

sendo que:

$\mathrm{I}_{1}$ : Concentração de iniciador na Fase 1 (mol/L).

$\mathrm{I}_{2}$ : Concentração de iniciador na Fase 2 (mol/L).

$\mathrm{K}_{\mathrm{PI}}$ : Coeficiente de partição do iniciador.

\subsubsection{Condições iniciais para o Modelo 2}

Da equação 3.37, obtém-se:

$$
K_{P I}=\frac{N_{I 1} V_{2}}{N_{I 2} V_{1}}
$$

Os volumes das fases 1 e 2 e o número de mols de iniciador são definidos pelas equações a seguir.

$$
\begin{gathered}
V_{1}=\frac{m_{a 1}}{\rho_{A}}+\frac{N_{I 1} M_{I}}{\rho_{I}} \\
V_{2}=V_{P P}\left(1-y_{s}\right)
\end{gathered}
$$

\footnotetext{
${ }^{5}$ As quantidades de MAH e I na Fase 2 são pequenas em relação ao PP. Portanto, o volume da Fase 2 é, aproximadamente, o volume do PP na mesma.
} 


$$
N_{I}=N_{I 1}+N_{I 2}
$$

Resolvendo o sistema de equações 3.38-3.41, obtém-se os volumes iniciais das fases 1 e 2 e as concentrações iniciais de MAH e iniciador em cada fase. Estes valores, juntamente com a concentração global inicial de $\mathrm{MAH}$, são utilizados na solução do sistema de equações diferenciais do Modelo 2.

Para o Modelo 2, tem-se a seguinte nomenclatura:

$\mathrm{N}_{11}$ : Número de mols de iniciador na Fase 1 (mol);

$\mathrm{N}_{\mathrm{A} 1}$ : Número de mols de MAH na Fase 1 (mol);

$\mathrm{C}_{11}$ : Concentração de iniciador na Fase 1 (mol/L);

$\mathrm{C}_{\mathrm{A} 1}$ : Concentração de $\mathrm{MAH}$ na Fase 1 (mol/L);

$\mathrm{C}_{\mathrm{A} 2}$ : Concentração de $\mathrm{MAH}$ na Fase 2 (mol/L);

$\mathrm{C}_{\mathrm{A}}$ : Concentração global de $\mathrm{MAH}$ no meio reacional (mol/L);

$\mathrm{V}_{1}$ : Volume da Fase $1(\mathrm{~L})$;

$\mathrm{V}_{2}$ : Volume da Fase $2(\mathrm{~L})$;

$\mathrm{V}$ : Volume total (L);

$\mathrm{F}_{\text {As } 1}$ : Taxa de transferência de $\mathrm{MAH}$ da Fase 1 para a Fase $2(\mathrm{~mol} / \mathrm{s})$;

$\mathrm{R}_{01}$ : Concentração de radicais $\mathrm{R}_{0}$ na Fase 1. (mol/L);

$\mathrm{R}_{02}$ : Concentração de radicais $\mathrm{R}_{0}$ na Fase 2. (mol/L);

$\mathrm{R}_{\mathrm{A} 01}$ : Concentração de radicais $\mathrm{R}_{\mathrm{A} 0}$ na Fase 1 (mol/L);

$\rho_{A}$ : Densidade do MAH (g/L);

$\rho_{\mathrm{l}}$ : Densidade do iniciador $(\mathrm{g} / \mathrm{L})$;

$\rho_{1}$ : Densidade da Fase 1 (g/L);

$\mathrm{m}_{1}$ : Massa da Fase $1(\mathrm{~g})$;

$\mathrm{m}_{\mathrm{A} 1}$ : Massa de MAH na Fase $1(\mathrm{~g})$;

$\mathrm{M}_{\mathrm{A}}$ : Massa molecular do $\mathrm{MAH}(\mathrm{g} / \mathrm{mol})$;

$\mathrm{M}_{1}$ : Massa molecular do iniciador ( $\left.\mathrm{g} / \mathrm{mol}\right)$;

$\mathrm{f}_{1}$ : Eficiência do iniciador na Fase 1;

$\mathrm{S}_{\mathrm{A}}$ : Solubilidade de MAH em PP (mol/L); 


\subsection{Análise dos valores ajustados para os parâmetros}

\subsubsection{Análise de parâmetros cinéticos}

Nos modelos, são ajustados valores para as constantes de velocidade das reações em diferentes temperaturas. Uma comparação destes parâmetros é feita utilizando-se dados de constantes de velocidade e energias de ativação, fornecidos pela literatura.

\subsubsection{Análise de parâmetros físicos}

Giudici (2007) estudou a modelagem matemática do processo de enxerto de MAH em PP, considerando um sistema reacional composto de uma única fase homogênea e utilizou o equacionamento descrito no item 3.1.2.2 (com exceção da equação 3.22). Neste estudo foi observado que o modelo representa bem as tendências de dados experimentais. No presente trabalho, este modelo é incrementado com parâmetros físicos de duas formas diferentes (Modelos 1 e 2). Para se discutir estes novos parâmetros, foram estimados os coeficientes de atividade dos reagentes no meio, através do método de contribuição de grupos, UNIFAC. Com estes coeficientes, é possível estudar o equilíbrio de fases da mistura.

\subsubsection{Obtenção do coeficiente de atividade (Método UNIFAC)}

Para se prever propriedades termodinâmicas, convém considerar uma molécula como sendo um agregado de grupos funcionais. Diversas propriedades podem ser estimadas através da contribuição desses grupos. A idéia básica deste tipo de método é que existem milhares de compostos químicos de interesse, porém, 
o número de grupos funcionais que os compõem é muito menor. Desta forma, assume-se que a propriedade física de um fluido é a soma das contribuições feitas pelos grupos constituintes das moléculas (REID, 1988).

O método UNIFAC permite calcular o coeficiente de atividade dos constituintes de uma mistura. Segundo Reid (1988), o coeficiente de atividade molecular é separado em duas partes: uma parte chamada combinatorial, que considera as diferenças no tamanho e na forma das moléculas da mistura, e uma parte chamada residual que considera as energias de interação entre os grupos. $O$ UNIFAC tem sido modificado e revisado nos últimos anos. No presente trabalho foi utilizado o modelo apresentado por Jakob et al (2006), que está descrito a seguir.

$$
\begin{aligned}
& \ln \gamma_{i}=\ln \gamma_{i}^{C}+\ln \gamma_{i}^{R} \\
& \ln \gamma_{i}^{C}=1-V_{i}^{\prime}+\ln \left(V_{i}^{\prime}\right)-5 q_{i}\left[1-\frac{V_{i}}{F_{i}}+\ln \left(\frac{V_{i}}{F_{i}}\right)\right] \\
& V_{i}^{\prime}=\frac{r_{i}^{3 / 4}}{\sum_{j} x_{j} r_{j}^{3 / 4}} \\
& V_{i}=\frac{r_{i}}{\sum_{j} x_{j} r_{j}} \\
& F_{i}=\frac{q_{i}}{\sum_{j} x_{j} q_{j}} \\
& r_{i}=\sum_{k} v_{k}^{(i)} R_{k} \\
& q_{i}=\sum_{k} v_{k}^{(i)} Q_{k}
\end{aligned}
$$


sendo que $R_{k}$ e $Q_{k}$ são tabelados em função do grupo.

$$
\begin{aligned}
& \ln \gamma_{i}^{R}=\sum_{k} v_{k}^{(i)}\left(\ln \Gamma_{k}-\ln \Gamma_{k}^{(i)}\right) \\
& \ln \Gamma_{k}=Q_{k}\left(1-\ln \left(\sum_{m} \Theta_{m} \Psi_{m k}\right)-\sum_{m} \frac{\Theta_{m} \Psi_{k m}}{\sum_{n} \Theta_{n} \Psi_{n m}}\right) \\
& \Theta_{m}=\frac{Q_{m} X_{m}}{\sum_{n} Q_{n} X_{n}} \\
& X_{m}=\frac{\sum_{j} v_{m}^{(j)} x_{j}}{\sum_{j} \sum_{n} v_{n}^{(j)} x_{j}} \\
& \Psi_{n m}=\exp \left(-\frac{a_{n m}+b_{n m} T+c_{n m} T^{2}}{T}\right)
\end{aligned}
$$

sendo que:

$a_{n m}, b_{n m}, c_{n m}$ : Parâmetros de interação;

C: Parte combinatorial do coeficiente de atividade;

$F_{\mathrm{i}}$ : Fração da área superficial do composto i na mistura;

$q_{i}$ : Área superficial relativa de Van der Waals do composto i na mistura;

$\mathrm{Q}_{\mathrm{k}}$ : Área superficial relativa de Van der Waals do subgrupo k na mistura;

$r_{\mathrm{i}}$ : Volume relativo de Van der waals do composto i na mistura;

$\mathrm{R}$ : Parte residual do coeficiente de atividade;

T: Temperatura absoluta $(\mathrm{K})$;

$\mathrm{V}_{\mathrm{i}}$ : Fração volume/mol do composto i na mistura;

$V_{\mathrm{i}}$ : Fração volume/mol modificada do composto i na mistura;

$\mathrm{X}_{\mathrm{m}}$ : Fração molar do subgrupo $\mathrm{m}$;

$\mathrm{x}_{\mathrm{j}}$ : Fração molar do componente j na mistura;

$\mathrm{w}_{\mathrm{i}}$ : Fator ponderante;

$\gamma_{i}$ : Coeficiente de atividade do composto i; 
$\Gamma_{\mathrm{k}}$ : Coeficiente de atividade de grupo para o subgrupo k;

$\Theta_{\mathrm{m}}$ : Fração de área superficial do grupo $\mathrm{m}$;

$\Psi_{\mathrm{nm}}$ : Parâmetro de interação de grupos;

$\mathrm{v}_{\mathrm{k}}^{(\mathrm{i})}$ : Número de subgrupos $\mathrm{k}$ no componente i.

\subsubsection{Estimativa do coeficiente de partição do iniciador}

No Modelo 2, considera-se que a quantidade adicionada de iniciador se divide entre as fases 1 e 2, seguindo uma proporção. Esta proporção é definida pelo coeficiente de partição do iniciador $\left(\mathrm{K}_{\mathrm{PI}}\right)$. O Modelo 2 também considera que a solubilidade do iniciador nas fases 1 e 2 é alta em relação às quantidades utilizadas deste reagente no processo. Desta forma, entende-se que o coeficiente de partição do iniciador é determinado através da igualdade de atividades deste componente nas duas fases em questão, considerando infinita diluição em ambas. $O$ equacionamento à seguir descreve a obtenção do $K_{P I}$ através deste conceito.

$$
\begin{aligned}
& a_{I, 1}=a_{I, 2} \\
& x_{I, 1} \gamma_{I, 1}^{\infty}=x_{I, 2} \gamma_{I, 2}^{\infty} \\
& \frac{x_{I, 1}}{x_{I, 2}}=\frac{\gamma_{I, 2}^{\infty}}{\gamma_{I, 1}^{\infty}}
\end{aligned}
$$

$$
K_{P I}=\frac{I_{1}}{I_{2}}=\frac{x_{I, 1} \frac{1}{\overline{M_{1}}}}{x_{I, 2} \frac{1}{\overline{M_{2}}}}=\frac{\gamma_{I, 2}^{\infty}}{\gamma_{I, 1}^{\infty}} \frac{\overline{M_{2}}}{\overline{M_{1}}}
$$

As quantidades de iniciador utilizadas no processo, em geral são baixas. Considera-se que as frações molares de iniciador nas fases 1 e 2 são baixas e não afetam significativamente a massa molecular média de cada fase. Portanto, as 
massas moleculares médias das fases 1 e 2, são as próprias massas moleculares do MAH e do PP respectivamente.

Com base nos estudos de Shi et al (2001, 2006), foi utilizada uma massa molecular média de $45000 \mathrm{~g} / \mathrm{mol}$ para o PP. Desta forma, o coeficiente de partição do iniciador pode ser calculado através da equação 3.58 .

$$
K_{P I}=459,2 \frac{\gamma_{I, 2}^{\infty}}{\gamma_{I, 1}^{\infty}}
$$

\subsubsection{Estimativa da solubilidade entre reagentes}

Nos Modelos 1 e 2, são utilizados parâmetros referentes às solubilidades de reagentes nas diferentes fases. A solubilidade de um componente em uma mistura pode ser calculada conforme descrito a seguir.

Com o coeficiente de atividade obtido pelo método UNIFAC, é possível calcular a atividade de um componente em uma mistura através da equação 3.59.

$$
a=\exp \left(\ln \gamma_{i}+\ln x_{i}\right)
$$

Com esta expressão, é possível fazer uma analise prévia do equilíbrio de fases através do gráfico da atividade em função da composição da mistura (binária).

Para a obtenção da solubilidade, foi utilizado o algoritmo de cálculo descrito por Pessôa ${ }^{6}$, com base nos conceitos apresentados por Prausnitz (1980). Neste método, o cálculo é feito de forma iterativa conforme descrito à seguir.

a) Especificam-se a temperatura $(T)$, a pressão $(P)$ e a composição da alimentação (z).

b) Estimam-se as composições das fases líquidas em equilíbrio ( $x^{\mathrm{L} 1}$ e $\left.x^{\mathrm{L2}}\right)$

c) Para cada composto presente, calcula-se o valor de $\mathrm{K}_{\mathrm{i}}$, dado por:

\footnotetext{
${ }^{6}$ Pessôa, P. (USP, São Paulo) Notas de aula, 2007.
} 


$$
K_{i}=\frac{\gamma_{i}^{L 2}}{\gamma_{i}^{L 1}}
$$

d) Obtém-se o valor da fração da fase $L 1, \Psi$, resolvendo-se a equação:

$$
\sum_{i=1}^{c} \frac{Z_{i}\left(1-K_{i}\right)}{1-\psi\left(1-K_{i}\right)}=0
$$

e) Recalcula-se a composição da fase L2 por meio de:

$$
x_{i}^{L 2}=\frac{Z_{i}}{1-\psi\left(1-K_{i}\right)}
$$

f) Recalcula-se a composição da fase 1 por meio de:

$$
X_{i}^{\prime L 1}=K_{i} X_{i}^{L 2}
$$

g) Comparam-se os valores calculados com os valores estimados. Se forem diferentes, retorna-se ao passo c; se forem iguais, verifica-se o valor de $\psi$; caso $0<$ $\Psi<1$, o cálculo está terminado e as composições calculadas são as composições em equilíbrio, caso contrário, haverá apenas uma fase líquida.

Este método permite estimar solubilidades a fim de se verificar os valores dos parâmetros ajustados nos modelos 1 e 2. Conforme descrito no item 3.1.4, a fração solúvel de MAH em PP, utilizada no Modelo 1, fornece um valor inicial de concentração de MAH efetiva. Este valor deve se verificado utilizando-se a solubilidade estimada de MAH em PP.

3.3.2.4 Análise do parâmetro fração segregada

O parâmetro fração segregada não pode ser analisado quantitativamente. 
Este parâmetro tem a função de representar a dificuldade de homogeneização. Como o sistema se trata de um meio muito viscoso, torna-se inviável a utilização de métodos que estimem os coeficientes de transporte de massa dos componentes. Portanto, a análise dos valores ajustados para este parâmetro, é feita com base nas condições utilizadas nos experimentos (temperatura, forma dos reagentes, rotação etc.).

Notação referente às análises dos parâmetros:

$a_{\mathrm{i}}$ : Atividade do componente i na mistura;

$a_{1,1}$ : Atividade do iniciador na Fase 1;

$a_{1,2}$ : Atividade do iniciador na Fase 2;

$\mathrm{X}_{\mathrm{I}, 1}$ : Fração molar de iniciador na Fase 1;

$\mathrm{x}_{\mathrm{l}, 2}$ : Fração molar de iniciador na Fase 2;

$x_{i}^{j}$ : Fração molar estimada do componente i na fase $j$;

$\mathrm{x}_{\mathrm{i}}^{\mathrm{j}}$ : Fração molar calculada do componente i na fase $\mathrm{j}$;

$\gamma_{i}^{j}$ : Coeficiente de atividade do componente i na fase j;

$\gamma_{I, 1}^{\infty}:$ Coeficiente de atividade para infinita diluição do iniciador na Fase 1;

$\gamma_{I, 2}^{\infty}$ : Coeficiente de atividade para infinita diluição do iniciador na Fase 2;

$\overline{M_{1}}$ : Massa molecular média da Fase 1;

$\overline{M_{2}}$ : Massa molecular média da Fase 2;

$K_{i}$ : Coeficiente de partição do componente i;

$\Psi$ : Fração da fase L1 na mistura;

$z_{i}$ : Fração do componente i na alimentação. 


\section{RESULTADOS}

Os modelos descritos na metodologia foram testados utilizando-se dados experimentais de grau de enxerto em função das concentrações iniciais de MAH e de iniciador. Foram testados também, dados de evolução do grau de enxerto com o tempo e de variação da massa molecular média. Os modelos foram aplicados em dados experimentais de diferentes autores. A Tabela 4.1 mostra as condições nas quais foram realizados os experimentos.

Tabela 4.1 - Condições dos experimentos.

\begin{tabular}{|c|c|c|c|c|c|}
\hline Autor & $\begin{array}{c}\text { Temperatura } \\
\left({ }^{\circ} \mathrm{C}\right)\end{array}$ & $\begin{array}{l}\text { Tempo de } \\
\text { reação (min) }\end{array}$ & Iniciador utilizado & $\begin{array}{c}\text { Rotação(a) } \\
(\mathrm{rpm})\end{array}$ & $\begin{array}{l}\text { Forma } \\
\text { do PP }\end{array}$ \\
\hline $\begin{array}{l}\text { Güldoğan } \\
\text { et al, } 2003\end{array}$ & 130 & 10,00 & $\begin{array}{c}\text { Peróxido de } \\
\text { dicumila (DCP) }\end{array}$ & 14 & $\begin{array}{l}\text { Grãos } \\
\text { / Pó }\end{array}$ \\
\hline $\begin{array}{l}\text { Shi et al, } \\
2006\end{array}$ & 180 & 7,00 & $\begin{array}{c}\text { Peróxido de } \\
\text { dicumila (DCP) }\end{array}$ & 50 & Grãos \\
\hline $\begin{array}{l}\text { Shi et al, } \\
2001\end{array}$ & 185 & 2,00 & $\begin{array}{c}\text { Peróxido de } \\
\text { dicumila (DCP) }\end{array}$ & 120 & Pó \\
\hline $\begin{array}{l}\text { Akzo, } \\
2007\end{array}$ & 220 & 12,00 & $\begin{array}{c}\text { Di (terc- } \\
\text { butilperoxiisopropil) } \\
\text { Benzeno (Px14) }\end{array}$ & 200 & Pó \\
\hline $\begin{array}{l}\text { Cha e } \\
\text { White, } \\
2001\end{array}$ & 230 & $\begin{array}{c}10,00(\mathrm{M})^{(\mathrm{b})} \\
3,11(\mathrm{E})\end{array}$ & $\begin{array}{l}\text { 2,5-dimetil-2,5-bis-(t- } \\
\text { butilperoxi) hexano } \\
\text { (DBHA) }\end{array}$ & 100 & Grãos \\
\hline $\begin{array}{l}\text { Chang e } \\
\text { White, } \\
2003\end{array}$ & 230 & 5,00 & $\begin{array}{l}\text { 2,5-dimetil-2,5-di-(t- } \\
\text { butilperoxi)hexano } \\
\text { (DHBP) }\end{array}$ & 100 & ? \\
\hline
\end{tabular}

(a) Rotação do impulsor do misturador e/ou das roscas da extrusora. (b) M e E se referem aos experimentos realizados com misturador e extrusora respectivamente.

A seguir são mostrados os resultados de cada um dos modelos.

\subsection{Resultados das simulações com o Modelo 1}

O Modelo 1 foi testado com os dados publicados nos seis artigos encontrados. Os resultados estão representados através da referência. As simulações foram feitas com os dados de Güldoğan et al (2003), Shi et al (2006), 
Shi et al (2001), Akzo (2007), Cha e White (2001) e Chang e White (2003). Os resultados das simulações estão detalhados a seguir.

\subsubsection{Güldoğan et al (2003)}

Neste artigo, são comparados os graus de enxerto obtidos em experimentos realizados com o PP em forma de grãos e na forma de pó.

A Figura 24 mostra os resultados do modelo comparados com os dados publicados por Güldoğan et al (2003).
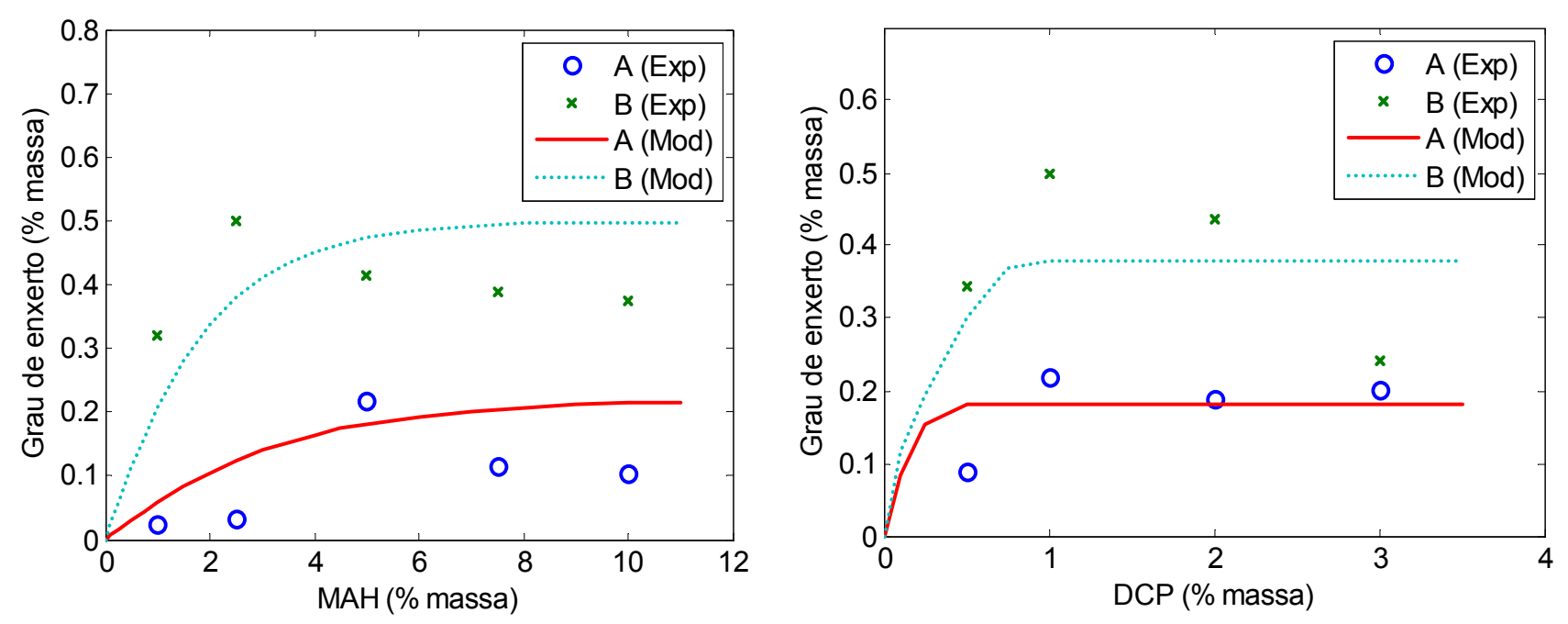

Figura 24 - Resultados da simulação com os dados de Güldoğan et al (2003), através do Modelo 1. A: PP em grãos. B: PP em pó. "Exp" representa os dados experimentais e "Mod" representa a predição do modelo. Os eixos MAH e DCP representam as concentrações iniciais destes reagentes em cada experimento.

Nos dados de grau de enxerto em função da concentração inicial de MAH foi utilizado $1 \%$ em massa de DCP. Nos dados de grau de enxerto em função da concentração inicial de DCP foi utilizado 5\% em massa de MAH para o caso do PP em grãos e 2,5\% em massa de MAH para o caso do PP em pó. 


\subsubsection{Shi et al (2006)}

Neste trabalho, o autor introduz o conceito de nano-reator, que é um composto sólido (argila montmorilonita) que possui galerias, as quais armazenam o iniciador. De acordo com Shi et al (2006), o uso de nano-reatores no processo melhora a distribuição do MAH ao longo do PP e aumenta a eficiência do iniciador devido à baixa taxa de geração de radicais primários. Estes dois aspectos foram considerados na modelagem desse caso.

A Figura 25 mostra os resultados do modelo comparados com os dados publicados por Shi et al (2006).
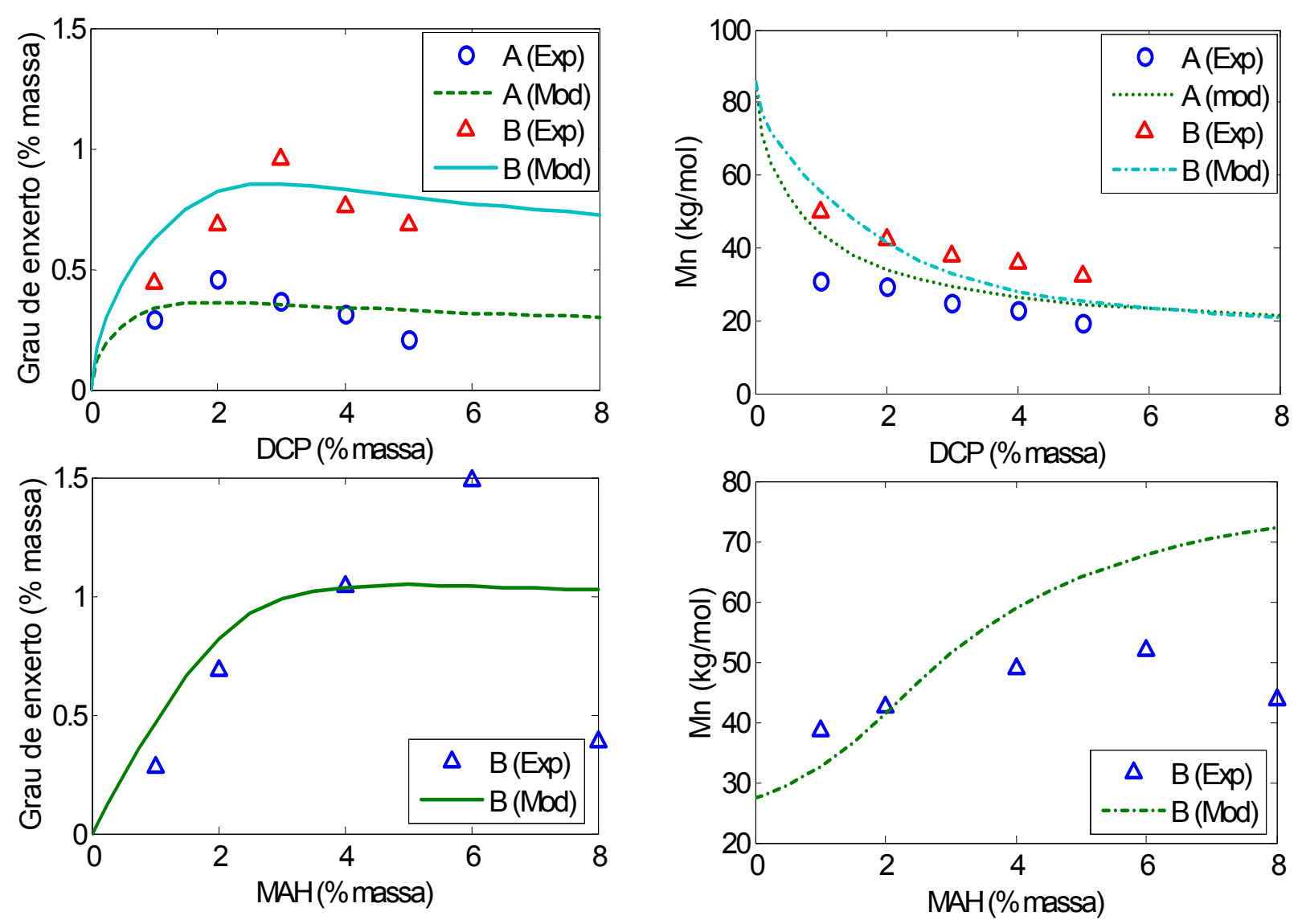

Figura 25 - Resultados da simulação com os dados de Shi et al (2006), através do Modelo 1. Mn é a massa molecular média numérica de PP obtida ao fim de cada reação. "A" representa o processo convencional e "B" representa o processo que utilizou o nano-reator. Na comparação dos processos (gráficos superiores) foi utilizado $\mathrm{MAH}=2 \%$ (massa) e os gráficos inferiores apresentam resultados obtidos com DCP $=2 \%$ (massa). 
4.1.3 Shi et al (2001)

O mesmo autor que publicou o trabalho abordado no item 4.1.2 possui um trabalho anterior, no qual ele estudou o processo convencional em uma extrusora.

A Figura 26 mostra os resultados do modelo comparados com os dados publicados por Shi et al (2001).

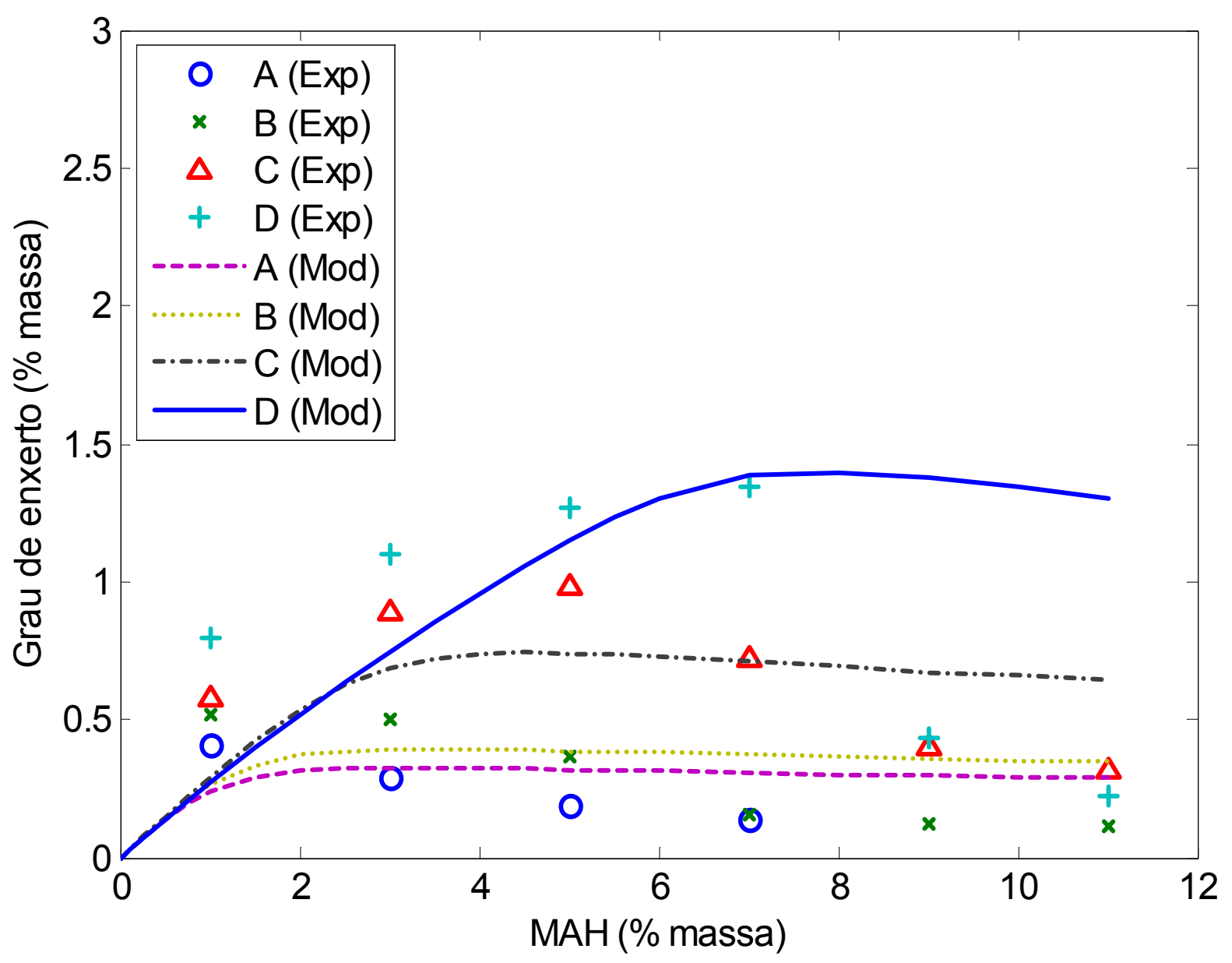

Figura 26 - Resultados da simulação com os dados de Shi et al (2001), através do Modelo 1. As curvas representam diferentes concentrações de DCP: $A=0,6 \%, B=0,8 \%, C=2 \%$ e $D=5 \%$ (massa). 
O Modelo 1 também foi testado com dados de um estudo experimental realizado pelo fabricante de iniciadores, Akzo.

A Figura 27 mostra os resultados do modelo comparados com os dados publicados por Akzo (2007).
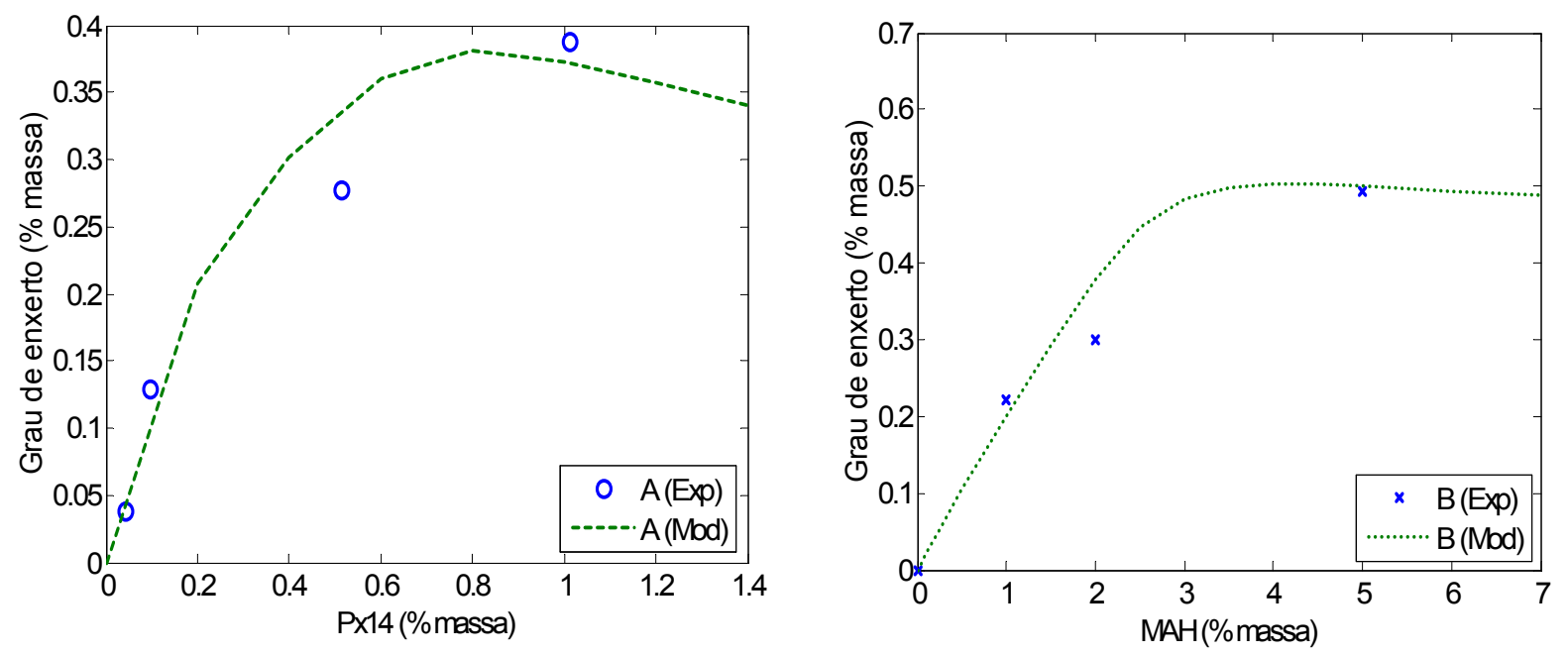

Figura 27 - Resultados da simulação com os dados de Akzo (2007), através do Modelo 1. A: MAH = 2\% (massa) e B: Px14 = 0,513 \% (massa).

\subsubsection{Cha e White (2001)}

Neste estudo foram realizadas reações de enxerto em tanque de mistura e em extrusora.

A Figura 28 mostra os resultados do modelo comparados com os dados publicados por Cha e White (2001). 

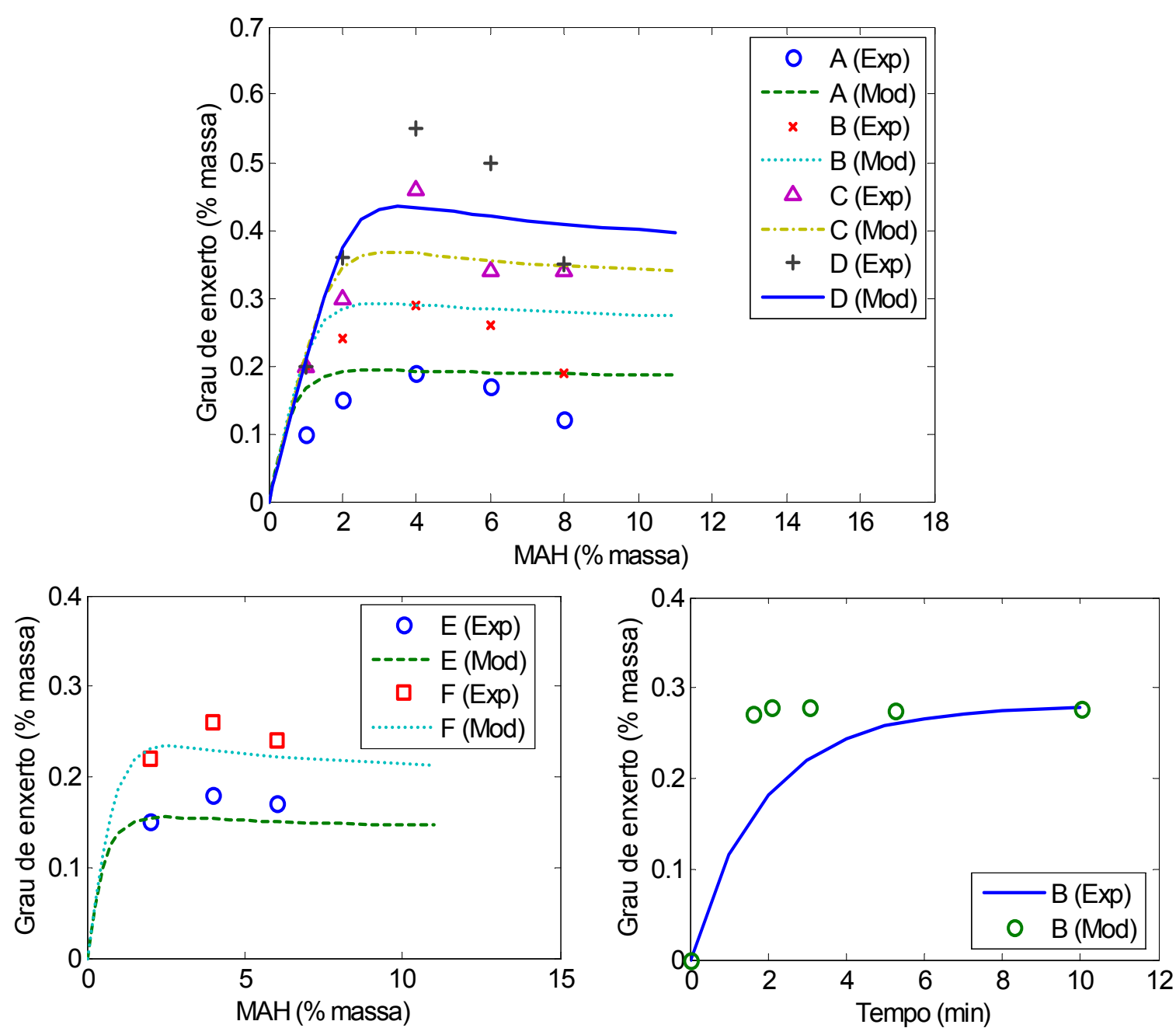

Figura 28 - Resultados da simulação com os dados de Cha e White (2001), através do Modelo 1. Concentrações de DBHA para o processo realizado no tanque de mistura: $A=0,18 \%, B=0,37 \%, C$ $=0,55 \%$ e $D=0,73 \%$ (massa). Concentrações de DBHA para o processo realizado na extrusora: $E=$ $0,18 \%$ e $F=0,36 \%$ (massa).

\subsubsection{Chang e White (2003)}

Este artigo descreve um estudo voltado para a configuração dos tipos de extrusoras. Neste estudo, foi realizado um experimento preliminar o qual foi testado pelo Modelo 1.

A Figura 29 mostra os resultados do modelo comparados com os dados publicados por Chang e White (2003). 

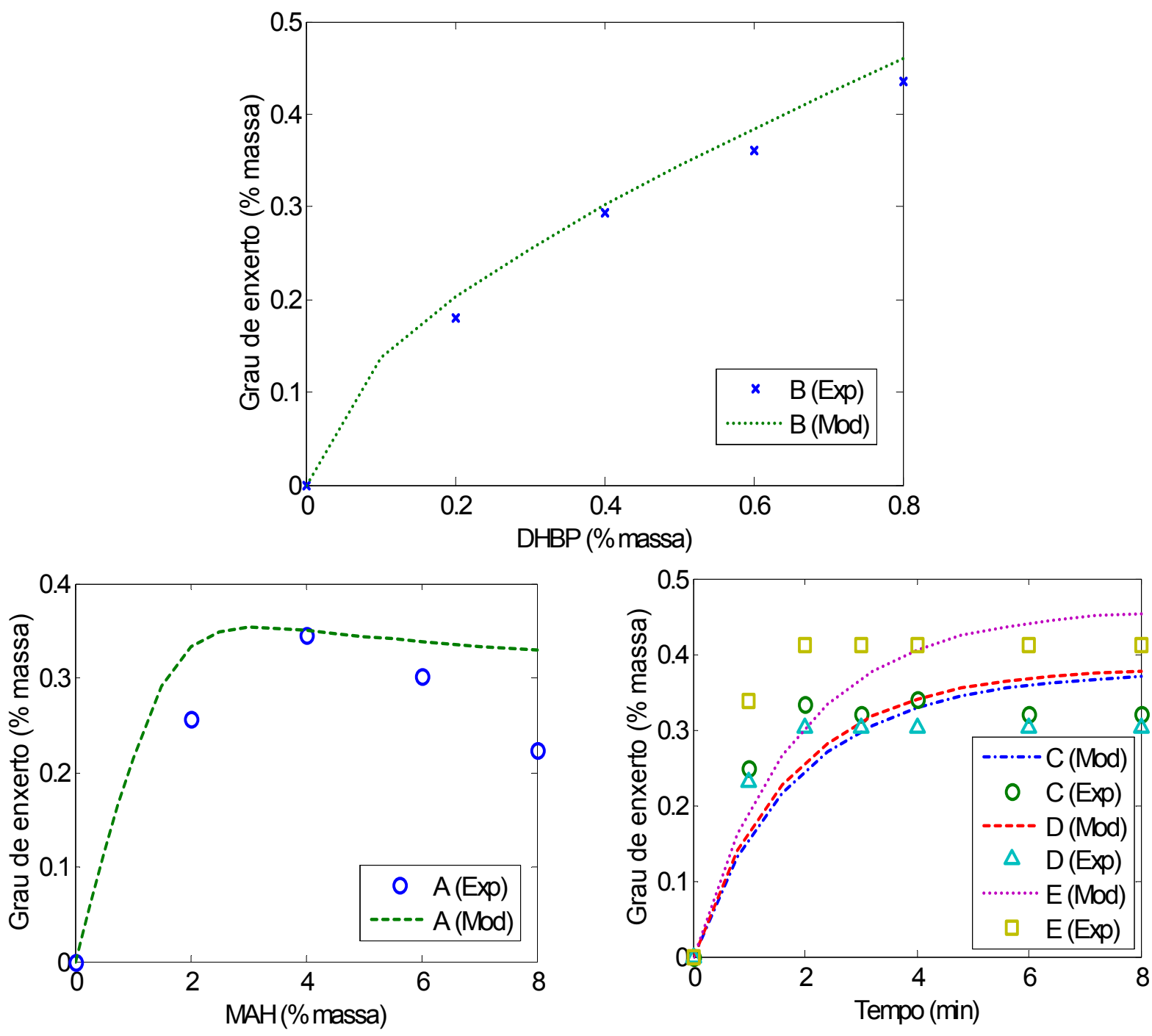

Figura 29 - Resultados da simulação com os dados de Chang e White (2003), através do Modelo 1. A: $\mathrm{DHBP}=0,5 \%, \mathrm{~B}: \mathrm{MAH}=5 \%, \mathrm{C}: \mathrm{MAH}=5 \%$ e DHBP $=0,5 \%, \mathrm{D}: \mathrm{MAH}=3 \%$ e DHBP $=0.5 \%$, $\mathrm{E}: \mathrm{MAH}=5 \%$ e DHBP $=0,7 \%$ (Porcentagens em massa).

\subsection{Resultados dos parâmetros ajustáveis do Modelo 1}

Os parâmetros cinéticos e físicos definidos na metodologia tiveram seus valores ajustados de forma a obter as melhores validações do modelo aos dados experimentais.

A Tabela 4.2 mostra os valores dos parâmetros ajustados para o Modelo 1. 
Tabela 4.2 - Parâmetros ajustados no Modelo 1.

\begin{tabular}{|c|c|c|c|c|c|c|c|}
\hline Autor & $\begin{array}{l}\text { Güldogan } \\
\text { et al, } 2003\end{array}$ & $\begin{array}{l}\text { Shi et al, } \\
2006 \text { (C) }\end{array}$ & $\begin{array}{l}\text { Shi et al, } \\
2006 \text { (NR) }\end{array}$ & $\begin{array}{c}\text { Shi et al, } \\
2001\end{array}$ & $\begin{array}{l}\text { Akzo, } \\
2007\end{array}$ & $\begin{array}{l}\text { Cha e } \\
\text { White, } \\
2001\end{array}$ & $\begin{array}{c}\text { Chang e } \\
\text { White, } \\
2003\end{array}$ \\
\hline $\begin{array}{c}\text { Temperatura } \\
\left({ }^{\circ} \mathrm{C}\right)\end{array}$ & 130 & 180 & 180 & 185 & 220 & 230 & 230 \\
\hline Iniciador & $\mathrm{DCP}$ & DCP & DCP & DCP & $P \times 14$ & $\mathrm{DBHA}$ & DHBP \\
\hline ys & $\begin{array}{c}0,56(\mathrm{~g}) \\
0(\mathrm{p})\end{array}$ & 0,1 & 0,1 & 0 & 0 & 0 & 0 \\
\hline ysolA & $\begin{array}{l}0,08(\mathrm{~g}) \\
0,30(\mathrm{p})\end{array}$ & 0,25 & 0,65 & 0,35 & 0,35 & 0,4 & 0,4 \\
\hline $\mathrm{S}_{\text {I }}\left(\begin{array}{c}\% \text { massa } \\
f\end{array}\right.$ & $\begin{array}{c}0,15 \\
0,6\end{array}$ & $\begin{array}{l}25,9 \\
0,62\end{array}$ & $\begin{array}{l}25,9 \\
0,75\end{array}$ & $\begin{array}{l}27,1 \\
0,64\end{array}$ & $\begin{array}{c}14 \\
0,66\end{array}$ & $\begin{array}{c}9,2 \\
0,68\end{array}$ & $\begin{array}{c}36 \\
0,68\end{array}$ \\
\hline$k_{d}\left(s^{-1}\right)$ & $8,00 \mathrm{E}-3$ & $1,00 \mathrm{E}-2$ & $8,00 \mathrm{E}-3$ & $2,02 \mathrm{E}-2$ & $1,00 \mathrm{E}-2$ & $1,58 \mathrm{E}-2$ & $1,58 \mathrm{E}-2$ \\
\hline $\mathrm{k}_{\mathrm{fp}, 0}(\mathrm{~L} / \mathrm{mol} . \mathrm{s})$ & $8,80 E+2$ & $2,80 E+3$ & $2,80 \mathrm{E}+3$ & $3,50 E+3$ & $6,55 E+3$ & $8,50 E+3$ & $8,50 \mathrm{E}+3$ \\
\hline $\mathrm{K}_{\mathrm{fo}}(\mathrm{L} / \mathrm{mol} . \mathrm{s})$ & $4,00 E+1$ & $2,00 E+3$ & $2,00 E+3$ & $2,82 \mathrm{E}+3$ & $4,50 \mathrm{E}+4$ & $6,59 \mathrm{E}+4$ & $6,59 \mathrm{E}+4$ \\
\hline $\mathrm{K}_{\mathrm{fp}}{ }^{\prime}(\mathrm{L} / \mathrm{mol} . \mathrm{s})$ & $1,00 E+0$ & $5,50 \mathrm{E}+0$ & $5,50 \mathrm{E}+0$ & $5,70 \mathrm{E}+0$ & $1,00 \mathrm{E}+1$ & $1,78 \mathrm{E}+1$ & $1,78 \mathrm{E}+1$ \\
\hline $\mathrm{k}_{\mathrm{a}, 0}$ (L/mol.s) & $1,00 E+5$ & $4,00 \mathrm{E}+5$ & $4,00 E+5$ & $4,92 \mathrm{E}+5$ & $4,30 \mathrm{E}+6$ & $5,21 \mathrm{E}+6$ & $5,21 \mathrm{E}+6$ \\
\hline $\mathrm{k}_{\mathrm{a}}(\mathrm{L} / \mathrm{mol} . \mathrm{s})$ & $1,00 E+3$ & $5,00 \mathrm{E}+3$ & $5,00 E+3$ & $1,76 \mathrm{E}+4$ & $3,00 \mathrm{E}+4$ & $4,82 \mathrm{E}+4$ & $4,82 \mathrm{E}+4$ \\
\hline $\mathrm{k}_{\mathrm{cs}}\left(\mathrm{s}^{-1}\right)$ & $8,10 \mathrm{E}+5$ & $6,10 \mathrm{E}+6$ & $6,10 \mathrm{E}+6$ & $7,29 E+6$ & $2,40 \mathrm{E}+7$ & $3,08 \mathrm{E}+7$ & $3,08 \mathrm{E}+7$ \\
\hline $\mathrm{k}_{\mathrm{t}}(\mathrm{L} / \mathrm{mol} . \mathrm{s})$ & $5,50 \mathrm{E}+6$ & $7,00 \mathrm{E}+7$ & $7,00 \mathrm{E}+7$ & $8,57 \mathrm{E}+7$ & $7,80 \mathrm{E}+8$ & $2,43 E+9$ & $2,43 \mathrm{E}+9$ \\
\hline
\end{tabular}

C: Processo convencional; NR: Processo que utilizou o nano-reator; g: Polipropileno processado na forma de grãos; p: Polipropileno processado na forma de pó; $\mathrm{S}$ : Solubilidade do iniciador; Ex: $10^{\mathrm{x}}$.

As Figuras 30 a 33 mostram os resultados da aplicação da lei de Arrhenius (curvas) aos valores de constante de velocidade ajustados no Modelo 1 (pontos).
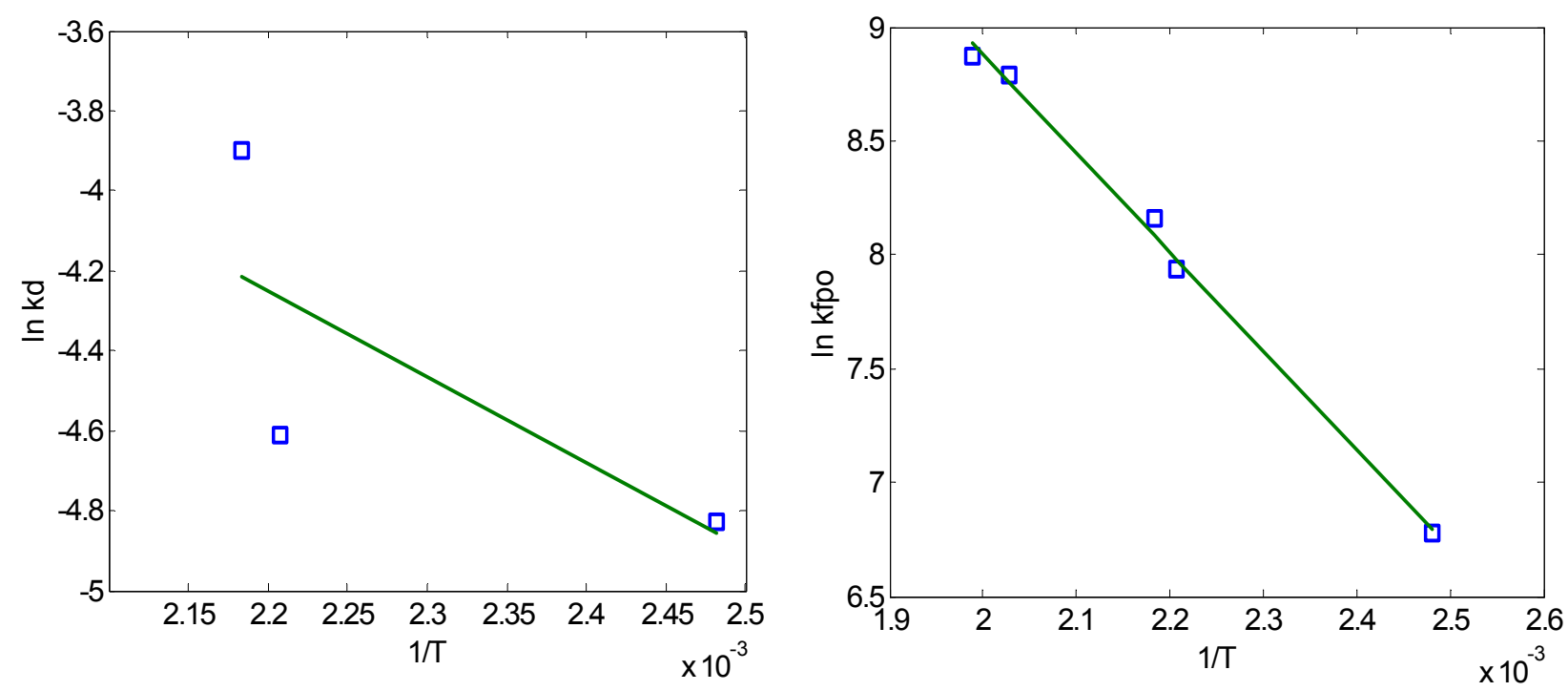

Figura 30 - Modelo 1: Lei de Arrhenius aplicada aos valores ajustados de $k_{d}$ e $k_{f p, 0}$. 

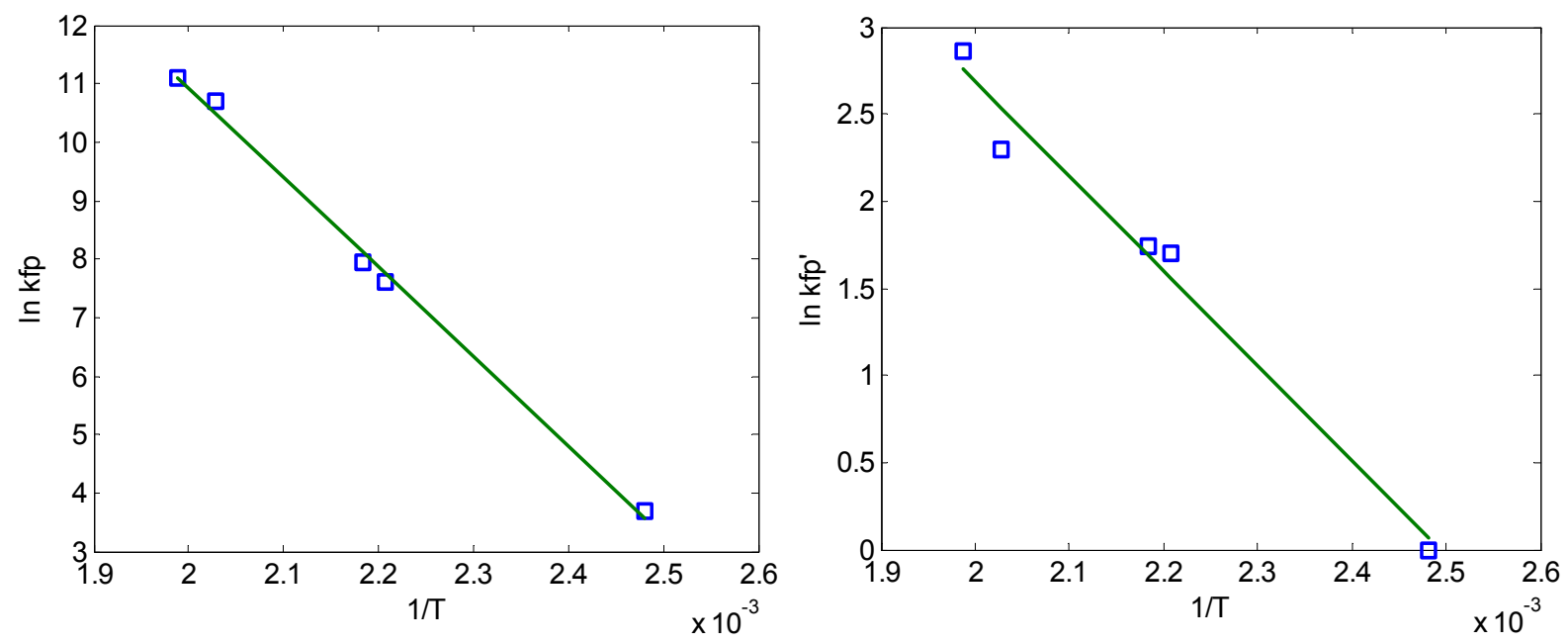

Figura 31 - Modelo 1: Lei de Arrhenius aplicada aos valores ajustados de $k_{f p}$ e $k_{f p}$.
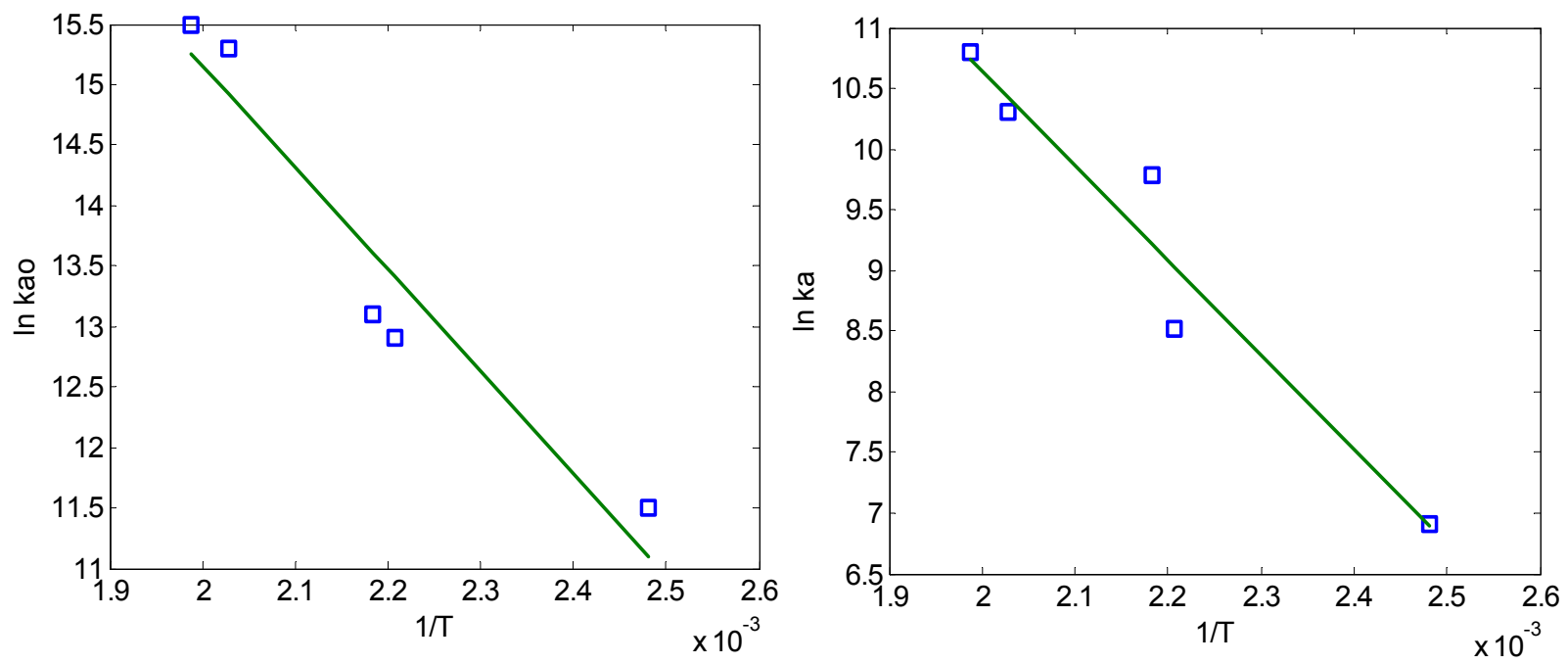

Figura 32 - Modelo 1: Lei de Arrhenius aplicada aos valores ajustados de $\mathrm{k}_{\mathrm{a}, 0}$ e $\mathrm{k}_{\mathrm{a}}$.
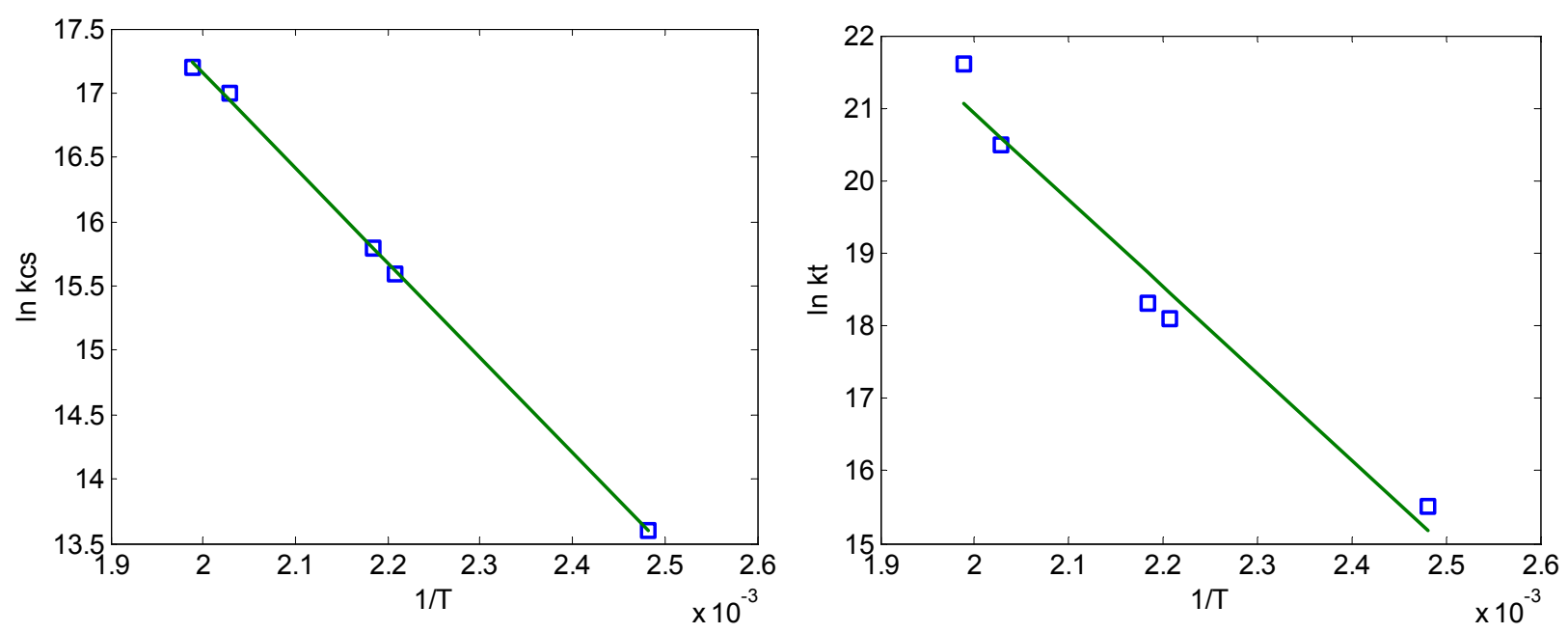

Figura 33 - Modelo 1: Lei de Arrhenius aplicada aos valores ajustados de $\mathrm{k}_{\mathrm{cs}}$ e $\mathrm{k}_{\mathrm{t}}$. 
As curvas da Lei de Arrhenius ajustada aos dados das simulações geram valores de energia de ativação $\left(E_{j}\right)$. A Tabela 4.3 mostra estes resultados.

Tabela 4.3 - Valores de energia de ativação obtidos no Modelo 1.

\begin{tabular}{cc}
\hline Energia de ativação (kcal/mol) \\
\hline$E_{d}$ & 4,29 \\
$E_{\mathrm{fp}, 0}$ & 8,59 \\
$E_{\mathrm{fp}}$ & 30,40 \\
$E_{\mathrm{fp}}$ & 10,80 \\
$E_{\mathrm{a}, 0}$ & 16,70 \\
$\mathrm{E}_{\mathrm{a}}$ & 15,50 \\
$\mathrm{E}_{\mathrm{cs}}$ & 14,70 \\
$\mathrm{E}_{\mathrm{t}}$ & 23,80 \\
\hline
\end{tabular}

\subsection{Discussão dos parâmetros ajustáveis do Modelo 1}

\subsubsection{Discussão das constantes de velocidade ajustadas no Modelo 1}

Sistemas reacionais envolvendo polímeros possuem inúmeras espécies químicas e diferentes reações que ocorrem simultaneamente. As reações nesse tipo de sistema podem ser interpretadas através de diferentes mecanismos, o que torna difícil a comparação dos parâmetros cinéticos. Devido a essa complexidade, a mesma reação considerada em diferentes processos, pode não possuir o mesmo valor de constante cinética em cada processo, devido aos diferentes mecanismos envolvidos. Para a comparação dos parâmetros cinéticos obtidos no presente trabalho, foram coletados dados de diferentes fontes. Porém, a validade desta comparação é ponderada pela semelhança entre os processos que geraram os dados a serem comparados (Modelo 1 e fontes da literatura).

Neste item é feita a comparação entre os valores dos parâmetros cinéticos ajustados e os valores retirados da literatura. No item 5 são discutidas as discrepâncias encontradas. 
A Tabela 4.4 mostra a comparação dos valores de $k_{d}$ ajustados com os valores retirados de Akzo (2006) e Cha e White (2001).

Tabela 4.4 - Modelo 1: Comparação entre os valores de $k_{d}$.

\begin{tabular}{cccccc}
\hline Iniciador & \multicolumn{3}{c}{ DCP } & Px14 & DBHA \\
Temperatura $\left({ }^{\circ} \mathrm{C}\right)$ & 130 & 180 & 185 & 220 & 230 \\
\hline $\mathrm{k}_{\mathrm{d}}$ ajustado $\left(\mathrm{s}^{-1}\right)$ & $8,00 \mathrm{E}-03$ & $1,00 \mathrm{E}-02$ & $2,02 \mathrm{E}-02$ & $1,00 \mathrm{E}-02$ & $1,58 \mathrm{E}-02$ \\
$\mathrm{k}_{\mathrm{d}}\left(\right.$ Akzo, 2006) $\left(\mathrm{s}^{-1}\right)$ & $1,53 \mathrm{E}-04$ & $2,34 \mathrm{E}-02$ & $3,64 \mathrm{E}-02$ & $1,54 \mathrm{E}-01$ & $2,07 \mathrm{E}-01$ \\
$\mathrm{k}_{\mathrm{d}}($ Cha e White, 2001$)\left(\mathrm{s}^{-1}\right)$ & - & - & $4,90 \mathrm{E}-02$ & - & $6,10 \mathrm{E}-01$ \\
\hline
\end{tabular}

Para o DHBP não foram encontrados dados cinéticos na literatura, porém ela é uma molécula bem parecida com o DBHA, sendo válida a mesma comparação feita para o DBHA na Tabela 4.4.

As Tabelas 4.5 e 4.6 mostram as comparações das demais constantes de velocidade nas temperaturas de $185^{\circ} \mathrm{C}$ e $230^{\circ} \mathrm{C}$ respectivamente.

Tabela 4.5 - Modelo 1: Comparação de constantes de velocidade à $185^{\circ} \mathrm{C}$.

\begin{tabular}{cccccc}
\hline $\begin{array}{c}\text { Constante de } \\
\text { velocidade }\end{array}$ & $\begin{array}{c}\text { Valor } \\
\text { ajustado }\end{array}$ & $\begin{array}{c}\text { Giudici } \\
(2007)\end{array}$ & $\begin{array}{c}{ }^{*} \text { Zhu et al } \\
(2003)\end{array}$ & $\begin{array}{c}\text { Kruse et al } \\
(2003)\end{array}$ & $\begin{array}{c}\text { Berzin et al } \\
(2000)\end{array}$ \\
\hline $\mathrm{k}_{\mathrm{fp}, 0}(\mathrm{~L} / \mathrm{mol} . \mathrm{s})$ & $3,50 \mathrm{E}+3$ & $2,58 \mathrm{E}+4$ & $2,70 \mathrm{E}+07$ & $9,75 \mathrm{E}+02$ & - \\
$\mathrm{K}_{\mathrm{fp}}(\mathrm{L} / \mathrm{mol} . \mathrm{s})$ & $2,82 \mathrm{E}+3$ & $2,58 \mathrm{E}+3$ & - & - & - \\
$\mathrm{k}_{\mathrm{fp}}(\mathrm{L} / \mathrm{mol} . \mathrm{s})$ & $5,70 \mathrm{E}+0$ & 0,00 & - & - & - \\
$\mathrm{k}_{\mathrm{a}, 0}$ (L/mol.s) & $4,92 \mathrm{E}+5$ & $7,00 \mathrm{E}+6$ & $2,85 \mathrm{E}+06$ & - & - \\
$\mathrm{k}_{\mathrm{a}}\left(\mathrm{L} / \mathrm{mol}^{\prime} \mathrm{s}\right)$ & $1,76 \mathrm{E}+4$ & $2,73 \mathrm{E}+4$ & $1,09 \mathrm{E}+04$ & - & - \\
$\mathrm{k}_{\mathrm{cs}}\left(\mathrm{s}^{-1}\right)$ & $7,29 \mathrm{E}+6$ & $2,10 \mathrm{E}+3$ & $3,00 \mathrm{E}+03$ & $3,66 \mathrm{E}+01$ & - \\
$\mathrm{k}_{\mathrm{t}}(\mathrm{L} / \mathrm{mol} . \mathrm{s})$ & $8,57 \mathrm{E}+7$ & $1,99 \mathrm{E}+8$ & $1,99 \mathrm{E}+08$ & $8,79 \mathrm{E}+08$ & $3,42 \mathrm{E}+08$ \\
\hline
\end{tabular}

${ }^{*}$ Zhu et al (2003) utiliza uma temperatura de $190^{\circ} \mathrm{C}$ na simulação com os dados de Shi et al (2001).

Tabela 4.6 - Modelo 1: Comparação de constantes de velocidade à $230^{\circ} \mathrm{C}$.

\begin{tabular}{ccccc}
\hline $\begin{array}{c}\text { Constante de } \\
\text { velocidade }\end{array}$ & $\begin{array}{c}\text { Valor } \\
\text { ajustado }\end{array}$ & Giudici $(2007)$ & $\begin{array}{c}\text { Kruse et al } \\
(2003)\end{array}$ & $\begin{array}{c}\text { Berzin et al } \\
(2000)\end{array}$ \\
\hline $\mathrm{k}_{\mathrm{fp}, 0}(\mathrm{~L} / \mathrm{mol} . \mathrm{s})$ & $8,5 \mathrm{E}+3$ & $3,05 \mathrm{E}+5$ & $2,74 \mathrm{E}+03$ & - \\
$\mathrm{k}_{\mathrm{fp}}(\mathrm{L} / \mathrm{mol} . \mathrm{s})$ & $6,59 \mathrm{E}+4$ & $3,05 \mathrm{E}+5$ & - & - \\
$\mathrm{k}_{\mathrm{fp}}(\mathrm{L} / \mathrm{mol} . \mathrm{s})$ & $1,78 \mathrm{E}+1$ & 0,00 & - & - \\
$\mathrm{k}_{\mathrm{a}, 0}(\mathrm{~L} / \mathrm{mol} . \mathrm{s})$ & $5,21 \mathrm{E}+6$ & $7,67 \mathrm{E}+6$ & - & - \\
$\mathrm{k}_{\mathrm{a}}\left(\mathrm{L} / \mathrm{mol}^{-s}\right)$ & $4,82 \mathrm{E}+4$ & $2,99 \mathrm{E}+4$ & - & - \\
$\mathrm{k}_{\mathrm{cs}}\left(\mathrm{s}^{-1}\right)$ & $3,08 \mathrm{E}+7$ & $2,10 \mathrm{E}+3$ & $5,79 \mathrm{E}+02$ & - \\
$\mathrm{k}_{\mathrm{t}}(\mathrm{L} / \mathrm{mol} . \mathrm{s})$ & $2,43 \mathrm{E}+9$ & $2,56 \mathrm{E}+9$ & $1,10 \mathrm{E}+09$ & $3,43 \mathrm{E}+08$ \\
\hline
\end{tabular}

A Tabela 4.7 mostra a comparação das energias de ativação obtidas no Modelo 1. 
Tabela 4.7 - Modelo 1: Comparação das energias de ativação obtidas.

\begin{tabular}{ccccccc}
\hline $\begin{array}{c}\text { Energia de } \\
\text { ativação } \\
(\mathrm{kcal} / \mathrm{mol})\end{array}$ & $\begin{array}{c}\text { Valor } \\
\text { ajustad } \\
\mathrm{o}\end{array}$ & $\begin{array}{c}\text { *Giudici } \\
(2007)\end{array}$ & $\begin{array}{c}\text { ledema } \\
\text { et al } \\
(2001)\end{array}$ & $\begin{array}{c}\text { Akzo } \\
(2006)\end{array}$ & $\begin{array}{c}\text { Kruse et al } \\
(2003)\end{array}$ & $\begin{array}{c}\text { Berzin et } \\
\text { al (2000) }\end{array}$ \\
\hline $\mathrm{E}_{\mathrm{d}}(\mathrm{DCP})$ & 4,29 & - & - & 36,5 & - & - \\
$\mathrm{E}_{\mathrm{fpo}}$ & 8,59 & 25,10 & - & - & 10,50 & - \\
$\mathrm{E}_{\mathrm{fp}}$ & 30,40 & 48,50 & 535,00 & - & - & - \\
$\mathrm{E}_{\mathrm{fp}}$ & 10,80 & 0,00 & - & - & - & - \\
$\mathrm{E}_{\mathrm{a} 0}$ & 16,70 & 0,93 & - & - & - & - \\
$\mathrm{E}_{\mathrm{a}}$ & 15,50 & 0,93 & - & - & - & - \\
$\mathrm{E}_{\mathrm{cs}}$ & 14,70 & 0,00 & - & - & 28,10 & - \\
$\mathrm{E}_{\mathrm{t}}$ & 23,80 & 26,00 & 8,92 & - & 2,30 & 0,02 \\
\hline
\end{tabular}

*Valores calculados através da lei de Arrhenius aplicada aos dados publicados.

\subsubsection{Discussão dos valores de solubilidade do iniciador no meio reacional}

O método UNIFAC permitiu calcular os coeficientes de atividade dos iniciadores em PP. Com os valores obtidos, foi possível calcular a atividade desses compostos na mistura com o polipropileno através da equação 3.59. Foram consideradas misturas binárias (Iniciador + PP) no cálculo dos coeficientes de atividade. O tamanho médio numérico de cadeias de PP utilizado no cálculo foi o de 45000 (SHI et al, 2001). De modo geral a curva de atividade em função da composição se encontra toda abaixo do valor 1, conforme mostrado na Figura 34.

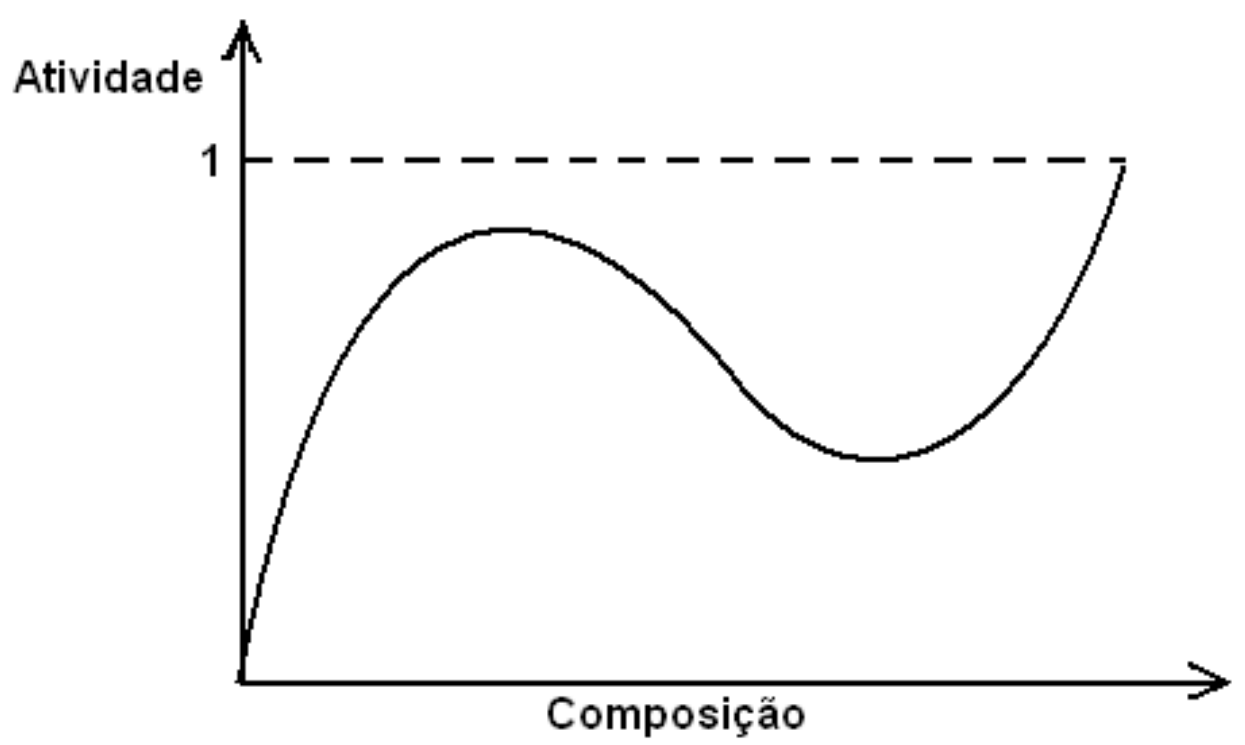

Figura 34 - Curva típica de atividade em função da composição. 
Para este caso geral, a determinação das composições das fases é feita através do algoritmo apresentado no item 3.3.2.3.

A grandeza atividade é definida conforme a equação 4.1.

$a_{i}=\frac{\hat{f}_{i}}{f_{i}^{\text {ref }}}$

sendo:

$a_{i}$ : Atividade do componente i na mistura;

$\hat{f}_{i}$ : Fugacidade do componente i na mistura;

$f_{i}^{r e f}$ : Fugacidade do componente i num estado de referência (usa-se comumente o composto puro nas mesmas condições de temperatura e no mesmo estado de agregação que está a mistura).

Para que haja equilíbrio entre duas fases, é necessário que seus componentes possuam o mesmo valor de fugacidade em ambas. A Figura 35 mostra um caso específico de equilíbrio de fases.

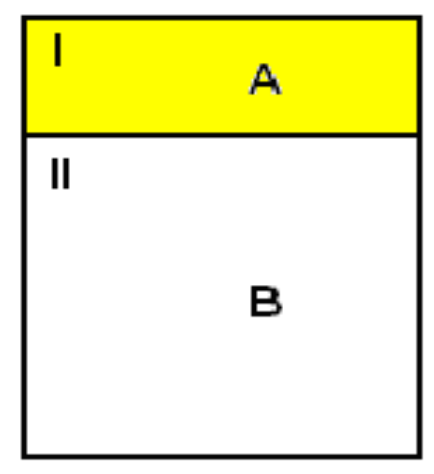

A e B Puros

$$
\boldsymbol{f}_{\mathrm{A}}^{\prime} \neq \boldsymbol{f}_{\mathrm{A}}^{\| \prime}
$$

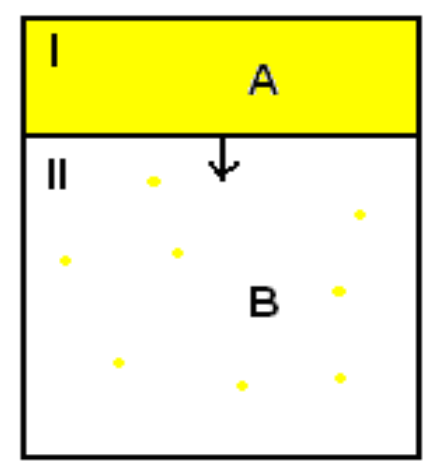

A se dissolvendo em $B$

$$
\boldsymbol{f}_{\mathrm{A}}^{\prime} \neq \boldsymbol{f}_{\mathrm{A}}^{\| \prime}
$$

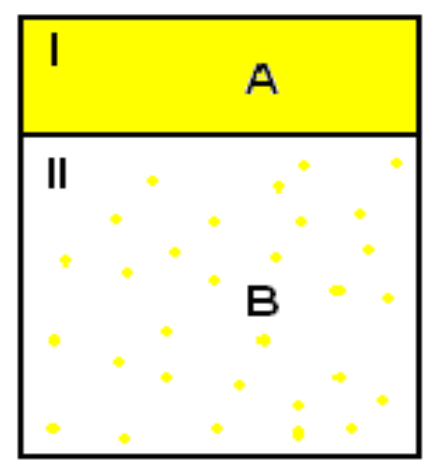

Equilíbrio de fases

$$
f_{\mathrm{A}}^{\prime}=\boldsymbol{f}_{\mathrm{A}}^{\|}
$$

Figura 35 - Caso específico de equilíbrio de fases.

Neste caso, o composto A é parcialmente solúvel em $B$ e o $B$ é completamente insolúvel ${ }^{7}$ em A.

\footnotetext{
${ }^{7}$ Completamente insolúvel indica uma solubilidade bem baixa, desprezível.
} 
Quando o equilíbrio é atingido, a fugacidade de $A$ na fase $I\left(\mathrm{f}_{\mathrm{A}}^{\prime}\right)$ se iguala a fugacidade de $A$ na fase II $\left(f_{A} \|\right)$. De acordo com a equação 4.1, no equilíbrio, o valor de atividade na fase II será 1 , pois a fugacidade de A na fase I é a própria fugacidade de referência (A puro).

Para o caso dos iniciadores, o limite de solubilidade é facilmente identificado, pois as curvas de atividade em função da composição extrapolam o valor 1.

A Figura 36 permite obter os limites de solubilidade do DCP em PP para as diferentes temperaturas. Os valores destes limites são obtidos nos pontos em que a as curvas interceptam o valor 1. A Figura 37 indica baixa solubilidade de PP em $\operatorname{DCP}\left(<1 \%\right.$ para $180^{\circ} \mathrm{C}$ e $185^{\circ} \mathrm{C}$ e praticamente insolúvel à $130^{\circ} \mathrm{C}$ ). Esta baixa solubilidade é confirmada pela Figura 36 , onde o ponto de mínimo se encontra muito próximo a $100 \%$ de DCP.

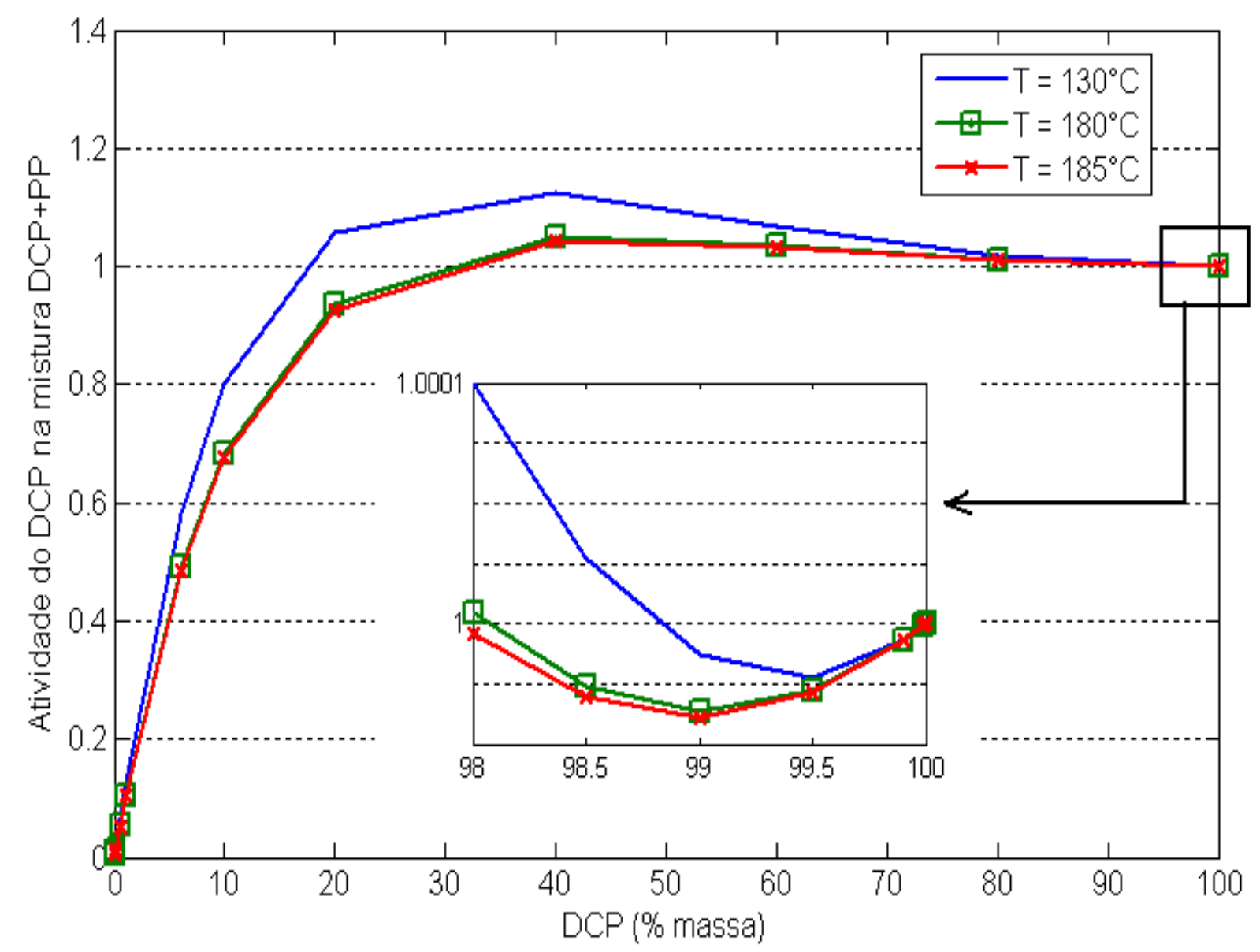

Figura 36 - Variação da atividade do DCP com a composição na mistura DCP + PP em diferentes temperaturas. 

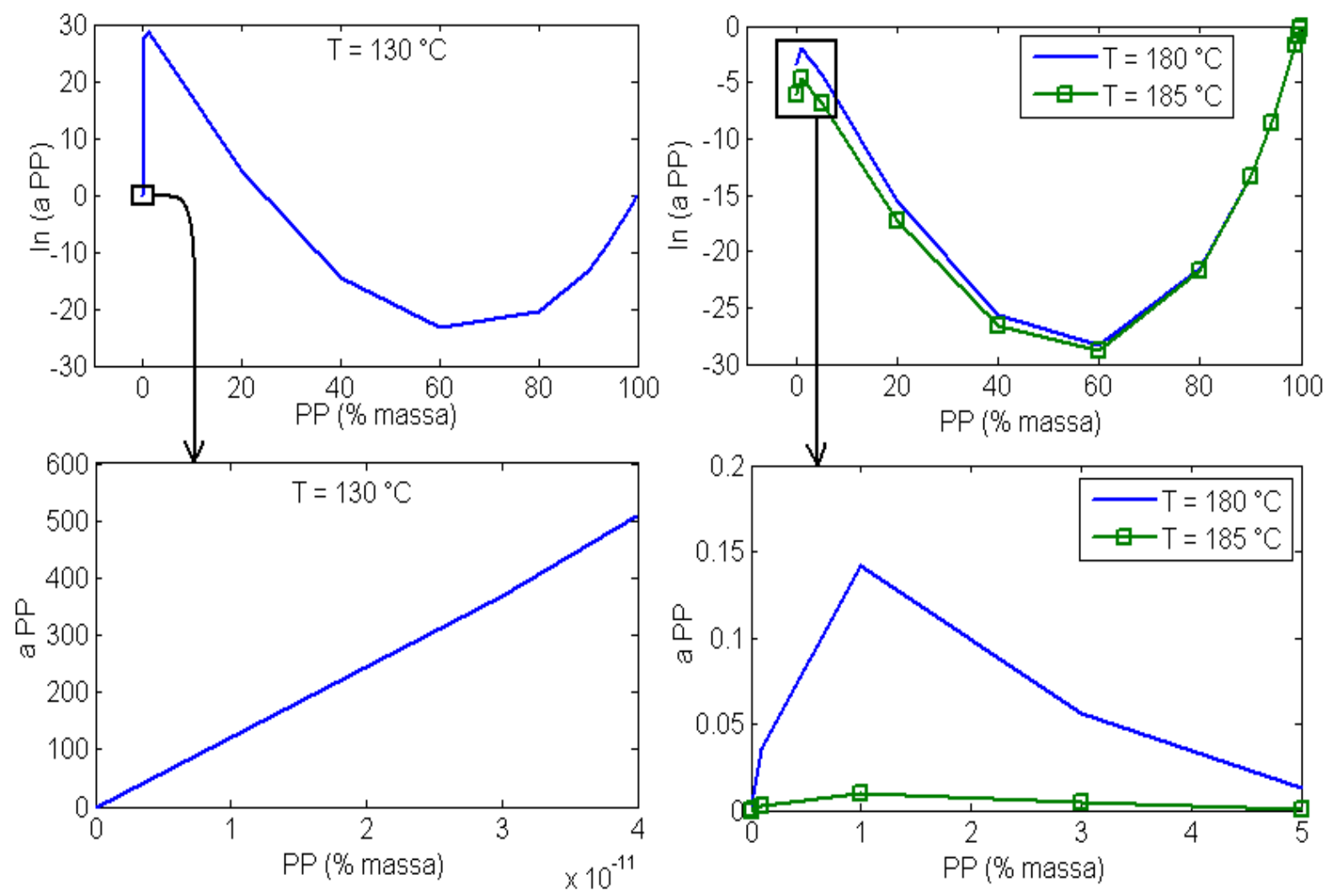

Figura 37 - Variação da atividade do PP com a composição na mistura DCP + PP em diferentes temperaturas.

A Figura 38 mostra as curvas de atividade dos demais iniciadores, conforme previsto pelo método UNIFAC.

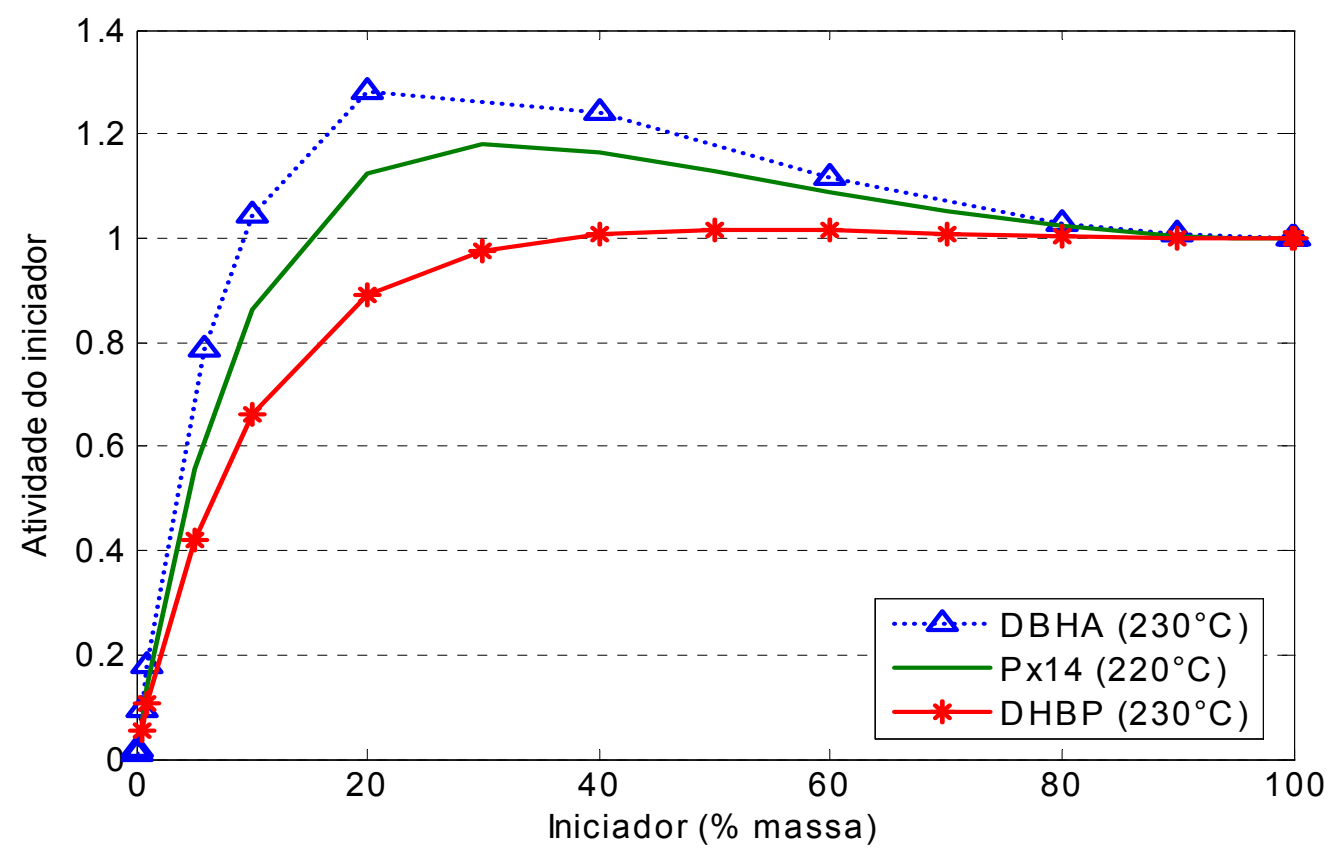

Figura 38 - Curvas de atividade de iniciadores na mistura Iniciador + PP. 
Os demais iniciadores têm comportamento semelhante ao DCP na mistura com PP. Verifica-se que os valores de limite de solubilidade encontrados para todos os iniciadores em PP são altos o bastante para que suas quantidades utilizadas nos experimentos sejam completamente solubilizadas.

A Tabela 4.8 mostra comparações dos valores do parâmetro solubilidade do iniciador no meio reacional.

Tabela 4.8 - Comparação dos valores de solubilidade do iniciador em PP.

\begin{tabular}{cccc}
\hline Iniciador & $\begin{array}{c}\text { Temperatura } \\
\left({ }^{\circ} \mathrm{C}\right)\end{array}$ & $\begin{array}{c}\text { Solubilidade } \\
\text { ajustada } \\
(\% \text { massa })\end{array}$ & $\begin{array}{c}\text { Solubilidade } \\
\text { estimada } \\
(\% \text { massa })\end{array}$ \\
\hline & 130 & 0,15 & 16,6 \\
DCP & 180 & 25,90 & 25,9 \\
& 185 & 27,10 & 27,1 \\
Px14 & 220 & 14,00 & 14,0 \\
DBHA & 230 & 9,20 & 9,2 \\
DHBP & 230 & 36,00 & 36,0 \\
\hline
\end{tabular}

Como as solubilidades estimadas para os iniciadores são maiores do que as concentrações utilizadas nos experimentos, o parâmetro descrito no item 3.1.3.1, não deveria fazer efeito sobre o Modelo 1. Na Tabela 4.9 observa-se que a solubilidade ajustada para o DCP a $130^{\circ} \mathrm{C}$ é baixa o bastante para afetar o modelo. Este dado discrepante é discutido no item 5.

\subsubsection{Discussão dos valores de fração solúvel de MAH em PP}

Conforme descrito no item 3.1.3.2, supõe-se no Modelo 1 que a quantidade de MAH que participa da reação é uma fração da sua quantidade total adicionada. Portanto, o valor ajustado de fração solúvel deve gerar uma concentração inicial de MAH que não ultrapasse sua solubilidade em PP.

A Figura 39 mostra as curvas de atividade de MAH em PP para as diferentes temperaturas estudadas. 

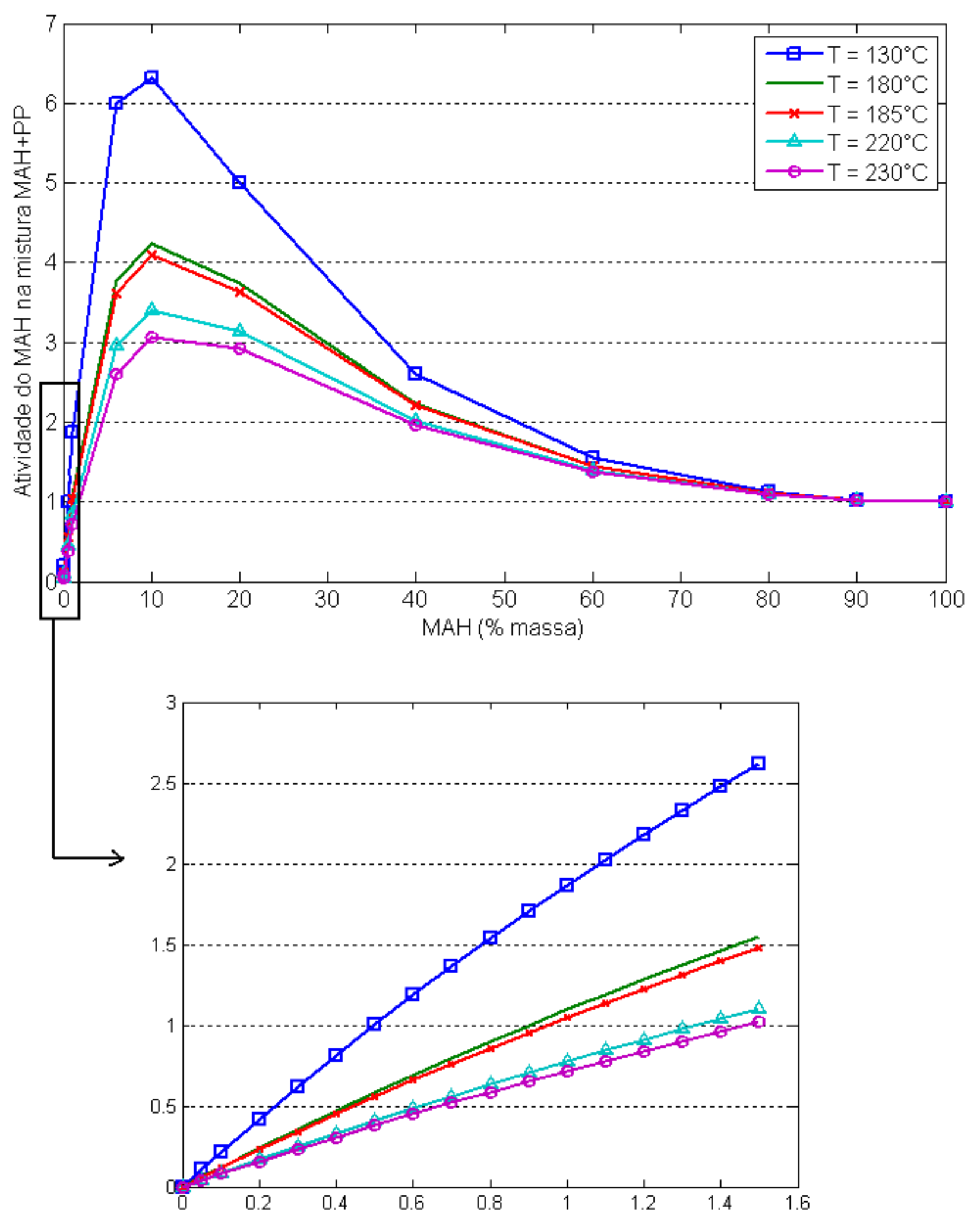

Figura 39 - Curvas de atividade de MAH para a mistura MAH + PP em diferentes temperaturas.

A Figura 40 mostra a comparação indireta do parâmetro fração solúvel de MAH em PP. 


\begin{tabular}{|c|c|c|c|c|c|}
\hline $\begin{array}{l}\text { Temperatura } \\
\text { (Referência) }\end{array}$ & $\begin{array}{c}\text { MAH } \\
\text { Adicionado } \\
\text { (\% massa) }\end{array}$ & $\begin{array}{l}\text { Fração } \\
\text { solúvel } \\
\text { (Ajuste) }\end{array}$ & $\begin{array}{c}\text { Fração } \\
\text { segregada } \\
\text { (Ajuste) }\end{array}$ & $\begin{array}{c}\text { MAH } \\
\text { solubilizado } \\
\text { (Ajuste) } \\
\text { (\% massa) }\end{array}$ & $\begin{array}{c}\text { Solubilidade } \\
\text { estimada de MAH } \\
\text { em PP } \\
\text { (\% massa })\end{array}$ \\
\hline \multirow{5}{*}{$\begin{array}{c}130^{\circ} \mathrm{C} \\
\text { Güldoğan et } \\
\text { al (2003) }\end{array}$} & 1 & \multirow{5}{*}{$\begin{array}{c}\text { Grãos: } \\
0,08\end{array}$} & \multirow{5}{*}{$\begin{array}{c}\text { Grãos: } \\
0,56 \\
\text { Pó: } \\
0\end{array}$} & $\begin{array}{l}0,18(\mathrm{G}) \\
0,30(\mathrm{P})\end{array}$ & \multirow{5}{*}{0,50} \\
\hline & 2,5 & & & $\begin{array}{l}0,45(\mathrm{G}) \\
0,75(\mathrm{P})\end{array}$ & \\
\hline & 5 & & & $\begin{array}{l}0,91(\mathrm{G}) \\
1,50(\mathrm{P})\end{array}$ & \\
\hline & 7,5 & & & $\begin{array}{l}1,36(\mathrm{G}) \\
2,25(\mathrm{P})\end{array}$ & \\
\hline & 10 & & & $\begin{array}{l}1,82(\mathrm{G}) \\
3,00(\mathrm{P})\end{array}$ & \\
\hline \multirow{5}{*}{$\begin{array}{l}180^{\circ} \mathrm{C} \\
\text { Shi et al } \\
(2006)^{(a)}\end{array}$} & 0,5 & \multirow{5}{*}{0,25} & \multirow{5}{*}{0,1} & 0,14 & \multirow{5}{*}{0,90} \\
\hline & 1 & & & 0,28 & \\
\hline & 2 & & & 0,56 & \\
\hline & 3 & & & 0,83 & \\
\hline & 4 & & & 1,11 & \\
\hline \multirow{6}{*}{$\begin{array}{l}185^{\circ} \mathrm{C} \\
\text { Shi et al } \\
(2001)\end{array}$} & 1 & \multirow{6}{*}{0,35} & \multirow{6}{*}{0} & 0,35 & \multirow{6}{*}{0,95} \\
\hline & 3 & & & 1,05 & \\
\hline & 5 & & & 1,75 & \\
\hline & 7 & & & 2,45 & \\
\hline & 9 & & & 3,15 & \\
\hline & 11 & & & 3,85 & \\
\hline \multirow{3}{*}{$\begin{array}{c}220^{\circ} \mathrm{C} \\
\text { Akzo }(2007)\end{array}$} & 1 & \multirow{3}{*}{0,35} & \multirow{3}{*}{0} & 0,35 & \multirow{3}{*}{1,22} \\
\hline & 2 & & & 0,7 & \\
\hline & 5 & & & 1,75 & \\
\hline \multirow{6}{*}{$\begin{array}{c}230^{\circ} \mathrm{C} \\
\text { Cha \& White } \\
(2001) \mathrm{e} \\
\text { Chang \& } \\
\text { White (2003) }\end{array}$} & 1 & \multirow{6}{*}{0,4} & \multirow{6}{*}{0} & 0,4 & \multirow{6}{*}{1,47} \\
\hline & 2 & & & 0,8 & \\
\hline & 4 & & & 1,6 & \\
\hline & 5 & & & 2,0 & \\
\hline & 6 & & & 2,4 & \\
\hline & 8 & & & 3,2 & \\
\hline
\end{tabular}

Figura 40 - Análise dos valores de fração solúvel de MAH em PP. G e P representam grãos e pó respectivamente. (a) Valores referentes ao processo convencional.

\subsubsection{Discussão dos valores de fração segregada ajustados no Modelo 1}

Conforme mostrado na Tabela 4.1, no Modelo 1 considera-se que a maior segregação ocorre para a temperatura mais baixa estudada $\left(130^{\circ} \mathrm{C}\right)$ para o caso de 
PP em grãos. Nesta mesma temperatura considera-se que o polipropileno em pó possui contato suficiente com os demais reagentes de modo que não há segregação. $O$ valor do parâmetro fração segregada diminui com o aumento da temperatura, estabelecendo relação com a viscosidade do meio. O aumento da rotação também influencia na diminuição da segregação devido à homogeneização do meio, que tende a aumentar. Conforme descrito na metodologia, não são feitas comparações com os valores obtidos de fração segregada, estes seguem uma coerência relativa de acordo com os diferentes casos.

\subsection{Resultados das simulações com o Modelo 2}

O Modelo 2 foi testado com os dados de Güldoğan et al (2003) e Shi et al $(2001,2006)$. Nestes estudos o iniciador utilizado foi o peróxido de dicumila. Supõese que as temperaturas utilizadas nestes casos são favoráveis à simulação com o Modelo 2, pois estão abaixo do ponto de ebulição do MAH. Os resultados do modelo comparados com os dados experimentais estão representados nas figuras a seguir.
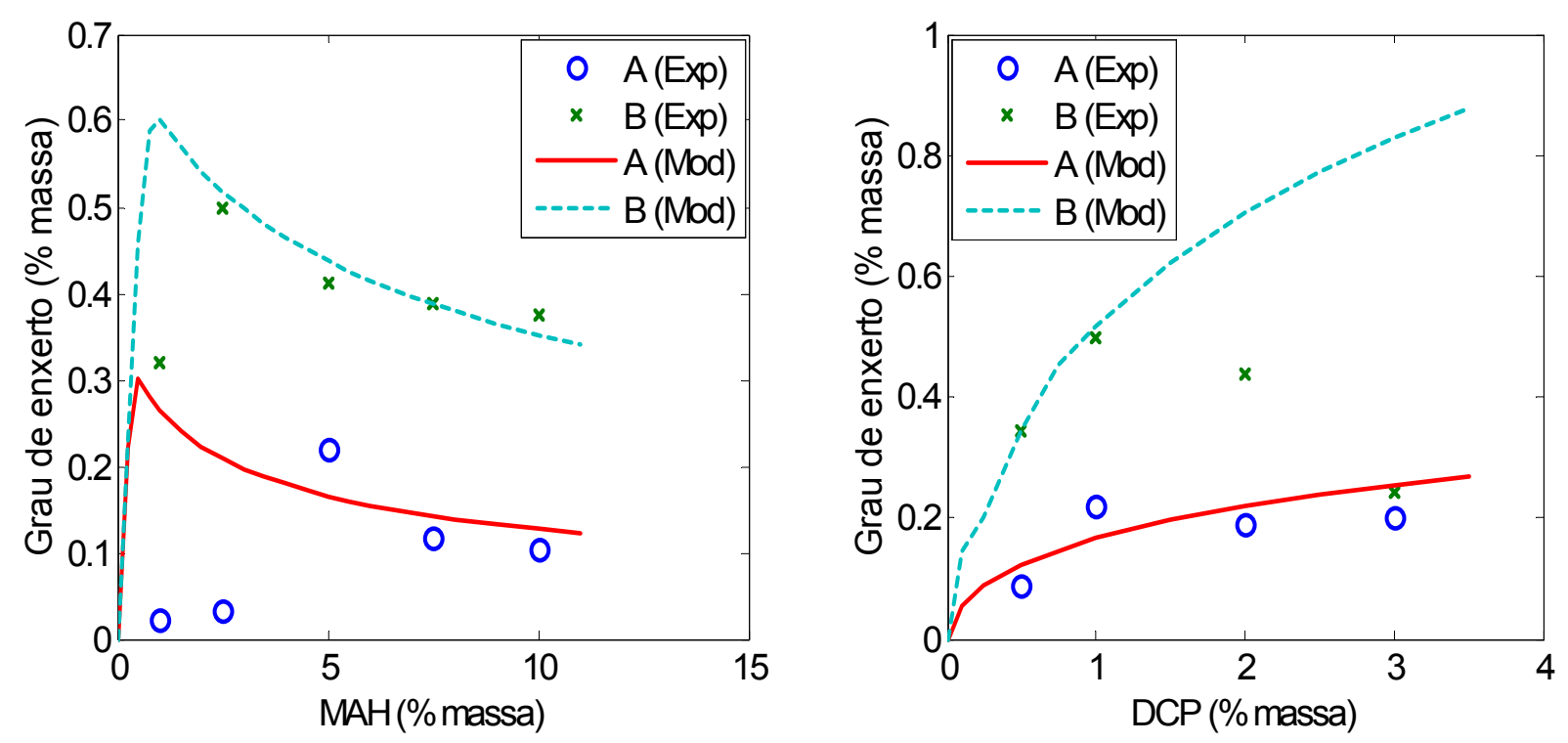

Figura 41 - Resultados da simulação com os dados de Güldoğan et al (2003), através do Modelo 2. A: PP em grãos e B: PP em pó. 

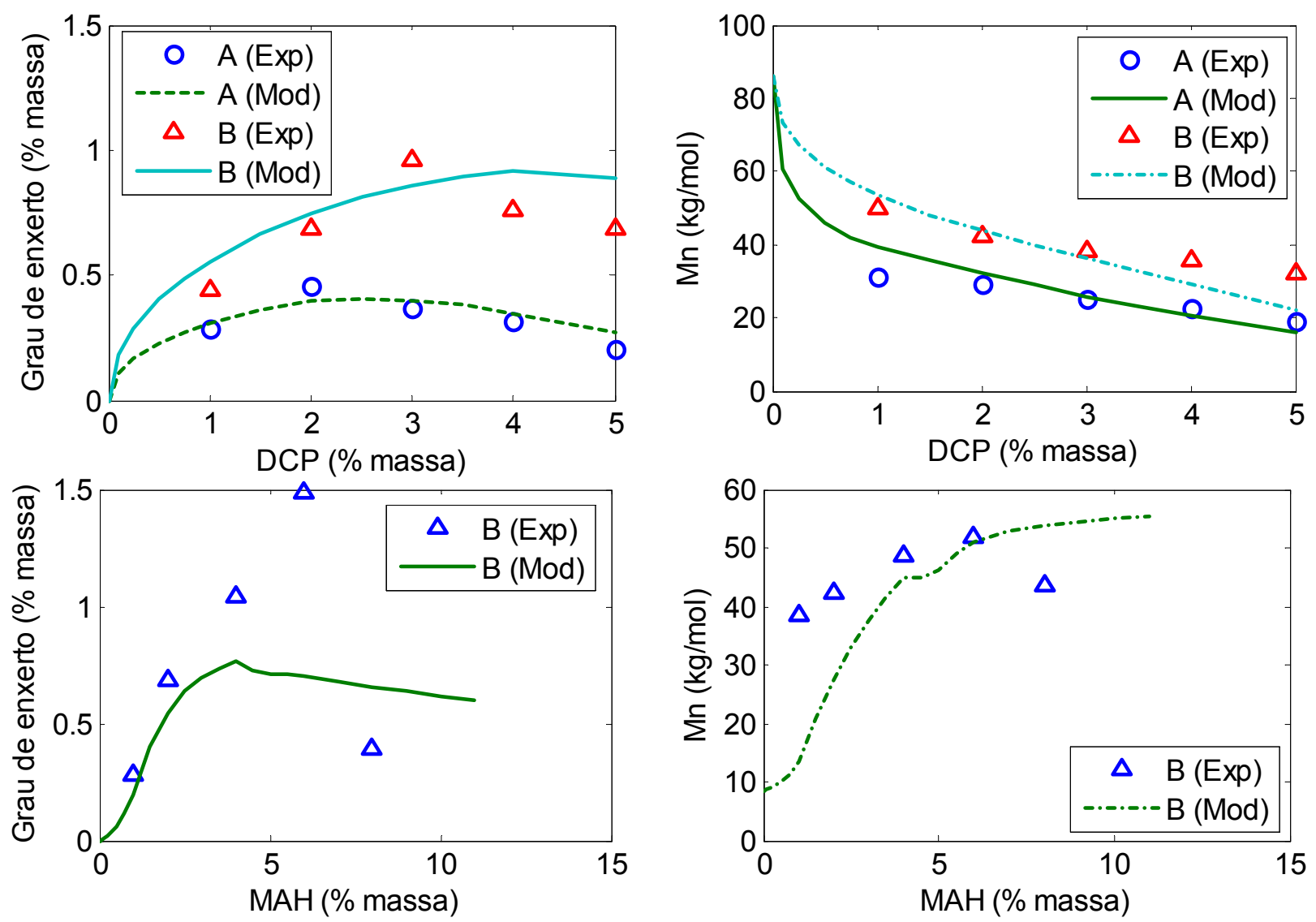

Figura 42 - Resultados da simulação com os dados de Shi et al (2006), através do Modelo 2. A: Convencional. B: Nano-reator.

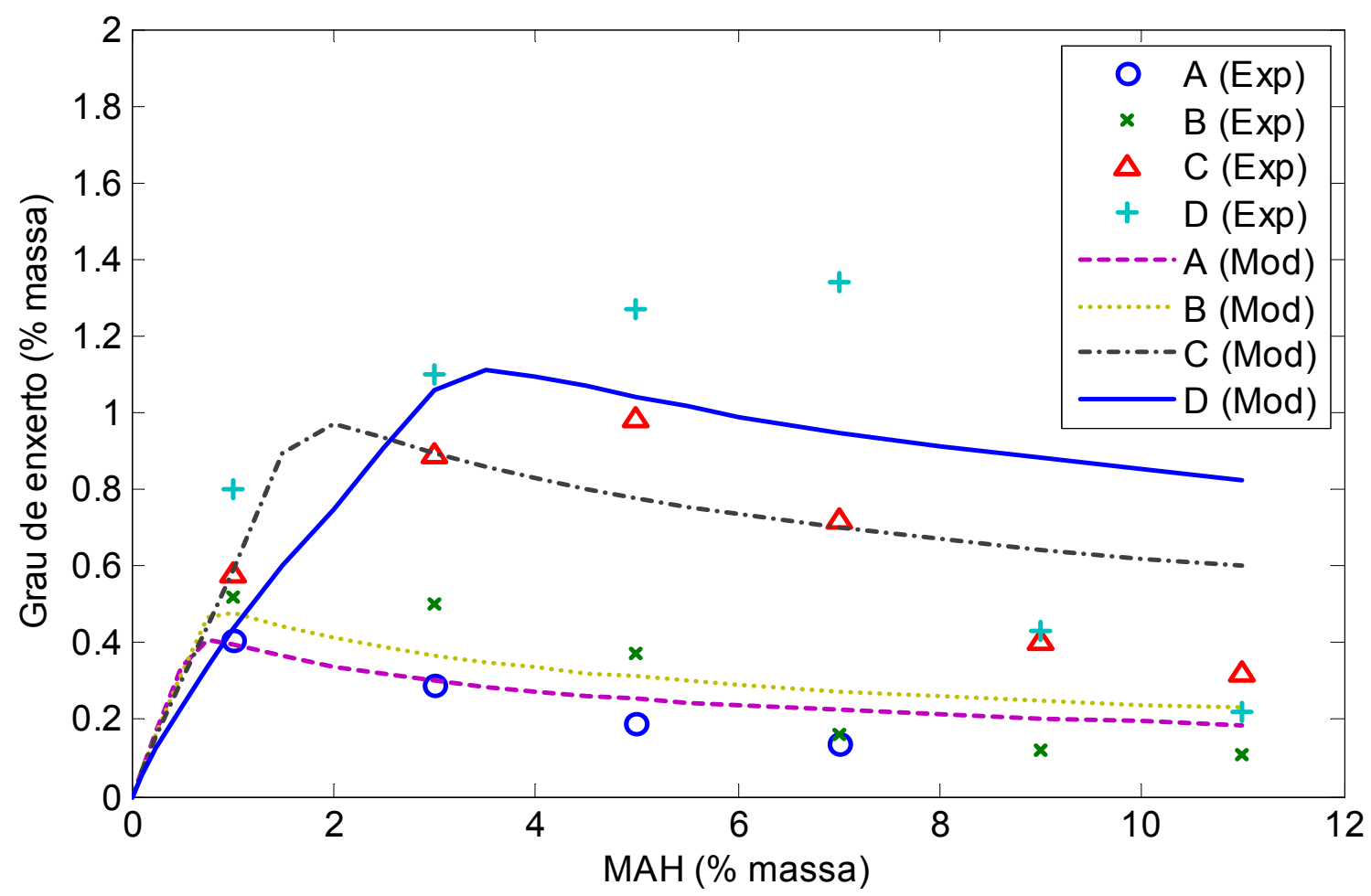

Figura 43 - Resultados da simulação com os dados de Shi et al (2001), através do Modelo 2. Concentrações de DCP: $A=0,6 \%, B=0,8 \%, C=2 \%$ e $D=5 \%$ (massa). 


\subsection{Resultados dos parâmetros ajustáveis do Modelo 2}

A Figura 44 mostra os valores dos parâmetros ajustados no Modelo 2.

\begin{tabular}{|c|c|c|c|c|c|c|}
\hline Referência & \begin{tabular}{|l|} 
Güldogan \\
et al, 2003 \\
\end{tabular} & $\begin{array}{l}\text { Shi et al, } \\
2006(C)\end{array}$ & $\begin{array}{l}\text { Shi et al, } \\
2006 \text { (NR) }\end{array}$ & $\begin{array}{c}\text { Shi et al, } \\
2001\end{array}$ & \multicolumn{2}{|c|}{ Segregação (ys) } \\
\hline $\begin{array}{c}\text { Temperatura } \\
\left({ }^{\circ} \mathrm{C}\right)\end{array}$ & 130 & 180 & 180 & 185 & \multirow{4}{*}{$\begin{array}{c}\text { Güldogan et al, } \\
2003 \\
\text { Grãos } \\
\text { Pó }\end{array}$} & \multirow{4}{*}{$\begin{array}{c}\text { ys } \\
0,80 \\
0,40\end{array}$} \\
\hline $\mathrm{S}_{\mathrm{A}}(\%$ massa $)$ & 0,5 & 0,95 & 4,0 & 0,95 & & \\
\hline $\mathrm{K}_{\mathrm{PI}}$ & 15,34 & 20,67 & 10 & 21,33 & & \\
\hline$f_{1}$ & 1 & 1 & 1 & 1 & & \\
\hline$f_{2}$ & 0,6 & 0,62 & 0,75 & 0,62 & \multirow{6}{*}{$\begin{array}{c}\text { Shi et al, } 2001 \\
\text { DCP }=0,6 \% \\
\text { DCP }=0,8 \% \\
\text { DCP }=2,0 \% \\
\text { DCP }=5,0 \%\end{array}$} & \multirow{6}{*}{$\begin{array}{c}\text { ys } \\
0,47 \\
0,43 \\
0,00 \\
0,00\end{array}$} \\
\hline$k_{d}\left(s^{-1}\right)$ & $1,50 \mathrm{E}-4$ & $1,00 \mathrm{E}-2$ & $8,00 \mathrm{E}-3$ & $3,64 \mathrm{E}-2$ & & \\
\hline $\mathrm{k}_{\mathrm{fp}, 0}$ (L/mol.s) & $5,80 E+2$ & $2,74 \mathrm{E}+3$ & $2,74 \mathrm{E}+3$ & $1,58 \mathrm{E}+4$ & & \\
\hline $\mathrm{k}_{\mathrm{fp}}(\mathrm{L} / \mathrm{mol} . \mathrm{s})$ & $8,20 E+1$ & $9,84 \mathrm{E}+3$ & $9,84 \mathrm{E}+3$ & $1,50 \mathrm{E}+4$ & & \\
\hline $\mathrm{k}_{\mathrm{fp}}(\mathrm{L} / \mathrm{mol} . \mathrm{s})$ & $2,00 E+0$ & $3,86 \mathrm{E}+0$ & $3,86 \mathrm{E}+0$ & $1,20 E+1$ & & \\
\hline $\mathrm{k}_{\mathrm{a}, 0}$ (L/mol.s) & $1,50 \mathrm{E}+6$ & \begin{tabular}{|l|}
$1,58 \mathrm{E}+7$ \\
\end{tabular} & $1,58 \mathrm{E}+7$ & $2,00 \mathrm{E}+7$ & & \\
\hline $\mathrm{k}_{\mathrm{a}}$ (L/mol.s) & $1,00 E+3$ & $2,51 \mathrm{E}+3$ & $2,51 \mathrm{E}+3$ & $4,80 E+4$ & \multirow{3}{*}{$\begin{array}{c}\text { Shi et al, } 2006 \\
\text { Todos os } \\
\text { casos }\end{array}$} & ys \\
\hline $\mathrm{k}_{\mathrm{cs}}\left(\mathrm{s}^{-1}\right)$ & $4,40 \mathrm{E}+3$ & $1,95 \mathrm{E}+5$ & $1,95 E+5$ & $2,72 \mathrm{E}+5$ & & \multirow{2}{*}{0,00} \\
\hline $\mathrm{k}_{\mathrm{t}}$ (L/mol.s) & $1,80 \mathrm{E}+5$ & $4,50 \mathrm{E}+7$ & $4,50 \mathrm{E}+7$ & $5,00 \mathrm{E}+7$ & & \\
\hline
\end{tabular}

Figura 44 - Parâmetros ajustados no Modelo 2.

As Figuras 45 à 48 mostram os resultados da aplicação da lei de Arrhenius aos valores de constante de velocidade ajustados no Modelo 2.
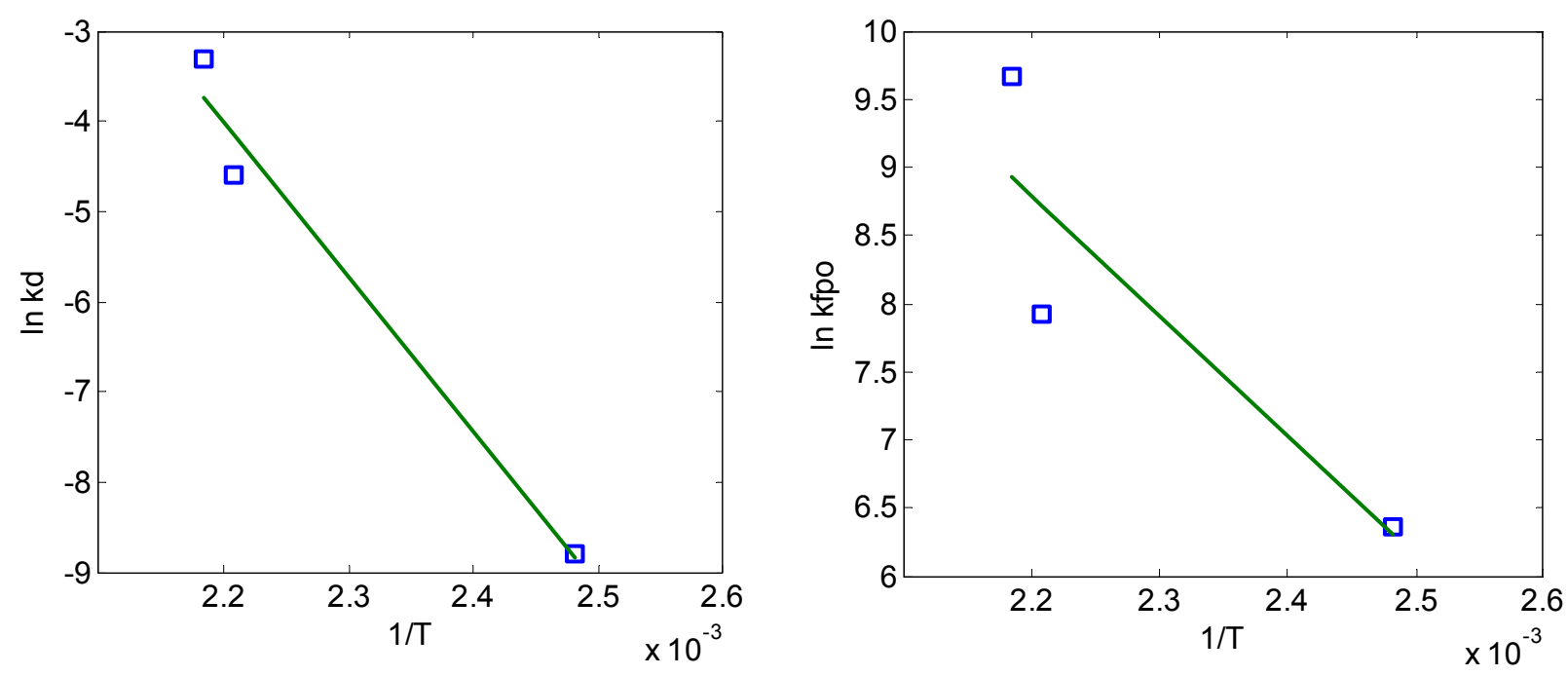

Figura 45 - Modelo 2: Lei de Arrhenius aplicada aos valores ajustados de $k_{d}$ e $k_{f p, 0}$. 

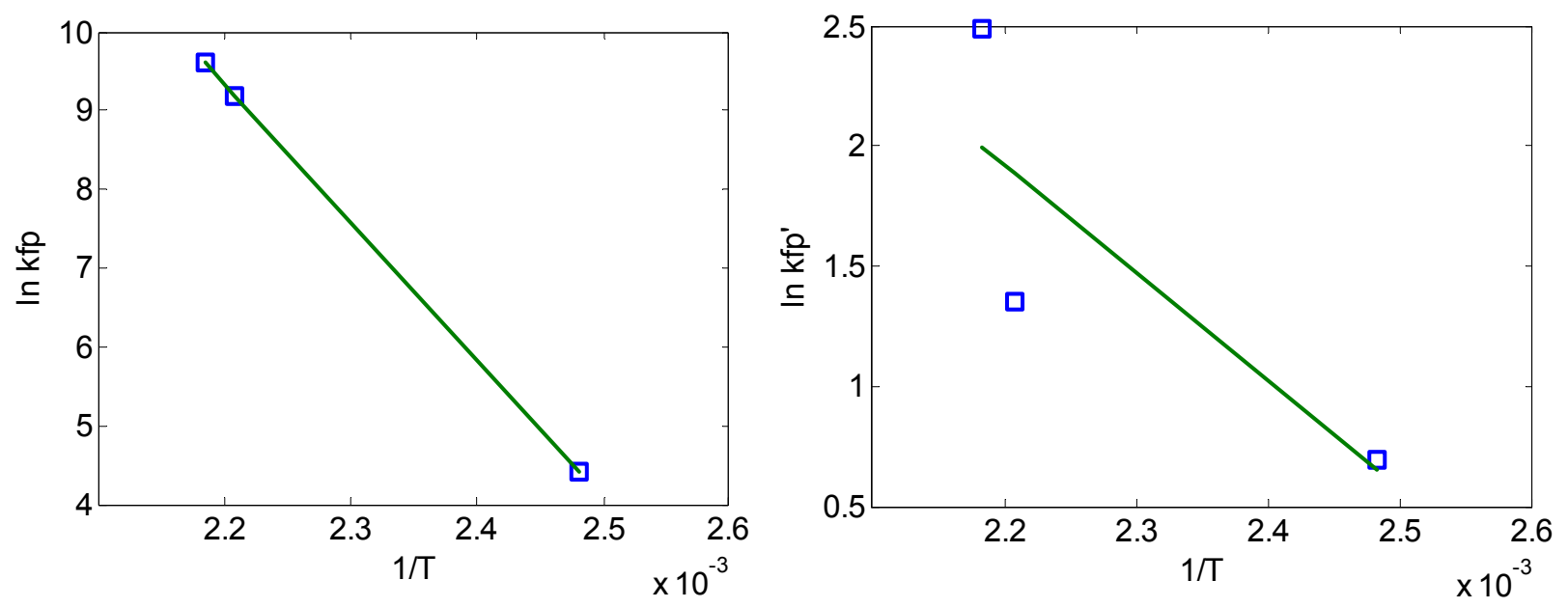

Figura 46 - Modelo 2: Lei de Arrhenius aplicada aos valores ajustados de $\mathrm{k}_{\mathrm{fp}}$ e $\mathrm{k}_{\mathrm{fp}}$.
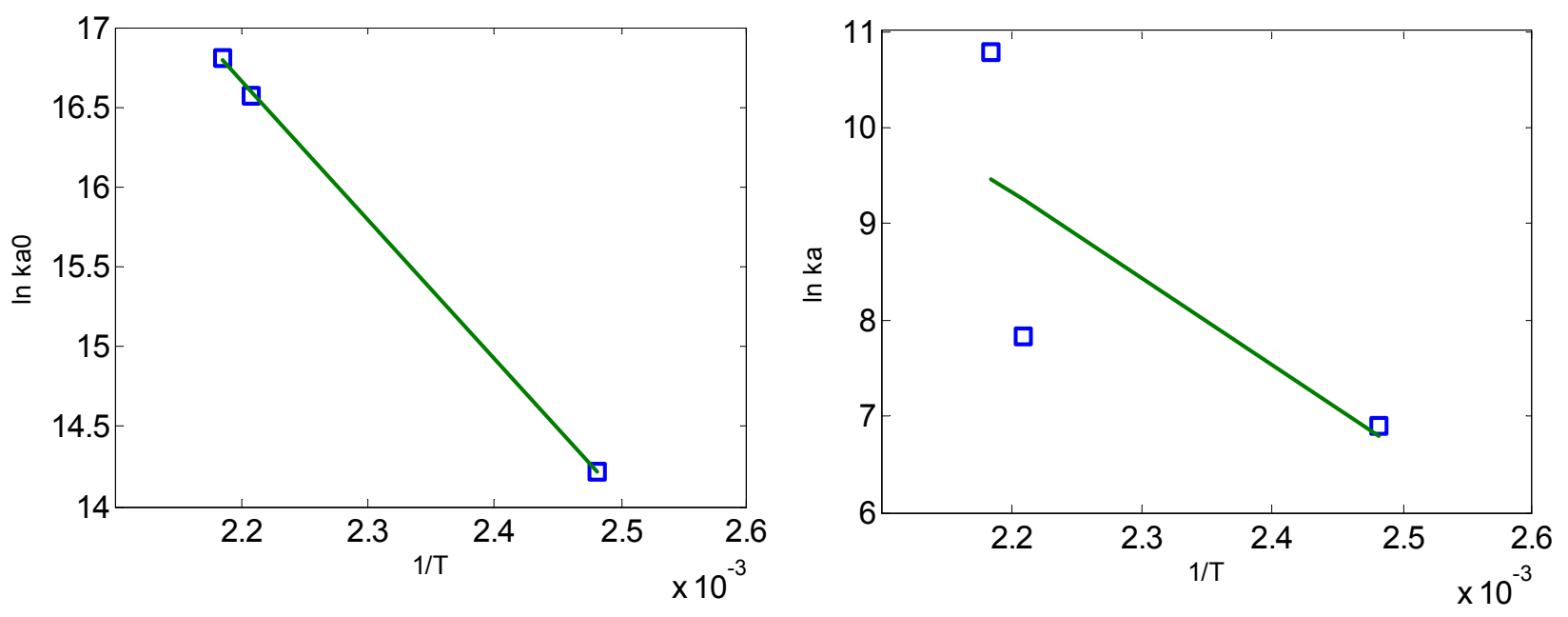

Figura 47 - Modelo 2: Lei de Arrhenius aplicada aos valores ajustados de $k_{a, 0}$ e $k_{a}$.
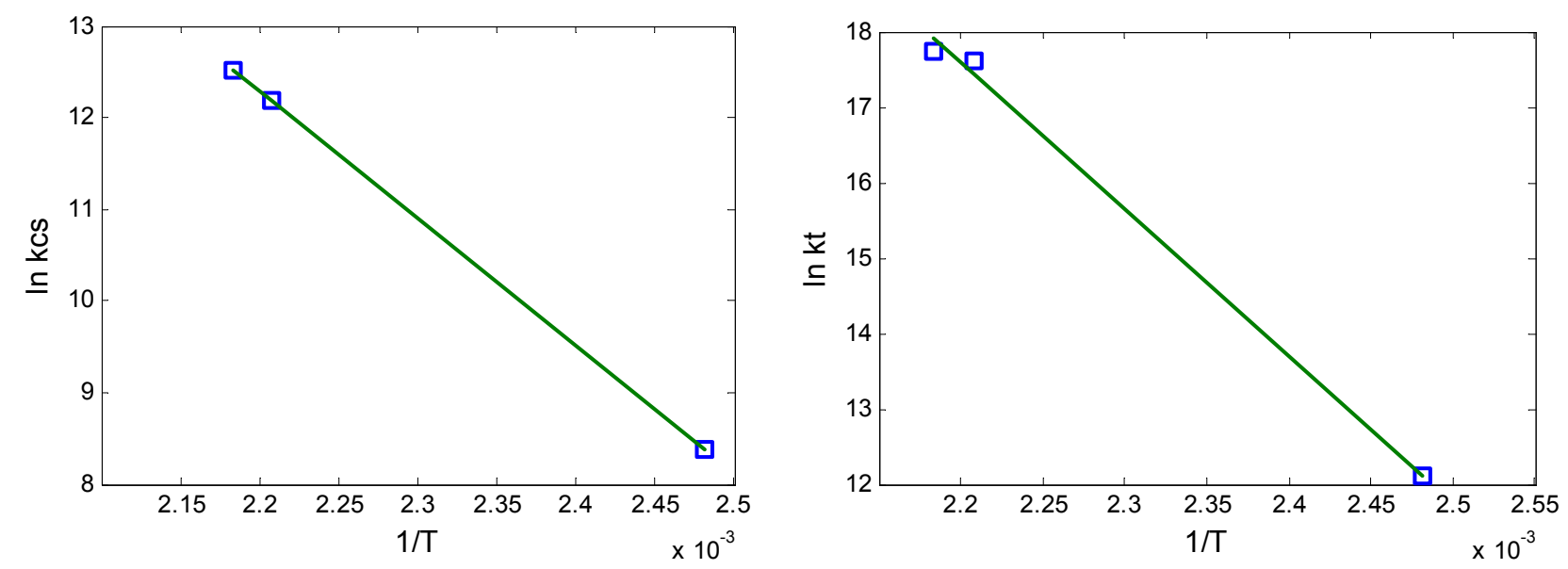

Figura 48 - Modelo 2: Lei de Arrhenius aplicada aos valores ajustados de $\mathrm{k}_{\mathrm{cs}}$ e $\mathrm{k}_{\mathrm{t}}$. 
A Tabela 4.9 mostra os parâmetros cinéticos obtidos através do ajuste da lei de Arrhenius aos valores de constante de velocidade utilizados nas simulações.

Tabela 4.9 - Valores de energia de ativação obtidos no Modelo 2.

\begin{tabular}{cc}
\hline \multicolumn{2}{c}{ Energia de ativação $(\mathrm{kcal} / \mathrm{mol})$} \\
\hline$E_{\mathrm{d}}$ & 34,0 \\
$\mathrm{E}_{\mathrm{fp}, 0}$ & 17,6 \\
$\mathrm{E}_{\mathrm{fp}}$ & 34,7 \\
$\mathrm{E}_{\mathrm{fp}}$ & 8,96 \\
$\mathrm{E}_{\mathrm{a}, 0}$ & 17,2 \\
$\mathrm{E}_{\mathrm{a}}$ & 17,9 \\
$\mathrm{E}_{\mathrm{cs}}$ & 27,5 \\
$\mathrm{E}_{\mathrm{t}}$ & 38,6 \\
\hline
\end{tabular}

\subsection{Discussão dos parâmetros ajustáveis do Modelo 2}

4.6.1 Discussão das constantes de velocidade ajustadas no Modelo 2

As Tabelas 4.10 à 4.12 mostram comparações dos valores ajustados para as constantes de velocidade das reações e energias de ativação.

Tabela 4.10 - Modelo 2: Comparações da constante de decomposição do iniciador.

\begin{tabular}{cccc}
\hline Iniciador & \multicolumn{3}{c}{ DCP } \\
Temperatura $\left({ }^{\circ} \mathrm{C}\right)$ & 130 & 180 & 185 \\
\hline $\mathrm{k}_{\mathrm{d}}$ ajustado $\left(\mathrm{s}^{-1}\right)$ & $1,50 \mathrm{E}-04$ & $1,00 \mathrm{E}-02$ & $3,64 \mathrm{E}-02$ \\
$\mathrm{k}_{\mathrm{d}}\left(\right.$ Akzo, 2006) $\left(\mathrm{s}^{-1}\right)$ & $1,53 \mathrm{E}-04$ & $2,34 \mathrm{E}-02$ & $3,64 \mathrm{E}-02$ \\
$\mathrm{k}_{\mathrm{d}}($ Cha e White, 2001$)\left(\mathrm{s}^{-1}\right)$ & - & - & $4,90 \mathrm{E}-02$ \\
\hline
\end{tabular}

Tabela 4.11 - Modelo 2: Comparações de constantes de velocidade à $185^{\circ} \mathrm{C}$.

\begin{tabular}{cccccc}
\hline $\begin{array}{c}\text { Constante de } \\
\text { velocidade }\end{array}$ & Ajuste & $\begin{array}{c}\text { Giudici } \\
(2007)\end{array}$ & $\begin{array}{c}\text { Zhu et al } \\
(2003)\end{array}$ & $\begin{array}{c}\text { Kruse et } \\
\text { al }(2003)\end{array}$ & $\begin{array}{c}\text { Berzin et } \\
\text { al (2000) }\end{array}$ \\
\hline $\mathrm{k}_{\mathrm{fp}, 0}(\mathrm{~L} / \mathrm{mol} . \mathrm{s})$ & $1,58 \mathrm{E}+4$ & $2,58 \mathrm{E}+4$ & $2,70 \mathrm{E}+7$ & $9,75 \mathrm{E}+2$ & - \\
$\mathrm{k}_{\mathrm{fp}}(\mathrm{L} / \mathrm{mol} . \mathrm{s})$ & $1,50 \mathrm{E}+4$ & $2,58 \mathrm{E}+3$ & - & - & - \\
$\mathrm{k}_{\mathrm{fp}}(\mathrm{L} / \mathrm{mol} . \mathrm{s})$ & $1,20 \mathrm{E}+1$ & 0,00 & - & - & - \\
$\mathrm{k}_{\mathrm{a}, 0}(\mathrm{~L} / \mathrm{mol} . \mathrm{s})$ & $2,00 \mathrm{E}+7$ & $7,00 \mathrm{E}+6$ & $2,85 \mathrm{E}+6$ & - & - \\
$\mathrm{k}_{\mathrm{a}}(\mathrm{L} / \mathrm{mol} . \mathrm{s})$ & $4,80 \mathrm{E}+4$ & $2,73 \mathrm{E}+4$ & $1,09 \mathrm{E}+4$ & - & - \\
$\mathrm{K}_{\mathrm{cs}}\left(\mathrm{s}^{-1}\right)$ & $2,72 \mathrm{E}+5$ & $2,10 \mathrm{E}+3$ & $3,00 \mathrm{E}+3$ & $3,66 \mathrm{E}+1$ & - \\
$\mathrm{k}_{\mathrm{t}}(\mathrm{L} / \mathrm{mol} . \mathrm{s})$ & $5,00 \mathrm{E}+7$ & $1,99 \mathrm{E}+8$ & $1,99 \mathrm{E}+8$ & $8,79 \mathrm{E}+8$ & $3,42 \mathrm{E}+8$ \\
\hline
\end{tabular}


Tabela 4.12 - Modelo 2: Comparação das energias de ativação obtidas.

\begin{tabular}{ccccccc}
\hline $\begin{array}{c}\text { Energia de } \\
\text { ativação } \\
(\mathrm{kcal} / \mathrm{mol})\end{array}$ & $\begin{array}{c}\text { Valor } \\
\text { ajustado }\end{array}$ & $\begin{array}{c}\text { Giudici } \\
(2007)\end{array}$ & $\begin{array}{c}\text { ledema } \\
(2001)\end{array}$ & $\begin{array}{c}\text { Akzo } \\
(2006)\end{array}$ & $\begin{array}{c}\text { Kruse et } \\
\text { al (2003) }\end{array}$ & $\begin{array}{c}\text { Berzin et al } \\
(2000)\end{array}$ \\
\hline$E_{\mathrm{d}}$ & 34,00 & - & - & 36,5 & - & - \\
$\mathrm{E}_{\mathrm{fp}, 0}$ & 17,60 & 25,10 & - & - & 10,5 & - \\
$\mathrm{E}_{\mathrm{fp}}$ & 34,70 & 48,50 & 535,00 & - & - & - \\
$\mathrm{E}_{\mathrm{fp}}$ & 8,96 & 0,00 & - & - & - & - \\
$\mathrm{E}_{\mathrm{a}, 0}$ & 17,20 & 0,93 & - & - & - & - \\
$\mathrm{E}_{\mathrm{a}}$ & 17,90 & 0,93 & - & - & - & - \\
$\mathrm{E}_{\mathrm{cs}}$ & 27,50 & 0,00 & - & - & 28,1 & - \\
$\mathrm{E}_{\mathrm{t}}$ & 38,60 & 26,00 & 8,92 & - & 2,30 & 0,02 \\
\hline
\end{tabular}

As discrepâncias encontradas nestas comparações são discutidas no item 5.

4.6.2 Discussão dos valores de solubilidade do MAH em PP

A Tabela 4.13 mostra a comparação dos valores de solubilidade de MAH em PP ajustados para o Modelo 2.

Tabela 4.13 - Modelo 2: Comparação dos valores de solubilidade de MAH em PP.

\begin{tabular}{ccc}
\hline Temperatura $\left({ }^{\circ} \mathrm{C}\right)$ & $\begin{array}{c}\text { Solubilidade ajustada } \\
(\% \text { massa })\end{array}$ & $\begin{array}{c}\text { Solubilidade estimada pelo } \\
\text { método UNIFAC }(\% \text { massa })\end{array}$ \\
\hline 130 & 0,50 & 0,50 \\
$180(\mathrm{C})$ & 0,95 & 0,90 \\
$180(\mathrm{NR})$ & 4,0 & $*$ \\
185 & 0,95 & 0,95
\end{tabular}

* Dado não estimado devido à presença dos nano-reatores no processo.

4.6.3 Discussão dos valores do coeficiente de partição do iniciador $\left(K_{P I}\right)$

Nas simulações, foram utilizados os valores de $\mathrm{K}_{\mathrm{PI}}$ estimados conforme descrito no item 3.3.2.2. A Tabela 4.14 mostra os valores de $K_{P I}$ utilizados nas simulações. 
Tabela 4.14 - Coeficientes de partição utilizados nas simulações.

\begin{tabular}{cc}
\hline Temperatura $\left({ }^{\circ} \mathrm{C}\right)$ & $\mathrm{K}_{\mathrm{PI}}$ \\
\hline 130 & 15,34 \\
$180(\mathrm{C})$ & 20,67 \\
$180(\mathrm{NR})$ & $10,00^{*}$ \\
185 & 21,33 \\
\hline *Valor ajustado (não estimado através do item 3.3.2.2).
\end{tabular}

*Valor ajustado (não estimado através do item 3.3.2.2).

O estudo de equilíbrio de fases entre o DCP e O MAH é necessário para se verificar a consideração de uma única fase composta por estes componentes (Fase 1). Foram estimadas as solubilidades destes compostos entre si através do método UNIFAC, juntamente com o algoritmo descrito no item 3.3.2.3. A Figura 49 mostra o diagrama de fases para a mistura líquida MAH+DCP obtido através desses métodos.

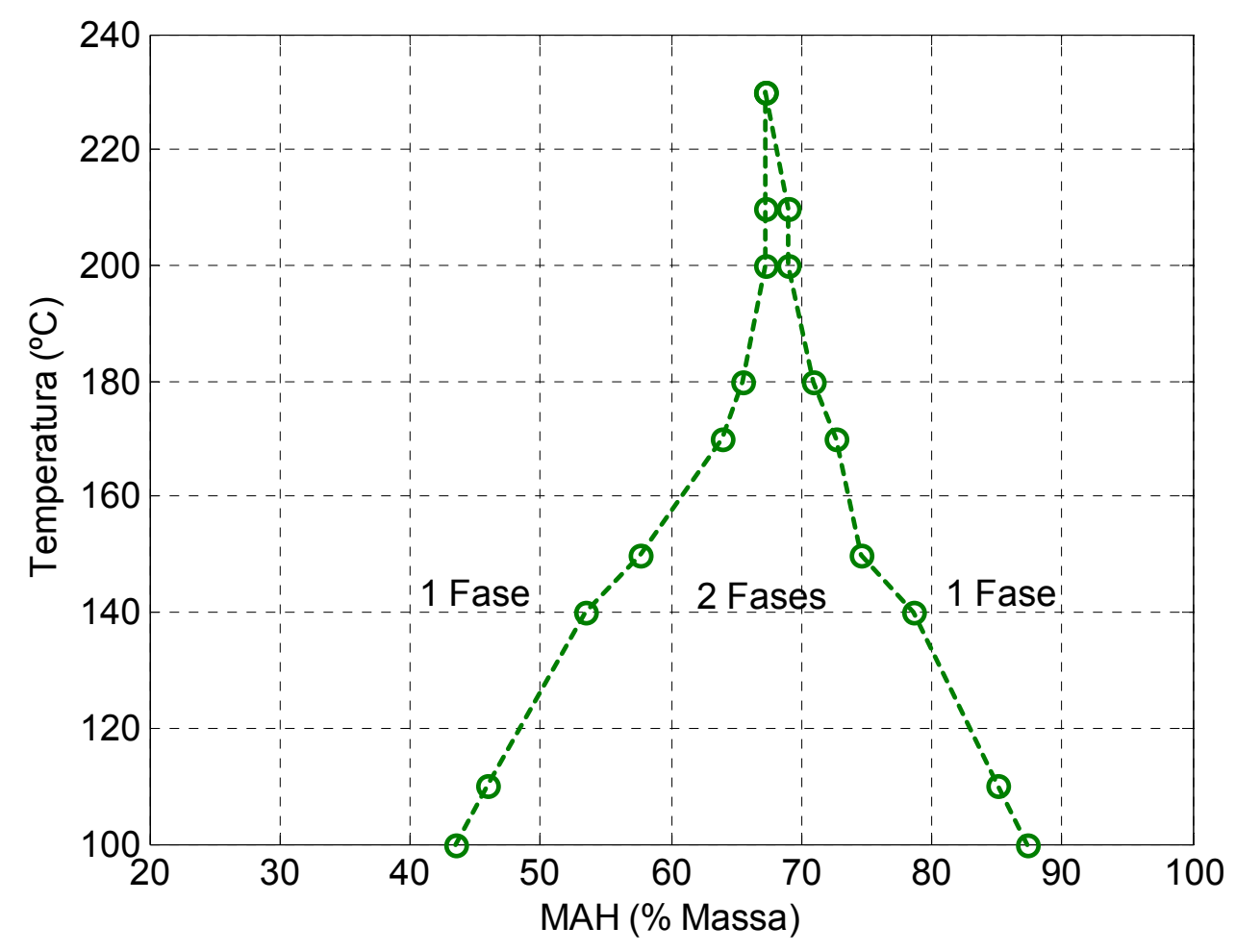

Figura 49 - Diagrama de fases da mistura líquida DCP+MAH.

Verifica-se que para os estudos realizados às temperaturas de 180 e $185^{\circ} \mathrm{C}$ existe uma pequena faixa de composições na qual se formam duas fases $(66 \%$ $71 \%$ ). Para a simulação com os dados de Güldogan et al (2003), cuja temperatura 
de reação é $130^{\circ} \mathrm{C}$, há uma faixa mais extensa de composições (51\%-83\%) que formam duas fases. A aplicação do algoritmo apresentado no item 3.3.2.3 foi feita considerando-se dois algarismos significativos para os valores de composição das fases. Com esta consideração, torna-se difícil determinar com exatidão a temperatura limite para a formação de duas fases (ponto de máximo do gráfico da Figura 49). Porém, não é necessária a determinação do valor exato deste ponto. A consideração de uma única fase contendo MAH e DCP (Fase 1) é discutida no item 5.

\subsubsection{Discussão do parâmetro fração segregada no Modelo 2}

No Modelo 2, considera-se que o baixo valor de temperatura utilizado nos experimentos de Güldogan et al (2003) contribui para a segregação para os dois casos estudados (PP em grãos e em pó). Como nesse estudo a temperatura de reação está abaixo da temperatura de fusão do $\mathrm{PP}$, considera-se uma segregação bem alta para o caso do PP na forma de grãos. Para as simulações com os dados de Güldogan et al (2003), foram considerados os dois tipos de segregação descritos na metodologia (regiões internas do PP e regiões não atingidas pelo iniciador).

Nas simulações com os dados de Shi et al (2006), apesar de se ter trabalhado com o PP na forma de grãos, admite-se que a temperatura utilizada permite fundir completamente o PP de modo à não haver segregação por regiões internas. Considera-se que as quantidades adicionadas de iniciador nos experimentos são suficientes para não gerar segregação referente à regiões não atingidas por este reagente.

Coerentemente, a temperatura utilizada por Shi et al (2001) nos experimentos também não gera segregação referente a regiões internas das partículas de PP. Porém, em alguns ensaios, foram utilizadas concentrações bem baixas de iniciador. Para estes casos foi considerada, no modelo, segregação referente a regiões não atingidas pelo iniciador. 


\section{DISCUSSÃO}

\subsection{Modelo 1}

5.1.1 Discussão dos resultados das simulações com o Modelo 1

Observa-se que as curvas do Modelo 1, relativas aos dados de grau de enxerto em função da concentração inicial de anidrido maleico, seguem uma tendência crescente para baixas concentrações iniciais de MAH. Este trecho inicial é bem representado pelo Modelo 1 para praticamente todos os casos estudados. Nesses gráficos de grau de enxerto em função da concentração inicial de MAH, observa-se que existe um ponto de máximo, ou seja, os dados experimentais seguem uma tendência decrescente com o aumento da concentração inicial de MAH a partir de um determinado ponto. O Modelo 1 representa esta tendência de forma menos acentuada em relação aos dados experimentais.

Nas simulações com dados de grau de enxerto em função da concentração inicial de iniciador, observa-se também uma tendência crescente para baixos valores. Este trecho também é bem representado pelo Modelo 1, fornecendo um ótimo ajuste para experimentos realizados numa faixa de baixas concentrações iniciais de iniciador (Dados de Akzo, 2007 e Chang e White, 2003). Nos dados de Güldogan et al., 2003 e SHI et al., 2006, também é observado o ponto de máximo grau de enxerto conforme se varia a concentração inicial de iniciador. Após este ponto de máximo, os dados experimentais de Güldogan et al (2003), no caso do PP em grãos, seguem uma tendência constante de grau de enxerto enquanto que os demais casos apresentam uma tendência decrescente. Observa-se que o modelo apresenta essa tendência decrescente para estudos com maiores concentrações de iniciador (dados de Shi et al, 2006). De forma semelhante, dentre os gráficos de grau de enxerto em função da concentração de $\mathrm{MAH}$, a tendência decrescente mais acentuada, foi obtida na simulação referente à $5 \%$ de iniciador com os dados de Shi et al (2001). 
O iniciador gera radicais primários, que são os responsáveis pela geração de macro-radicais, os quais poderão ser enxertados conforme descrito nas reações do item 3.1.2.1. A diminuição do grau de enxerto devido ao aumento excessivo das concentrações iniciais de iniciador e/ou MAH, pode ser explicada através da reação do $\mathrm{MAH}$ com os radicais primários (reação vi). Esta observação sugere que o ponto de máximo e esse comportamento decrescente são sensíveis ao parâmetro $\mathrm{k}_{\mathrm{a}, 0}$. Esta sensibilidade é constatada nas simulações, porém de forma limitada. Baixos valores de grau de enxerto podem estar associados não somente à perda de reagentes através da reação vi, mas também através da condição heterogênea do meio. Os parâmetros físicos considerados no Modelo 1 (solubilidade do iniciador no meio, fração solúvel de MAH em PP e fração segregada) permitem representar essa heterogeneidade, fornecendo, em geral, bons resultados de grau de enxerto para os casos estudados.

No estudo de Shi et al (2006), a massa molecular média numérica de PP, aumenta com a concentração inicial de MAH. Isto acontece, pois o aumento das concentrações de MAH favorece as reações de enxerto (reações vi, vii e viii), diminuindo a reação de cisão de cadeias (reação v). Neste caso, a curva do modelo possui a mesma tendência dos dados experimentais, porém, o resultado quantitativo é insatisfatório. A massa molecular média de PP diminui com o aumento da concentração inicial de iniciador. Este comportamento pode ser explicado com base na taxa de cisão, que aumenta com a concentração de radicais backbone. O aumento da quantidade de iniciador no meio gera um aumento nas taxas das reações i e ii, gerando mais radicais backbone. Nesta simulação o modelo fornece razoáveis resultados quantitativos. Ainda nesse mesmo estudo, observa-se no gráfico de GExMAH, para o caso dos nano-reatores, que o modelo representa bem os dados experimentais até a concentração de 4\% de MAH inicial. Esta mesma observação é válida para o gráfico MnxMAH. Conforme descrito no trabalho de Shi et al (2006), a argila utilizada como nano-reator (montmorilonita) possui interações favoráveis com o MAH. Com base nisto, o aumento excessivo de MAH (acima de 4\%) pode gerar efeitos não previsíveis pelo Modelo 1.

Nas simulações do grau de enxerto em função do tempo observa-se que as tendências estão corretamente representadas e o fim da reação (quando o grau de enxerto se torna constante) pode ser predito com certa exatidão. 


\subsubsection{Discussão dos parâmetros ajustados no Modelo 1}

Os valores ajustados de constante de velocidade, em geral, possuem concordância com a lei de Arrhenius (Figuras 30 à 33). Para as temperaturas de $180^{\circ} \mathrm{C}$ e $185^{\circ} \mathrm{C}$, em geral, obtêm-se valores próximos aos dados retirados da literatura, com exceção do valor de $\mathrm{k}_{\mathrm{cs}}$ que possui maior discrepância (Tabelas 4.4 e 4.5). No presente estudo, o valor ajustado para este parâmetro é bem maior do que os valores apresentados pelos demais autores. Como as reações de cisão não afetam o grau de enxerto, esse ajuste se deve somente à simulação com os dados de massa molecular média numérica de PP (SHI et al, 2006). O Modelo 1 foi testado somente neste conjunto de dados para simular a Mn do PP, não havendo o estudo deste tipo de simulação com dados em outras temperaturas. Os dados de $\mathrm{k}_{\mathrm{cs}}$ obtidos para as demais temperaturas foram ajustados com base na energia de ativação encontrada na literatura. Uma justificativa para o alto valor ajustado de $\mathrm{k}_{\mathrm{cs}}$ pode ser feita com base no mecanismo proposto para as reações de terminação. Como o processo é realizado com o polímero na forma fundida, entende-se que as reações de terminação entre macro-radicais são limitadas pela difusão. No modelo, é atribuído um único valor de constante de velocidade $\left(k_{t}\right)$ para as reações de terminação entre moléculas pequenas $\left(R_{0}\right.$ e $\left.R_{A o}\right)$ e entre macro-radicais. Para os radicais backbone este parâmetro gera uma taxa de terminação maior do que a taxa real, consequentemente, obtem-se uma concentração mais baixa destes radicais durante o processo. Desta forma, o alto valor de $\mathrm{k}_{\mathrm{cs}}$ pode estar compensando esta baixa concentração.

O parâmetro $\mathrm{k}_{\mathrm{d}}$, para a temperatura de $130^{\circ} \mathrm{C}$, apresenta um valor discrepante em relação à literatura. No experimento realizado a $130^{\circ} \mathrm{C}$ por Güldogan et al (2003), foi utilizada uma rotação muito baixa (14 rpm) com relação aos demais estudos. Neste caso o PP ainda não atingiu seu ponto de fusão $\left(\sim 166^{\circ} \mathrm{C}\right)$, gerando maior dificuldade de homogeneização do sistema. O valor discrepante de $k_{d}$ pode estar associado às condições relativamente anormais nas quais foram realizados os experimentos de Güldogan et al (2003). Este mesmo parâmetro apresentou valores discrepantes também para as temperaturas de $220^{\circ} \mathrm{C}$ e $230^{\circ} \mathrm{C}$. Como estas temperaturas estão acima do ponto de ebulição do 
MAH $\left(202^{\circ} \mathrm{C}\right)$, o baixo valor de $\mathrm{k}_{\mathrm{d}}$ ajustado para estes casos pode estar compensando uma perda de MAH por vaporização não considerada no modelo. Com base nessa discussão de temperaturas extremas, nas comparações de parâmetros e nos resultados obtidos, verifica-se que a temperatura ideal para o processo está em torno de $180^{\circ} \mathrm{C}$. Outra possível justificativa para as discrepâncias encontradas nos dados de $k_{d}$ se refere ao ajuste da eficiência do iniciador (f). No equacionamento do modelo encontra-se o produto $\mathrm{fk}_{\mathrm{d}}$, sendo assim, os desvios encontrados nas comparações entre os dados de $k_{d}$ podem estar relacionados à erros no ajuste das eficiências dos iniciadores.

Observa-se na Tabela 4.7, que os valores de energia de ativação das diferentes reações se encontram relativamente próximos aos dados retirados da literatura. Tanto para as constantes de velocidade como para as energias de ativação, observa-se que as discrepâncias encontradas entre os dados da literatura (entre um autor e outro) possuem a mesma ordem de grandeza dos desvios em relação aos valores ajustados no presente trabalho.

Um fator importante na avaliação dos parâmetros cinéticos é que não se têm informações detalhadas dos experimentos reportados na literatura. Discrepâncias podem estar associadas a casos em que se têm regiões com diferentes temperaturas dentro do reator, havendo assim, variações nas velocidades das reações. Outro fator importante nesta análise é que o estudo da simulação do processo de enxerto de anidrido maleico em polipropileno é recente, havendo pouca informação teórica a respeito. Sendo assim, não se tem base suficiente para fazer uma avaliação quantitativa mais aprofundada da cinética do processo.

$\mathrm{Na}$ Tabela 4.8 observa-se que as solubilidades estimadas para os iniciadores $(9,2$ - 36\%) estão acima das composições utilizadas nos experimentos $(0,5-5 \%)$, indicando que os iniciadores são completamente solúveis em PP nas condições estudadas. A solubilidade ajustada para a temperatura de $130^{\circ} \mathrm{C}(0,15 \%)$ está abaixo da solubilidade estimada e das quantidades de DCP adicionadas, produzindo efeito sobre a simulação. Uma possível explicação para este ajuste é que os experimentos foram conduzidos em condições desfavoráveis (baixa rotação e baixa temperatura), conforme já descrito neste item. Sendo assim, a reação foi processada em um meio bem viscoso e com baixa velocidade de mistura, dificultando o transporte de massa da fase pura de iniciador (Fase 3) para o meio reacional (Fase 2). As condições descritas no item 3.1.3.1 foram utilizadas como 
aproximação para este caso, uma vez que a solubilidade estimada é maior do que a ajustada. Supõe-se que a baixa solubilidade ajustada compensa as dificuldades de transporte de massa para este caso.

Observa-se na Tabela 4.2, que o parâmetro fração solúvel de MAH aumenta à medida que se aumenta a temperatura. O aumento de temperatura causa a diminuição da viscosidade do meio, facilitando a transferência de massa. Isto justifica o aumento da quantidade solubilizada do MAH. No modelo, foi considerado um valor único de fração solúvel de MAH para cada caso, com base em conceitos de transferência de massa: quanto maior a quantidade ou quanto menor a partícula, maior é a área de transferência de massa. Sendo assim, a quantidade de MAH solubilizada é diretamente proporcional à sua quantidade adicionada e inversamente proporcional ao tamanho de suas partículas (que se tornam gotículas após a fusão). Na Figura 40, os valores ajustados de MAH solubilizado que estão abaixo da solubilidade estimada, apresentam coerência, ou seja, a quantidade solubilizada não ultrapassou a solubilidade de MAH em PP antes do início das reações. Observa-se que uma parte dos valores de concentração de MAH solubilizado, gerados pelo ajuste de $\mathrm{y}_{\text {solA }}$, está acima da solubilidade estimada para a respectiva temperatura. Contudo, estes valores geraram resultados aceitáveis, mostrando que o uso destas concentrações é numericamente equivalente ao comportamento real do processo (possível dissolução de MAH durante a reação). Os valores estimados de solubilidade dependem da temperatura e das massas moleculares dos compostos, além do que, o método UNIFAC é válido para compostos líquidos à temperatura ambiente. Portanto, parâmetros estimados à partir deste método, podem conter desvios gerados por variações de temperatura e da massa molecular média do PP, dentre outros. No apêndice, são apresentados os grupos e os parâmetros de interação utilizados na aplicação do método UNIFAC aos diferentes casos.

Observa-se considerável segregação no estudo realizado por Güldoğan et al (2003) com PP em grãos. Isto pode ser explicado pela baixa rotação utilizada e pela forma da partícula, visto que para o PP em pó, o modelo sem segregação se ajusta bem aos dados. Com o aumento da temperatura percebe-se uma diminuição da segregação decorrente de menor viscosidade (Tabela 4.2). O aumento da rotação também contribui para a diminuição da segregação. 
Nos dados de Shi et al (2006), o modelo distingue o processo convencional do processo com o nano-reator através do aumento da eficiência do iniciador, do aumento da fração solúvel de MAH e da diminuição da constante de velocidade de decomposição do iniciador $\left(k_{d}\right)$. De acordo com Shi et al (2006), o aumento da eficiência do iniciador é decorrente da liberação controlada dos radicais primários de dentro para fora dos nano-tubos. Como a reação de decomposição do DCP é reversível dentro do nano-tubo, o mesmo se mantém puro por mais tempo do que se estivesse no meio reacional. Isto faz com que haja redução da perda de iniciador (maior eficiência). No modelo, foi considerado um valor mais baixo de $k_{d}$ para o experimento com os nano-reatores em relação ao processo convencional. Esta alteração foi feita para representar no modelo a lenta difusão dos radicais primários de dentro para fora do nano-tubo. Uma alternativa seria considerar inúmeros nanoreatores em paralelo processando a decomposição do iniciador e injetando radicais primários (produto da reação) no PP (Fase 2), que seria um reator semi-contínuo em série com os nano-tubos. $O$ baixo valor de $k_{d}$ produz o efeito desejado, mas não é um dado que possa ser estudado com a lei de Arrhenius. Para o caso que utiliza os nano-reatores, o modelo considera que o DCP está dissolvido no PP e demora mais para se decompor, compensando o tempo de difusão dentro do nano-reator. Desta forma, o ajuste da curva da lei de Arrhenius aos dados de $k_{d}$ obtidos, não envolveu o valor ajustado para o caso dos nano-reatores. Ainda neste estudo experimental, é considerada certa afinidade entre o MAH e o nano-reator (o-MMT). Com base nisto, supõe-se que o MAH está presente em maior concentração nas regiões próximas aos nano-reatores. No Modelo 1, este fenômeno foi levado em conta através do aumento do parâmetro $\mathrm{y}_{\text {solA }}$. Na Figura 40 este parâmetro não é analisado para o caso dos nano-reatores, pois se supõe que a o-MMT interfere no equilíbrio de fases.

\subsection{Modelo 2}

5.2.1 Discussão dos resultados das simulações com o Modelo 2 
O Modelo 2 representa melhor a tendência decrescente dos dados de grau de enxerto em função da concentração inicial de MAH com relação ao Modelo 1. Esta tendência é acentuada através do aumento do $\mathrm{K}_{\mathrm{Pl}}$, que indica considerável perda de iniciador para a Fase 1. De acordo com Akzo (2007), o decréscimo no grau de enxerto, quando se utilizam concentrações de MAH acima do valor ótimo, se deve à perda do peróxido para a fase de MAH separada do polímero fundido.

Nos experimentos de Güldogan et al (2003), realizados com o PP na forma de pó, o grau de enxerto cai de forma muito acentuada à medida que se aumenta a concentração de iniciador após o ponto de máximo. Nos dados de Shi et al (2006), essa tendência é menos acentuada, e o ponto de máximo se refere à um valor maior de DCP, o que permite melhor ajuste. Essa queda acentuada do grau de enxerto nos dados de Güldogan et al (2003) pode estar associada à um efeito de transporte de massa não considerado no Modelo 2. Uma possível explicação para este comportamento é a dissolução incompleta de DCP em PP, para os casos com maior concentração deste iniciador. Neste caso, mesmo possuindo alta solubilidade em PP, o DCP teria dificuldade de se dissolver na Fase 2 devido ao coeficiente de transporte de massa ser supostamente baixo.

Nas simulações com os dados de Shi et al (2006), observa-se bons resultados no ajuste do modelo aos dados de massa molecular média numérica (Figura 42). Com os dados deste autor, obtêm-se bons resultados para todos os conjuntos de dados, com exceção do grau de enxerto em função da concentração inicial de MAH. Neste caso, a curva do modelo apresenta um ponto de máximo seguido de uma tendência decrescente, porém, não apresenta um resultado quantitativamente satisfatório. A justificativa para este resultado segue a mesma discussão feita para o Modelo 1.

Observa-se na Figura 43, que após o ponto de máximo, os dados experimentais apresentam uma tendência decrescente que se acentua à medida que se aumenta a quantidade de DCP. O Modelo 2 apresenta essa tendência de forma menos acentuada e com declive constante em relação à concentração de DCP; apresenta também pontos de máximo deslocados em relação aos dados experimentais. Uma explicação para este comportamento pode ser o uso de diferentes mecanismos para algumas das reações envolvidas, em relação ao comportamento real do processo. Foi verificado, durante as simulações, que o parâmetro $k_{a, 0}$ é responsável pelo deslocamento do ponto de máximo das curvas e 
também pelo comportamento decrescente das mesmas. Porém, este parâmetro sozinho não é suficiente para modelar estes comportamentos de forma separada. A reação vi, que é responsável pela diminuição do grau de enxerto, pode seguir uma cinética diferente da que foi considerada no modelo. Um possível mecanismo equivalente a esta reação pode intensificar o consumo de MAH e I e gerar novos parâmetros para a modelagem. Outra consideração cinética importante a ser discutida é o mecanismo das reações de terminação. Estas reações ocorrem por desproporcionamento e possuem um único valor de constante de velocidade $\left(\mathrm{k}_{\mathrm{t}}\right)$ tanto para moléculas pequenas $\left(R_{0}\right.$ e $\left.R_{A 0}\right)$ quanto para moléculas grandes (macroradicais). Em estudos futuros, uma sugestão seria utilizar diferentes valores de $k_{t}$ de acordo com o tamanho da molécula.

\subsubsection{Discussão dos parâmetros ajustados no Modelo 2}

Os valores ajustados de constante de velocidade, em geral, possuem concordância com a lei de Arrhenius, apesar de haverem apenas três pontos para a comparação (Figuras 45 à 48). Os valores ajustados de $k_{d}$ estão de acordo com os dados retirados de Akzo (2006). A comparação das demais constantes de velocidade não fornece discrepâncias consideráveis. Para os dados de energia de ativação, em geral, obtém-se semelhança entre os valores ajustados e os dados da literatura. As discrepâncias destas comparações seguem a mesma discussão feita para o Modelo 1.

Os valores de solubilidade ajustados estão de acordo com as estimativas feitas pelo método UNIFAC. Os valores de $\mathrm{K}_{\mathrm{PI}}$ utilizados são os próprios valores estimados através do item 3.3.2.2. Para o caso dos nano-reatores, o baixo valor de $\mathrm{K}_{\mathrm{PI}}$ contempla o confinamento de parte do iniciador dentro dos nano-tubos.

Verifica-se através da Figura 49, que em alguns casos pode haver formação de duas fases na mistura MAH + DCP. Essa geração de duas fases interfere nas velocidades das reações dentro das gotas de $\mathrm{MAH}+\mathrm{DCP}$. A consideração de uma única fase para esta mistura gera uma composição intermediária em relação às composições das duas fases que, teoricamente, se formam em determinados casos. Consequentemente, as velocidades das reações dentro desta fase única 
(Fase 1), terão valores intermediários em relação às fases separadas. Desta forma, entende-se que os resultados finais de grau de enxerto não sofrem grande influência desta aproximação.

No Modelo 2, o processo que utiliza o nano-reator se distingue do processo convencional através do $k_{d}$ e da eficiência do iniciador (da mesma forma que foi considerada no Modelo 1) e também da solubilidade do MAH em PP e do $K_{P I}$. Considera-se que as reações ocorrem próximas ao nano-reator devido à afinidade do MAH com a o-MMT. Supõe-se que esta afinidade interfira no equilíbrio de fases, permitindo uma concentração de MAH acima de sua solubilidade no PP. No Modelo 2, foi ajustado o valor de 4\% para a solubilidade do MAH em PP no caso dos nanoreatores. Neste caso, não foi feita estimativa para este parâmetro devido à complexidade do sistema. O baixo valor de $\mathrm{K}_{\mathrm{PI}}$ ajustado para o caso dos nanoreatores considera que a quantidade de iniciador confinada na o-MMT participa das reações, mas não do equilíbrio de fases com o MAH. 


\section{CONCLUSÕES}

Conclui-se que ambos os modelos propostos no presente trabalho representam bem as tendências observadas nos dados experimentais.

O Modelo 1 é capaz de fornecer boa predição de grau de enxerto em processos realizados com baixas concentrações iniciais de $\mathrm{MAH}$ e/ou iniciador (abaixo do ponto de máximo grau de enxerto).

A utilização do parâmetro fração solúvel de MAH em PP forneceu uma pequena melhora nos resultados em relação ao modelo que considera meio homogêneo.

O Parâmetro fração segregada permite simular reações de enxerto com diferentes tamanhos de partícula de polipropileno.

Os valores de solubilidade do MAH em polipropileno, estimados através do método UNIFAC, estão de acordo com os valores de fração solúvel de MAH utilizados nas simulações.

Para os casos estudados, a solubilidade dos iniciadores em PP é alta (conforme estimado pelo método UNIFAC). Exceto para o ensaio conduzido à $130^{\circ} \mathrm{C}$, o parâmetro solubilidade dos iniciadores pôde ser desprezado no Modelo 1.

Com base nas propriedades físicas dos reagentes e nos resultados obtidos, conclui-se que temperaturas em torno de $180^{\circ} \mathrm{C}$ são ideais para o processo de enxerto estudado e para a simulação do mesmo através dos modelos desenvolvidos no presente trabalho.

O Modelo 2 apresentou resultados ligeiramente melhores que o Modelo 1, porém está bem mais fundamentado. Este modelo apresentou também, valores de parâmetros cinéticos e físicos mais próximos dos dados retirados da literatura quando comparado ao Modelo 1.

No Modelo 2, além de um bom desenvolvimento cinético, verifica-se um embasamento termodinâmico, indicando progresso na modelagem do processo de enxerto de anidrido maleico em polipropileno na forma fundida. 


\section{RECOMENDAÇÕES}

- Complementar o modelo no aspecto de transporte de massa dos componentes e da vaporização do anidrido maleico.

- Realizar experimentos de enxerto de anidrido maleico em polipropileno em condições controladas com o objetivo de possuir mais informações experimentais para utilizar na modelagem.

- $\quad$ Estudar as condições de transporte de massa no meio reacional através de fluido-dinâmica computacional.

- Estudar possibilidades de diferentes mecanismos reacionais do processo e fazer alterações no equacionamento do modelo. 


\section{REFERÊNCIAS BIBLIOGRÁFICAS}

AKZO NOBEL. Modification of polyolefins with maleic anhydride. Technical Bulletin HP 92.077.04. (2007), 12 p.

AKZO NOBEL. Initiators for high polymers. Code: 2161 BTB Communication. (2006). Disponível em: <http://www.akzonobel-polymerchemicals.com>. Acesso em: 01 Ago. 2008.

AKZO NOBEL. Crosslinking peroxides and polymer additives. Disponível em: $<$ http://www.akzonobel-polymerchemicals.com>. Acesso em: 01 Out. 2008.

BERZIN F. et al. Modeling of peroxide initiated controlled degradation of polypropylene in a twin screw extruder. Polymer Engineering and Science 40 No. 2 (2000), p. 344-356.

BETTINI S. H. P.; AGNELLI J. A. M. Grafting of maleic anhydride onto polypropylene by reactive processing. I. Effect of maleic anhydride and peroxide concentrations on the reaction. Journal of Applied Polymer Science 74 (1999), p. 247-255.

BETTINI S. H. P.; AGNELLI J. A. M. Grafting of maleic anhydride onto polypropylene by reactive processing. II. Effect of rotor speed and reaction time. Journal of Applied Polymer Science 74 (1999), p. 256-263.

BRANDRUP J.; Immergut E. H. Polymer Handbook. $3^{\text {a }}$ ed., Wiley Interscience, USA (1989).

CHA J.; WHITE J. L. Maleic anhydride modification of polyolefin in an internal mixer and a twin-screw extruder: experiment and kinetic model. Polymer Engineering and Science 41 No. 7 (2001), p 1227-1237.

CHANG D.; WHITE J. L. Experimental study of maleation of polypropylene in various twinscrew extruder systems. Journal of Applied Polymer Science 90 (2003) p. 1755-1764.

FOGLER H.S. Elements of chemical reaction engineering. $3^{a}$ Ed., Prentice-Hall of India. New Delhi, Î́ndia (2002).

GIUDICI, R. Mathematical modeling of the grafting of maleic anhydride onto polypropylene. Macromol. Symp 259 (2007), p. 254-264.

GMEHLING J.; LI J.; SCHILLER M. A modified UNIFAC model. 2. Present parameter matrix and results for different thermodynamic properties. Ind. Eng. Chem. Res., 32 (1993), P. 178-193.

GÜLDOĞAN, Y. et al. Comparison of maleic anhydride Grafting onto powder and granular polypropylene in the melt by reactive extrusion. Journal of Applied Polymer Science 92 (2004), p. 3675-3684. 
IEDEMA P. D. et al. Using molecular weight distributions to determine the kinetics of peroxideinduced degradation of polypropylene. Chemical Engineering Science 56 (2001), p. 3659-3669.

JAKOB $H$. et al. Further development of modified UNIFAC (Dortmund): Revision 3 and extension 5. Ind. Eng. Chem. Res. 45 (2006), p. 7924-7933.

KRUSE, T. M.; Wong, H.; Broadbelt, L. Mechanistic modeling of polymer pyrolysis: Polypropylene. Macromolecules 36 (2003), p. 9594-9607.

MARTINEZ J. M. G. EP Functionalization of Polypropylene with maleic anhydride by reactive extrusion. Intern Polym. Processing IX(4) (1994), p. 346-349.

MARTINEZ J. M. G. Modification of polypropylene by maleic anhydride - Study on reaction conditions using a batch process. Intern Polym. Processing IX(3) (1994), p. 246-251.

PAN B. et al. Photoinitiated grafting of maleic anhydride onto polypropylene. Journal of Polymer science: part A: polymer chemistry 42 (2004), p. 1953-1962.

PERRY R. H. Perry's Chemical Engeneers' Handbook. 6a Ed., McGraw-Hill book company, Singapore (1984).

PRAUSNITZ J.; ANDERSON T.; GRENS E.; ECKERT C.; HSIEH R.; O'CONNELL J. Computer calculations for multicomponent vapor-liquid and liquid-liquid equilibria. Prentice Hall international series. Englewood Cliffs (1980).

REID R. C.; PRAUSNITZ J. M.; POLING R. E. The Properties of Gases and Liquids. McGraw-Hill Book Co., Singapore (1988).

SBRT. Fabricação de lençol de PVC. (2006). Disponível em: < http://www.sbrt.ibict.br> . Acesso em: 24 Nov. 2008.

SEVERINI F. et al. Free Radical grafting of maleic anhydride in vapour phase on polypropylene film. Polymer 40 (1999), p. 7059-7064.

SHOSHENSKIY N. Safety data sheet: Perkadox BC-FF. Akzo Nobel, USA (2006).

SHOSHENSKIY N. Safety data sheet: Trigonox 101. Akzo Nobel, USA (2006).

SHOSHENSKIY N. Safety data sheet: Perkadox 14-40B-PD. Akzo Nobel, USA (2006).

SHI D. et al. Nano-reactors for controlling the selectivity of the free radical grafting of maleic anhydride onto polypropylene in the melt. Polymer engineering and science 46 (2006), p. 14431454. 
SHI D. et al. Functionalization of polypropylene with maleic anhydride by reactive extrusion: mechanism of melt grafting. Polymer 42 (2001), p. 5549-5557.

TROLEZ Y.; MACOSCO C.; BOILLOUX A. 6th Annual meeting of the polymer processing society 6. Nice, França (1990), p. 01-16.

ZHU Y.; AN L.; JIANG W. Monte Carlo simulation of the grafting of maleic anhydride onto polypropylene at higher temperature. Macromolecules 36 (2003), p. 3714-3720. 


\section{APÊNDICE}

APÊNDICE A - Grupos e parâmetros de interação considerados nas estimativas dos coeficientes de atividade através do método UNIFAC.

Tabela A1 - Grupos considerados para cada composto.

\begin{tabular}{|c|c|c|c|c|}
\hline Composto & Grupo & Principal & Secundário & $V_{k}^{(1)}$ \\
\hline \multirow{3}{*}{ MAH } & $\mathrm{ACH}$ & 3 & 9 & 2,00 \\
\hline & $\mathrm{CHO}$ & 10 & 20 & 1,00 \\
\hline & $\mathrm{HCOO}$ & 12 & 23 & 1,00 \\
\hline \multirow{4}{*}{ DCP } & $\mathrm{CH} 3$ & 1 & 1 & 4,00 \\
\hline & $\mathrm{ACH}$ & 3 & 9 & 10,00 \\
\hline & $A C$ & 3 & 10 & 2,00 \\
\hline & $\mathrm{CH}-\mathrm{O}$ & 13 & 26 & 2,00 \\
\hline \multirow{4}{*}{ Px14 } & $\mathrm{CH} 3$ & 1 & 1 & 10,00 \\
\hline & $\mathrm{ACH}$ & 3 & 9 & 4,00 \\
\hline & $A C$ & 3 & 10 & 2,00 \\
\hline & $\mathrm{CH}-\mathrm{O}$ & 13 & 26 & 4,00 \\
\hline \multirow{3}{*}{ DBHA } & $\mathrm{CH} 3$ & 1 & 1 & 10,00 \\
\hline & $\mathrm{CH} 2$ & 1 & 2 & 2,00 \\
\hline & $\mathrm{CH}-\mathrm{O}$ & 13 & 26 & 4,00 \\
\hline \multirow{3}{*}{ DHBP } & $\mathrm{CH} 3$ & 1 & 1 & 6,00 \\
\hline & $\mathrm{CH} 2$ & 1 & 2 & 2,00 \\
\hline & $\mathrm{CH}-\mathrm{O}$ & 13 & 26 & 4,00 \\
\hline \multirow{3}{*}{ PP } & $\mathrm{CH} 3$ & 1 & 1 & 1071,43 \\
\hline & $\mathrm{CH} 2$ & 1 & 2 & 1071,43 \\
\hline & $\mathrm{CH}$ & 1 & 3 & 1071,43 \\
\hline
\end{tabular}

Tabela A2 - Valores dos parâmetros de interação utilizados nos cálculos.

\begin{tabular}{cccccc}
\hline $\mathrm{n}$ & $\mathrm{m}$ & $a_{\mathrm{nm}}(\mathrm{K})$ & $\mathrm{b}_{\mathrm{nm}}$ & $a_{\mathrm{mn}}(\mathrm{K})$ & $\mathrm{b}_{\mathrm{mn}}$ \\
\hline 1 & 3 & 114,2000 & 0,0933 & 16,0700 & $-0,2998$ \\
1 & 10 & 875,8500 & 0,0000 & 256,2100 & 0,0000 \\
1 & 12 & 508,4000 & $-0,6215$ & 238,5000 & $-0,5358$ \\
1 & 13 & 233,1000 & $-0,3155$ & $-9,6540$ & $-3,2400$ \\
3 & 10 & $-365,5000$ & 1,8740 & 1011,0000 & $-2,1670$ \\
3 & 12 & 170,5000 & $-0,0239$ & 108,3000 & $-0,2620$ \\
3 & 13 & $-87,0800$ & $-0,1859$ & 179,0000 & 5,6200 \\
10 & 12 & $-160,7000$ & 0,0000 & 226,6000 & 0,0000 \\
12 & 13 & 209,0000 & $-0,6241$ & 235,7000 & 0,1314 \\
10 & 13 & 209,0000 & $-0,6241$ & 235,7000 & 0,1314 \\
\hline
\end{tabular}

$\mathrm{n}$ e $\mathrm{m}$ representam os grupos principais em interação. Os parâmetros $\mathrm{C}_{\mathrm{nm}}$

e $\mathrm{C}_{\mathrm{mn}}$ apresentam valor zero para todos os casos. 